\title{
Politics and socio-economics of ecosystem-based management of marine resources
}

\author{
Idea and coordination: Howard I. Browman, Konstantinos I. Stergiou
}

\section{CONTENTS*}

Browman HI, Stergiou KI

Introduction

$241-242$

Agardy T

Global marine conservation policy versus site-

level implementation: the mismatch of scale and

its implications

$242-248$

Fluharty D

Evolving ecosystem approaches to management

of fisheries in the USA ............................... 248-253

Hirshfield MF

Implementing the ecosystem approach: making

ecosystems matter .

Livingston PA

PICES' role in integrating marine ecosystem

research in the North Pacific ............................ 257-259

Misund OA, Skjoldal HR

Implementing the ecosystem approach: experiences from the North Sea, ICES, and the Institute

of Marine Research, Norway

Rice JC

Implementation of the Ecosystem Approach to Fisheries Management - asynchronous co-evolution at the interface between science and policy

\section{Introduction}

Howard I. Browman ${ }^{1, * *}$, Konstantinos I. Stergiou ${ }^{2}$

${ }^{1}$ Institute of Marine Research - Austevoll, 5392 Storebø, Norway Email: howard.browman@imr.no

${ }^{2}$ Aristotle University of Thessaloniki, School of Biology, Department of Zoology, Box 134, Thessaloniki 54124, Greece Email:kstergio@bio.auth.gr

The ecosystem-based approach (EA) to the management of marine resources has been the focus of several recent publications (e.g. Browman \& Stergiou 2004, Pikitch et al. 2004, Beddington \& Kirkwood 2005, Daan et al. 2005). Despite this flurry of articles, the often over-riding importance of political and socio-economic forces in establishing and implementing the EA have not been adequately addressed (but see Turrell 2004). Thus, we canvassed experts who are familiar with this side of the EA issue, and managers involved in the decision to adopt it as national/international policy. Our goal was to provide marine scientists with insights into the forces driving the adoption of policies such as the EA, and the mechanisms through which they are

\section{Rosenberg AA, McLeod KL}

Implementing ecosystem-based approaches to management for the conservation of ecosystem services ............................................................... 270-274

Sherman K, Sissenwine M, Christensen V, Duda A, Hempel G, Ibe C, Levin S, Lluch-Belda D, Matishov G, McGlade J, O'Toole M, Seitzinger S, Serra R, Skjoldal HR, Tang Q, Thulin J,

Vandeweerd V, Zwanenburg $K$

A global movement toward an ecosystem

approach to management of marine resources ........ 275-279

\section{Sumaila UR}

Differences in economic perspectives and implementation of ecosystem-based management of marine resources ............................................. 279-282

Tudela S, Short K

Paradigm shifts, gaps, inertia, and political agen-

das in ecosystem-based fisheries management ........ 282-286

Valdimarsson G, Metzner R

Aligning incentives for a successful ecosystem approach to fisheries management ....................... 286-291

Watson-Wright WM

Policy and science: different roles in the pursuit of solutions to common problems ....................... 291-296 operationalized (or not). We sought contributions from colleagues who have been engaged in the interaction of politics with science, and sought to cover as many perspectives as possible: non-governmental organizations (NGOs), government, research institutes and universities.

The contributors to this Theme Section (TS) describe the structural, technical, administrative, operational, socio-economic and scientific complexities associated with the adoption and implementation of a holistic EA. 'Ecosystem services', and the need to assess the cumulative impacts of all activities (extractive or otherwise) on the ecosystem, are emphasized in several of the contributions. The Large Marine Ecosystem (LME) concept emerges as a possible practical structure upon which the EA could be operationalized. The role of uncertainty at various levels of the science-policy interface, and its relation to implementing the EA, are taken up from various perspectives. Estimating fish abundance, and characterizing/predicting ecosystem structure and function, are inherently difficult, and the result will al- 
ways be fraught with uncertainty. The manner in which this uncertainty is dealt with depends upon the role that one plays in the management system. Stock assessment analysts and ecosystem modelers must focus on reducing uncertainty. Politicians, policy-makers and fisheries managers must consider this uncertainty within a precautionary approach: they must adopt the worst-case estimates and/or the concept of reversing the burden of proof (see Pikitch et al. 2004). These different perspectives on uncertainty come into play as part of policysupporting scientific advising (sensu Smith \& Link 2005). However, the same scrutiny is rarely applied to the scientific advice associated with policy formation (see Smith \& Link 2005).

Although we provided contributors with a series of questions that they could address, several issues that we viewed as important were not taken up. For example, the fact that governments in most of the developed world are reducing funding and personnel in the marine research sector begs the question: where are the funds that will allow a complete implementation of the EA going to come from? Further, the conservationist bent of the EA seems at odds with humanity's intensive-extensive (and unsustainable) exploitation of continental ecosystems through large-scale production of crops and livestock, with little if any thought towards preserving ecosystem health, biodiversity, endemic species, etc. This highlights a general lack of discussion concerning the moral, ethical and philosophical aspects of exploiting the sea (although see Dallmeyer 2003, Marra 2005). The overriding influence of politics, and of remunerated political lobbying, in the adoption of policy were not adequately addressed (but see, for instance Anonymous 1997, Masood 1997, Spurgeon 1997, Allisson 2001, Pauly 2003).

It is often maintained, either implicitly or explicitly, that scientists are naïve when it comes to policy issues and their implementation. Dunbar $(1987$, p. 6) stated:

There is a belief that the body scientific cannot judge these important matters, that scientists live in a confounded 'ivory tower' dreaming of test tubes, high theory or the genitalia of insects, and that it takes lawyers, businessmen or perhaps emancipated economists to come down to practicalities. This is a myth fomented and perpetuated by those same lawyers, businessmen, etc. It is poppycock; no one can know better than scientists how to get the best results and the most mileage out of science. A scientist looking for advice on the stock market goes to the relevant professional, and rightly expects lawyers and politicians to come to him for guidance in science.

We hope that this Theme Section will help us along this path.

Acknowledgements. H.I.B.'s ongoing research and his editorial activity for MEPS are supported by the Institute of Marine Research, Norway, by The Research Council of Norway, and by the Inter-Research Science Center.

\section{LITERATURE CITED}

Allisson EH (2001) Big laws, small catches: global ocean governance and the fisheries crisis. J Int Dev 13:933-950

Anonymous (1997) Politics and fisheries management. American Fisheries Society, Texas Chapter, Newsletter 23(4):5 (available at www.sdafs.org/tcafs/news/97vol23/ news23_4/v23n4.pdf)

Beddington J, Kirkwood G (eds) (2005) Fisheries: a future? Philos Trans R Soc Lond B Biol Sci 360:3-218

Browman HI, Stergiou KI (eds) (2004) Perspectives on ecosystem-based approaches to the management of marine resources. Mar Ecol Prog Ser 274:269-303

Dallmeyer DG (2003) Values at sea. Ethics for the marine environment. University of Georgia Press, Athens, GA

Daan N, Christensen V, Cury PM (eds) (2005) Quantitative ecosystem indicators for fisheries management. ICES J Mar Sci 62(3):307-614

Dunbar MJ (1987) Science policy? Ask a scientist. Can Res March:4-6

Marra J (2005) When will we tame the oceans? Nature 436:175-176

Masood E (1997) Fisheries science: all at sea when it comes to politics? Nature 386:105-106

Pauly D (2003) Ecosystem impacts of the world's marine fisheries. Global Change Newsl 55:21-23

Pikitch EK, Santora C, Babcock EA, Bakun A and 13 others (2004) Ecosystem-based fishery management. Science 305:346-347

Smith TD, Link JS (2005) Autopsy your dead...and living: a proposal for fisheries science, fisheries management and fisheries. Fish Fish 6:73-87

Spurgeon D (1997) Political interference skewed scientific advice on fish stocks? Nature 388:106

Turrell WR (2004) The policy basis of the 'Ecosystem Approach' to fisheries management. EuroGOOS Publication No. 21, EuroGOOS, Norrköping

\section{Global marine conservation policy versus site-level implementation: the mismatch of scale and its implications}

\section{Tundi Agardy}

\section{Sound Seas, 6620 Broad Street, Bethesda, Maryland 20186, USA Email: tundiagardy@earthlink.net}

The mismatch of scale. Addressing environmental issues requires recognition of problems, mobilization of resources to develop solutions, and leadership in driving change. These actions are best accomplished by 'thinking globally, acting locally'. However, environmental problems themselves are rarely local in scale, and piecemeal attempts to address them usually fail. This is particularly true in the conservation of the marine environment, where open marine ecosystems and the international nature of pollution, overexploitation, and of other threats dictate a large-scale multilateral response. The mismatch between large-scale thinking (embodied in marine policy) and small-scale conservation action has serious implications for our 
ability to reverse the tide of environmental degradation occurring in the world's oceans.

Virtually all the world's nearshore areas experience multiple threats that act simultaneously to degrade ecosystems and decrease ecosystem services (Millennium Assessment 2005). Threats originate both at the site of degradation and far away - from land, as well as from distant seas. Since oceans are the ultimate sink and the fate of coastal waters is strongly tied to the condition of coastal lands, rivers and estuaries, successful conservation requires addressing not only the use of the marine environment, but land use as well, far up into the watersheds. Yet actual conservation projects do not happen on the global or regional scale - they happen bit by bit, as a result of individuals, communities and institutions responding to a particular need at a particular site. Typical marine conservation interventions include marine protected areas (MPAs), regulations to protect critical habitat of a species, and fisheries restrictions for a particular fishery. The scale of these responses is usually far too small to address the bigger (and growing) problems of unsustainable use of resources, indirect degradation of marine ecosystems, and large scale declines in environmental quality, such as those brought about by climate change (Agardy 1999).

Thus, the scale at which conservation occurs in sitelevel management interventions cannot possibly match the scale of the problems occurring throughout geographically larger regions. In contrast, marine policy is generally developed at much larger scales: both national and global. These policy initiatives could in theory be broad enough to holistically address complex environmental problems in the oceans. In fact, several international instruments provide impetus for large scale cooperation, including the United Nations Convention on the Law of the Sea, UN Regional Seas Conventions and Action Plans, Global Programme of Action for the Protection of the Marine Environment from Land-based Activities, Jakarta Mandate on the Conservation and Sustainable Use of Marine and Coastal Biological Diversity, and the Ramsar Convention for wetland protection.

Yet although global treaties attempt to address discrepancies between small-scale interventions on the ground and large-scale coastal problems, most of these international instruments have not been effective in reversing environmental degradation (Speth 2004). The problem may indeed be that the scale of such policies is far too big to recognize the particular issues facing communities, or to take advantage of the unique opportunities for conservation that may exist in specific socio-political or cultural settings.

There are 2 additional reasons why global scale policy initiatives tend to fall short of meeting what are commonly held goals of coastal/ocean conservation. First, the interventions that they prescribe can be too generic to lead to solutions that fit the particular circumstances (environmental, economic, social, political) at a site. A recent example is the push for MPA policies that target setting aside $20 \%$ of marine areas as no-take reserves, regardless of the habitat or set of resources to be protected and the threats that these ecological communities actually face (Agardy et al. 2003). Second, generic policies are often unrealistically ambitious or not supported by financial commitments, thus leading nowhere (de Fontaubert \& Agardy 1998, Wang 2004). In this way, a mismatch occurs between what is actually happening and what decision makers assume is happening.

It is not for lack of want that coastal and marine conservation is failing. Many of the earth's 123 coastal countries have coastal management plans and legislation, and new governance arrangements and regulations are being developed every year. Based on an international questionnaire using letters and fax, Sorensen (1993) estimated that there were 142 coastal management initiatives outside the USA, and 20 international initiatives. By 2000, there were a total of 447 initiatives globally, the result of new initiatives since 1993 and of the improved ability to find coastal management initiatives through the use of the internet (Kay \& Alder 2005). The latest survey estimates that there are 698 coastal management initiatives operating in 145 nations or semi-sovereign states, including 76 at the international level (Kay \& Alder 2005).

What drives these initiatives and will likely drive them in the future is the recognition by governmental and non-governmental organizations (NGO) of problems that need to be addressed. This brings up another mismatch of scale, which commonly leads to lack of coordination in conservation initiatives and, in extreme cases, to open conflict. Conservation priorities set at the global or regional scale by big environmental NGOs such as the WWF, The Nature Conservancy, Conservation International, etc., or multilateral organizations such as the World Bank, are sometimes at odds with local or even national priorities. An example of this is the Mexican government's endorsement of a salt plant in Baja California, which was strongly (and successfully) opposed by the international environmental community on the grounds that the plant would disturb gray whales, even though top cetacean experts found this argument without merit. The priorities of the nation of Mexico were thus at odds with the priorities of internationals NGOs, and the ensuing conflict may have diverted attention and funds away from more critical threats to Baja California and the Gulf of California.

The way in which some of the biggest NGOs set their priorities has been a source of controversy (e.g. Chapin 2004); nonetheless, high profile priority-setting schemes drive the flows of resources to certain areas, at the ex- 
pense of other regions. When global scale priorities are not in harmony with local priorities, tensions emerge that threaten the long-term viability of conservation actions, including MPAs and other key tools of conservation.

MPAs and the mismatch of scale. MPAs are fast becoming the conservation tool of choice for dealing with habitat loss, they are increasingly being used to study and to manage fisheries problems, and they involve local communities and user groups in management of marine areas. Yet MPAs, and especially fisheries reserves, are usually far too small to be effective in addressing the complex suite of problems faced by most marine areas, especially when planners and conservation groups ignore the context - in terms of the environmental health and condition of surrounding waters and benthos - in which these islands of protection are sited (Allison et al. 1998, Jones in press). Most MPAs are not large enough to meet their stated objectives; even the often touted exception of the Great Barrier Reef Marine Park, the largest MPA in the world, highlights how degradation of a highly valued area can occur when land management and ocean management are not in synchrony.

When practitioners realized that few MPAs were meeting broad scale conservation objectives, and that an ad hoc, one-off approach would not lead to effective large scale conservation, the concept of MPA networks emerged as a way to strategically plan MPAs with the hope that the whole would then be greater than the sum of its parts. There is an obvious need for strategic MPA networks (Roberts et al. 2001). A system or network that links these areas has a dual nature: connecting physical sites deemed ecologically critical (ecological networks), and linking people and institutions in order to make effective conservation possible (human networks) (Agardy \& Wolfe 2002). Networks or systems of MPAs have great advantages in that they spread the costs of habitat protection across a wide array of user groups and communities while providing benefits to all, and networks also help to overcome the mismatch of scale (Agardy 2003b).

It is important to distinguish between MPA networks or systems that are strategically planned to protect the most ecologically critical habitats within a region, and networks of reserves that have a narrower focus and are designed to protect fisheries stocks or single species. The former are planned in a way that addresses links between land, freshwater, and coastal systems, while the latter focus on larval dispersal, and sources and sinks. Although fisheries reserve networks can and should be part of MPA systems, their benefits may have been exaggerated, and critical gaps in knowledge impede the development of such reserve networks for many species (Sale et al. 2005).

MPA networks are most successful in promoting large-scale conservation when their design is based upon recognition of the interconnectivity of freshwater, coastal and marine ecosystems and habitats. This requires a firm understanding of ecological functioning and of boundaries within various ecosystems, and gap analyses to determine what key sources or sinks, or links in the chain of interconnected habitats, are missing from the total MPA portfolio (Friedlander et al. 2003). And while it is true that planning MPA networks or systems requires information about connectivity and ecological processes (Possingham et al. 2000, Leslie et al. 2003), it would be a fallacy to assume that complete ecological knowledge is a prerequisite for moving forward. An MPA network or system can be designed with adaptive management in mind, so that protected areas are actually used to garner more applied ecological information, as well as information about the efficacy of management (Agardy 1997).

Because MPAs and networks of areas can target a wide range of objectives, and since they vary greatly in scope, the most comprehensive system of networks is hierarchical, working at multiple complementary scales or levels (Jones 1994, Agardy 2003b). Goals can vary at each level in the hierarchy. For instance, the explicit goal at the regional level may be to create a system in which all marine ecosystem or habitat types are represented within an ocean basin or a country's jurisdiction, while at a lower level (and within a geographically smaller target area) MPAs might be designed to protect the most ecologically important habitats within a region. At still another level, the management objective might be the conservation of a flagship marine species or set of species, with protected areas and management interventions tailored for the specific needs of the threatened species (Garcia Charton et al. 2000). Designing such strategic and functional networks requires an understanding of regional ecology and the multiple (and cumulative) threats affecting not only the ecosystems, but the linkages between them as well. Though our ecological understanding of such linkages is far from complete, many leading marine ecologists think that we have enough information to begin designing large-scale networks, which can then be amended and adapted as new knowledge accrues.

Systems ecology can thus overcome the mismatch of large-scale policy by helping us decide where protected areas should be sited and how they should be connected, in an ecologically-driven top-down approach. Identification of priority sites can be accomplished with computer algorithms and software such as MARXAN - as employed in rezoning the Great Barrier Reef Marine Park (see www.gbrmpa.gov.au) and in the Irish Sea Pilot (see www.jncc.gov.uk), or through delphic methods that utilize expert opinion to develop consensus on key sites. Implementation of the actual form of the protected area and of conservation policy at 
each site, however, must be be under bottom-up control, to fit the needs of each particular place. Protected areas or networks can thus be organized with partnerships or co-management with indigenous groups and local communities (Jentoft \& McCay 1995). The dynamic nature of a hierarchical marine conservation system should guarantee that any country taking part in the development of a protected area system will be proactive but responsive to needs at individual sites, and scientifically rigorous but socially flexible. Individual MPAs that are accepted by local communities and thus effective in the long term can be designed strategically so that there is synergy and complimentarity between all parts of the network.

Networked MPAs within a region can be administered by a variety of means, e.g. by a single overseeing agency that designs both networks and individual protected areas, by a coordinating body that ties together MPAs variously implemented by different government agencies, or by an umbrella framework such as the 'biosphere reserves', a designation of UNESCO's Man and Biosphere Programme (UNESCO 1996). In biosphere reserves, local communities become part of the network, ecologically critical areas are afforded strict protection while less important or less sensitive areas are managed for sustainable use, and the biosphere reserve designation itself carries international prestige and can help in raising funds (Agardy 1997, UNESCO 2000). In the case of coastal and marine resources shared by different countries, regional agreements may prove most effective, based on a better understanding of costs and benefits at the regional scale (Kimball 2001). An example of such a regional body in the terrestrial/freshwater environment is the Mekong River Commission (see www.mrcmekong.org) .

While networks can help overcome the mismatch between the large scale of marine problems and the small scale of most conservation interventions, even strategically planned networks do not necessarily lead to effective marine conservation at the largest scale (Christie et al. 2002). Identification of existing protected areas and tying them together into a regional initiative does not magically create large-scale conservation-although some international institutions have claimed to be achieving this. Since individual MPAs were historically established opportunistically rather than strategically, functional networks will require the creation of new MPAs to fill remaining gaps, even in areas where MPAs are common.

But even strategically designed networks can only be a starting point for effective conservation, rather than constituting an end goal. Recognizing that more is needed than MPA networks, planners have begun to explore the concept of marine corridors and protected seascapes. A marine corridor initiative uses an MPA network as a starting point, and analyzes which threats to marine ecosystems and biodiversity cannot be addressed through a spatial management scheme. In such corridors marine policies are directed not at the fixed benthic and marine habitat that typically is the target for protected area conservation, but rather at the water quality in the water column, and the marine organisms within it. The connections between the various MPAs in a network are maintained by policy initiatives or by reforming the environmental management of areas outside the MPAs. Corridor concepts provide a way for planners and decision makers to think about the broader oceanic context in which MPAs are sited, and to develop conservation interventions that complement spatial management. Marine corridors are nascent efforts that need further conceptualization and testing in real life situations.

Overcoming the mismatch of scale. Thus, despite recent strategic approaches to marine conservation, most interventions still occur in an ad hoc and opportunistic manner, as agencies and institutions follow their mandates without really considering how they contribute to the big picture beyond their regional, sectoral or agency boundaries (NRC 2001). An integrated, systematic and hierarchical approach to conservation and sustainable use is needed, to allow nations to address various geographic scopes and scales of continental marine conservation problems simultaneously in a more holistic manner (Griffis \& Kimball 1996). By using large marine regions (regional seas, semi-enclosed seas, or eco-regions) as the focus of management rather than using globally- or nationally-generated sectoral approaches that address marine problems issue by issue, multilateral agencies can cooperate to address the full spectrum of threats and embark on developing integrated, holistic solutions. For shared coastal and marine resources, regional agreements may indeed prove more effective than global agreements, especially when such agreements are based on a better understanding of costs and benefits accruing from shared responsibilities (Kimball 2001).

Admittedly, this prescription for holistic approaches to ocean management that strategically target entire ecosystems, yet catalyze 'individualized' conservation action appropriate to each site, is idealistic and might be considered unfeasible. Indeed, when Meir et al. (2004) assessed land-based conservation planning, they concluded that large-scale, long-term conservation plans are not as effective as short-term, opportunistic interventions. This casts doubt on the ability of the world community to move towards marine conservation in the strategic way called for in this contribution. Yet there are important differences between terrestrial and marine conservation; there are stronger arguments for regional conservation using networks of 
MPAs, the most important of which is the common property nature of marine resources, which calls for cooperative rather than individualistic responses. Furthermore, the simple decision rules that Meir et al. (2004) promote, such as focusing conservation efforts on areas with highest species diversity, are of questionable utility in the marine environment, where patterns of biodiversity are poorly known and where speciespoor areas such as upwelling regions are of great ecological importance (Agardy 2003b).

MPAs play a key role in such a strategic approach, not because they are a panacea, but rather because MPAs provide a mechanism to overcome 2 of the biggest obstacles to effective marine conservation. (1) MPAs can help to shed sectoral management and addressing the full suite of threats to marine ecology in a holistic manner, as they provide demonstration models of how to integrate management across all sectors (Villa et al. 2002), and in some cases demonstrate how to tie ocean management and coastal/watershed management together. (2) MPAs can help to overcome management paralysis that arises from the enormous scale and complexity of marine environmental problems, and from the strange but pervasive notion that the oceans are a single homogenous, fluid environment; MPAs provide an important 'sense of place' to specific habitats and ecological communities, showing that not all parts of the ocean are the same, thus raising the profile and perceived value of specific places in the public's eye. By attaching special importance to specific sites, MPAs not only create opportunities for regulations on use of the area, but also create impetus and political will to address problems that originate outside the area, such as land-based sources of pollution. Individual MPAs are on scales small enough to be tractable, while a series of MPAs in a strategic network can promote region-wide marine conservation.

There are important precedents for such integrated regional approaches, suggesting that strategic, large scale planning does hold promise for more effective marine conservation. One is the relatively recent coupling of coastal zone management with catchment basin or watershed management, as has occurred under the European Water Framework Directive and projects undertaken under the LOICZ (Land-Sea Interactions in the Coastal Zone) initiative. These fully integrated initiatives, with affecting and affected parties taking part in the planning process, have resulted in lower pollutant loads and improved conditions in some estuaries (Millennium Assessment 2005).

Regional approaches utilizing MPA networks and systems are also being developed for the Mediterranean Sea under the Barcelona Convention (the Mediterranean Regional Seas Agreement), in North America under the auspices of the North American
Commission on Environmental Cooperation, and at the national scale in countries ranging from Australia to the USA. Smaller regions such as the Gulf of Maine, shared by Canada and the USA, are also focal points for regional cooperation, as demonstrated by the multilateral work undertaken as part of UNEP's Global Program of Action (see www.gpa.unep.org) and the work of the Gulf of Maine Council (see www.gulfofmaine.org). Even at the state level, initiatives are under way to select sites as part of a strategic network of MPAs. In California, USA, for instance, the state legislation known as the Marine Life Protection Act (MLPA) has spurred a review of possible methodologies to identify sites for networks that would capture both representative and ecologically critical areas. This initiative is noteworthy in the context of this contribution, because the waters of the State of California encompass portions of 3 biogeographic provinces or eco-regions, and the MLPA initiative may provide a tangible model for designing regional MPA networks.

The nascent efforts in the Mediterranean to develop a representative system of MPAs are exemplary. A legal framework for multilateral cooperation already exists under the Barcelona Convention (Convention for the Protection of the Mediterranean Sea Against Pollution, adopted in 1976 and in force since 1978), with the participation of 22 parties from the riparian nations surrounding the Mediterranean. Though the original emphasis of the treaty was on pollution reduction, and the Convention is considered a success in this regard, the bulk of recent attention among the Parties has been on habitat and biodiversity conservation. Under the Protocol on Specially Protected Areas, the Parties have begun to assemble a list of regionally important areas called SPAMIs (Specially Protected Areas of Mediterranean Importance). Work is now underway to use the SPAMI list as a starting point to evaluate what is currently missing from the Mediterranean-wide protected area portfolio, in terms of both representation of all habitat types and in terms of adequately protected habitats and resources. Once this gap analysis is completed, the Parties to the Convention will have guidance on where to site new MPAs and how to amend existing ones. The end result could well be a much more effective protection of regional biodiversity, based on the economies of scale that MPA networks and systems provide, including better opportunities for management training, cooperative surveillance and enforcement, and standardized research protocols.

Through such regional conservation programs, goals such as conservation of biodiversity, including rare and threatened species, maintenance of natural ecosystem functioning at a regional scale, and management of fisheries, recreation, education, and research could be addressed in a more coordinated and complementary 
fashion (Agardy 2003a). The integrated approach is a natural response to a complex set of ecological processes and environmental problems, and is an efficient way to allocate scarce time and resources to addressing the issues that parties deem to be most critical. Nations and agencies that participate reap the benefits of more effective conservation, while bearing fewer costs by spreading management costs widely and by taking advantage of economies of scale in management training enforcement, etc. Through regional initiatives, a top-down holistic perspective can be matched to bottom-up site-appropriate interventions, and the priorities of international groups that funnel attention and money to conservation sites can be harmonized with local priorities and needs. But 3 things are required for such integrated, holistic approaches to succeed: ecological understanding, sensitivity to social and political factors, and leadership that understands and acknowledges a holistic view and has the strength of conviction to move a complicated agenda forward.

Ecological understanding is needed to realistically assess the threats to the marine environment: their nature, their scope, how they interact with one another, and what can be done about them. A knee jerk reaction to apply a generic policy prescription every time an environmental problem arises, without a true understanding of the threats and drivers behind them, can often result not only in failure of that particular intervention, but also create obstacles to future conservation (Agardy et al. 2003).

Social science needs to inform us about how solutions are developed to address threats at the site level. After all, conservation is not about managing ecosystems or other species, but about managing our own human species. In order to change human behavior, we must understand what drives people to use resources unsustainably, and what proximate and indirect drivers lead to bad governance and management (Christie 2004). Social science can also tell us what is feasible and sustainable-long after the cadre of visiting scientists and conservationists that initiate the conservation action are gone.

Finally, we must recognize the importance of true leadership and 'the power of one'-and identify individuals with the vision, commitment, and power to move forward. Such leadership could drive meaningful regional agreements that allow the development of strategically planned MPA networks, and at the same time address the wider context through pollution controls, harmonization of regional land use planning, river basin management, etc. Only visionary leaders in these regions will be able to rally the troops of committed individuals doing the small scale work that is conservation, and convert what are piecemeal and largely losing battles into a united front against coastal and ocean degradation.

\section{LITERATURE CITED}

Agardy TS (1997) Marine protected areas and ocean conservation. R.E. Landes, Austin, TX

Agardy T (1999) Ecosystem-based management: a marine perspective. In: Maltby E, Holdgate M, Acreman M, Weir A (eds) Ecosystem management-questions for science and society. RHIER, University of London, Egham, p 44-46

Agardy T (2003a) An environmentalist's perspective on responsible fisheries: the need for holistic approaches. In: Sinclair M, Valdimarsson G (eds) Responsible fisheries in the marine ecosystem. FAO, Rome, p 65-85

Agardy T (2003b) Optimal design of individual marine protected areas and MPA systems. In: Beaumer JP, Grant A, Smith DC (eds) Protected areas. Pro World Conf Aquatic Protected Areas, 8-12 August 2002. Australian Society for Fish Biology, Norh Beach, WA, p 111-119

Agardy T, Wolfe L (2002) Institutional options for integrated management of a North American marine protected areas network. Commission on Environmental Cooperation Report, CEC, Montreal. Available at: www.cec.org

Agardy T, Bridgewater P, Crosby MP, Day J and 7 others (2003) Dangerous targets: differing perspectives, unresolved issues, and ideological clashes regarding marine protected areas. Aquat Conserv Mar Freshw Ecosyst 13:1-15

Allison GW, Lubchenco J, Carr M (1998) Marine reserves are necessary but not sufficient for marine conservation. Ecol Appl 8(1):S79-S92

Chapin M (2004) A challenge to conservationists. Worldwatch Mag Nov/Dec:17-31

Christie P (2004) Marine protected areas as biological successes and social failures in southeast Asia. Am Fish Soc Symp 42:155-164

Christie P, White A, Deguit P (2002) Starting point or solution? Community-based marine protected areas in the Philippines. J Environ Manage 66:441-454

de Fontaubert C, Agardy T (1998) Implementing the protocol on specially protected areas and wildlife of the Cartagena Convention. Georgetown Int Environ Law Rev 10(3): 753-854

Friedlander A, Sladek Nowlis J, Sanchez JA, Appeldoorn R, Usseglio P, McCormick C, Bejarano S, Mitchell-Chui A (2003) Designing effective marine protected areas in Sea-flower Biosphere Reserve, Colombia, based on biological and sociological information. Conserv Biol 17(6): $1769-1784$

Garcia Charton JA, Williams ID, Perez Ruzafa A, Milazzo $M$ and 5 others (2000) Evaluating the ecological effects of Mediterranean marine protected areas: habitat, scale, and the natural variability of ecosystems. Environ Conserv 27(2):159-178

Griffis RB, Kimball KW (1996) Ecosystem approaches to coastal and ocean stewardship. Ecol Appl 6(3):708-712

Jentoft S, McCay B (1995) User participation in fisheries management, lessons drawn from international experiences. Mar Pol 19(3):227-246

Jones PJS (1994) A review and analysis of the objectives of marine nature reserves. Ocean Coast Manage 23(3):149-178

Jones PJS (in press) Collective action problems posed by no-take zones. Mar Pol

Kay R, Alder J (2005) Coastal planning and management, 2nd edn. EF\&N Spoon, London

Kimball L (2001) International ocean governance. IUCN, Gland

Leslie H, Rucklehaus M, Ball I, Andelman S, Possingham H (2003) Using siting algorithms in the design of marine reserve networks. Ecol Appl 13:S185-S198

Meir E, Andelman S, Possingham HP (2004) Does conserva- 
tion planning matter in a dynamic and uncertain world? Ecol Lett 7:625-622

Millennium Assessment (2005) Millennium ecosystem assessment, Vol I: Conditions and trends. In: Agardy T, Alder J (eds) Coastal systems and coastal communities, chapter 19. Available at: www.milleniumassessment.org

NRC (2001) Marine protected areas: tools for sustaining ocean ecosystems. Ocean Studies Board, National Research Council, Washington, DC

Possingham H, Ball I, Andelman S (2000) Mathematical models for identifying representative reserve networks. In: Ferson S, Burgman MA (eds) Quantitative methods in conservation biology. Springer-Verlag, New York, p 291-306

Roberts CM, Halpern B, Palumbi SR, Warner RR (2001) Designing marine reserve networks: why small, isolated protected areas are not enough. Conserv In Practice 2(3):12-19

Sale RF, Cowen RK, Danilowicz BS, Jones GP and 7 others (2005) Critical science gaps impede use of no-take reserves. Trends Ecol Evol 22(2)

Sorensen J (1993) The international proliferation of integrated coastal zone management efforts. Ocean Coast Manage 21(1-3):45-80

Speth JG (2004) Red sky at morning. Yale University Press, New Haven, CT

UNESCO (1996) Biosphere reserves: the Seville Strategy and the statutory framework of the World Network. UNESCO, Paris

UNESCO (2000) Solving the puzzle: the ecosystem approach and biosphere reserves. UNESCO, Paris

Villa F, Tunesi L, Agardy T (2001) Optimal zoning of a marine protected area: the case of the Asinara National Marine Reserve of Italy. Conserv Biol 16(2):515-526

Wang H (2004) Ecosystem management and its application to large marine ecosystems: science, law and politics. Ocean Dev Int Law 35:41-74

\section{Evolving ecosystem approaches to management of fisheries in the USA}

\section{David Fluharty}

\author{
School of Marine Affairs, University of Washington, \\ 3707 Brooklyn Ave. NE, Seattle, Washington 98105, USA \\ Email: fluharty@u.washington.edu
}

Introduction. Definitions of ecosystem approaches to management (EAM; acronyms are listed in Table 1) are replete in the fisheries management literature (Brodziak \& Link 2002, Garcia et al. 2003, FAO 2003). I define the ecosystem approach to management simply and pragmatically as 'using what is known about the ecosystem to manage fisheries.' This approach acknowledges that fisheries decisions take place in an ecosystem context and ecosystem knowledge can assist in managing fisheries production and identifying fishing effects on ecosystems. It draws attention to the fact that we are not yet applying the ecological knowledge that we presently have. Thus, I argue that effort to craft a consensus on the ecosystem approach to management is not required before actions are taken (Babcock \& Pikitch 2004). Such a consensus can evolve
Table 1. List of acronyms

\begin{tabular}{|ll}
\hline EAM & Ecosystem approach to management \\
EFH & Essential fish habitat \\
EPAP & Ecosystem Principles Advisory Panel \\
FEP & Fishery Ecosystem Plan \\
MSA & $\begin{array}{c}\text { Magnuson-Stevens Fishery Conservation and } \\
\text { Management Act }\end{array}$ \\
MSY & Maximum sustainable yield \\
NEPA & National Environmental Policy Act \\
NMFS & National Marine Fisheries Service \\
NOAA & National Oceanic and Atmospheric \\
& Administration \\
NPFMC & North Pacific Fishery Management Council \\
& (Anchorage, AK) \\
NRC & National Research Council \\
POC & Pew Oceans Commission \\
SFA & Sustainable Fisheries Act \\
USCOP & U.S. Commission on Ocean Policy \\
WPFMC & Western Pacific Fishery Management Council \\
& (Honolulu, HI)
\end{tabular}

from experience gained in actions implemented. Starting with a fisheries-centric approach makes sense, because fisheries are a key concern, and they are already managed at the ecosystem scale.

Ecosystem approaches to management in marine fisheries in the United States arguably originated in 1871, when Congress established the U.S. Commission of Fish and Fisheries, designed to reverse the decline in New England fisheries. Spencer Baird, the first Commissioner, initiated ecological studies including the dynamics of physical and chemical oceanography, because an understanding of fish '... would not be complete without a thorough knowledge of their associates in the sea, especially of such as prey upon them or constitute their food ...' (cited after Hobart 1995, p. VII). Today we continue to contemplate and debate implementation of EAM in federal fisheries. How far have we come in $140 \mathrm{yr}$ ? I suspect that we may be further than commonly thought. To convince you of this, I will focus on what is being done correctly in fishery management, and not on what has been done wrong. Remodeling a house or a fishery management system is a process of planning and adapting; it takes time, it is expensive, and the results are not apparent until the project is completed. Thus, I focus on the foundation being laid for EAM, rather than on the shabby exterior.

Shifting the baseline from the present to the future. The USA has changed direction with respect to fisheries management in favor of an ecosystem approach to management. The main drivers include: (1) improvement in scientific understanding of the dynamics of fished ecosystems; (2) reaction to the failure in achieving sustainable fisheries; (3) increase in public involvement and legal action; (4) demonstrable man- 
agement success in applying conservative fishery management tools; (5) added consideration of the protection of seabirds, sea turtles, marine mammals, and species that are rare or endangered; (6) strengthened requirements for management. Other factors are acting on the ecological and socio-economic context for fisheries management as well. Anoxic 'dead zones,' hazardous algal blooms, and climate variability and change are affecting the environment and fisheries. Increasing energy prices, changing technologies, and surging imports of cultured fish and shellfish are making the human dimensions of fisheries more vulnerable to environmental change. This uncertainty generates a demand for improving the ability to predict ecosystem changes. Together, these conditions are causing major rethinking of the incentive structure in fishing as human wants and needs are harmonized with sustaining marine ecosystems. EAM is a framework for providing the right kind of incentives for sustainable fisheries management (sensu Callicott \& Mumford 1997, Hanna 1998, Hilborn et al. 2005).

To address the prerequisites for EAM, i.e. sustainably managed fisheries, the U.S. Congress amended the Magnuson-Stevens Fishery Conservation and Management Act (MSA) [PL 94-265] in 1996. The Sustainable Fisheries Act (SFA) marked the legislative tipping point for changing federal fisheries management standards in significant ways: (1) maximum sustainable yield (MSY) was set as a limit; (2) rebuilding plans were required for fish stocks defined as overfished; (3) bycatch was to be 'minimized'; (4) essential fish habitat $(\mathrm{EFH})$ was to be protected. In addition, the National Marine Fisheries Service (NMFS) was charged with forming an Ecosystem Principles Advisory Panel to assess the extent to which ecosystem principles were being applied in fishery management and to advise on measures to increase their use.

These legislative mandates set in motion serious management reform efforts at the federal level. Full implementation of these measures is an important building block toward EAM. Let us examine what has happened as a result of the SFA, i.e. with regard to ending overfishing, counting bycatch, designating EFH and developing EAM.

Overfishing and rebuilding plans. Prior to 1996 it was possible for regional management councils to allow overfishing, i.e. to set a total allowable catch that was greater than the MSY. It was possible to substitute economic or other considerations for biological considerations in setting allowable catches. No standard was set for what catch level constituted 'overfishing.' Therefore, it was seldom feasible for the NMFS to override council decisions that allowed overfishing. When NMFS did challenge the scientific bases of these decisions, fishing interests circumvented the agency through appeals for political support from members of Congress (Hennessey \& Healy 2000).

The SFA set MSY as a limit and required that rebuilding plans be developed for overfished fisheries to restore them within a period of $10 \mathrm{yr}$. There are difficulties in making this policy fit all species, related to the utility of the MSY standard itself, and its application to very short- and long-lived species. However, the SFA has given NMFS a foothold for critical review of management decisions on catches, and it has given considerable legal leverage to environmental advocacy groups to challenge catch levels and the adequacy of rebuilding plans. This combination of internal and external forcing has brought virtually all of the overfished stocks in federal fisheries under rebuilding plans (NMFS 2003), although recovery may be slow in long-lived species. Still, concerns exist in the environmental community, because the SFA applies only to species fished under a current fishery management plan where stock assessments are made, as opposed to all other species (commercial or non-commercial). An EAM is included in the more sophisticated single-species stock assessments through consideration of environmental variability, risk, and other stochastic factors.

Bycatch minimization. Bycatch is an issue with which federal fishery managers have been wrestling for some time. SFA's new national standard focused more attention on the issue (NMFS 1998). The effect of the requirements to minimize bycatch and to lower mortality of bycatch has been difficult to monitor. NMFS has developed a bycatch website (www.nmfs.noaa.gov/ bycatch.htm) and a national approach to standardized bycatch monitoring (NMFS 2004a). Bycatch can present different characteristics in each fishery, area and season. Relatively few fisheries where bycatch is reliably known exist in federal waters, except in Alaska where industry-funded observers monitor significant portions (>80\%) of the total catch (Tagert 2004). Technical modifications of fishing gear are resulting in lower bycatch in some fisheries, and changes are being made in other fishing practices. Determining what is practicable in terms of bycatch minimization is far from precise (Steele 2004). More importantly from EAM perspectives, the SFA dealt primarily with bycatch of fishes in commercial fisheries. The NMFS approach to implementation went beyond bycatch of fishes to include bycatch in recreational fisheries, as well as bycatch of highly migratory fish species, as well as non-fish species such as seabirds, marine mammals and sea turtles, where some of the pressing bycatch issues occur.

Essential fish habitat (EFH). Under the SFA, NMFS was charged with developing regulatory guidelines for habitat protection within 6 months of passage of the Act. Formal amendment of each fishery management plan was required. EFH was defined as habitat used by man- 
aged species of fishes through all life history stages (i.e. those waters and substrates necessary to the fishes for the purpose of spawning, breeding, feeding, or growth to maturity), rather than habitat per se which sustained fishes and other ecosystem components. Therefore, managers were expected to identify habitat used by each of the approximately 1000 managed species and to determine how each habitat contributed to fishery production. In addition, the effect of fishing on habitats was to be assessed and measures were to be taken towards mitigating adverse impacts (Kurland 2004). Habitat areas of particular concern could be designated as well (NMFS 2001). The effort to designate EFH has vastly increased spatial and temporal understanding of fishes and their environments, and this has the potential to contribute greatly to EAM (Fluharty 2000).

Not surprisingly, the task of implementing EFH proved to be a gravely underfunded mandate to accomplish in an unrealistically compressed timeframe. Despite immediate response by NMFS to develop regulatory guidelines, it took until 2002 to finalize them. In the meantime, NMFS scientists and consultants worked overtime to compile and assess available data, develop regulatory amendments and push these through the regional council process. Eventually, the hastily developed plan amendments were judged to be inadequate (Coleman \& Travis 2000). This led to litigation and a negotiated settlement which specified new timeframes and requirements (Kurland 2004). New EFH protection designations in the 8 council regions now provide building blocks for an EAM, although they are only part of the foundations of EAM. Examples of these building blocks are large areas closed to bottom gear such as trawls, e.g. $95 \%$ of the federal waters surrounding the Aleutian Islands in Alaska (approximately 279000 square n miles). All major seamounts off Alaska are closed to trawling as well (see www.fakr.noaa.gov/ habitat/efh.htm). Thus, EAM is furthered by actions to protect EFH and aided by the synthesis of available data on habitats and fishing impacts. The process of developing these plans has identified significant data gaps. This allows prioritization of research on habitats and their relationships to fisheries, and on effects of fishing on habitats (Kurland 2004).

Besides the development of EFH protection measures, federal fishery management is advancing the use of marine protected areas (MPAs) on an increasingly broad scale as a tool in fishery management (NRC 2001). Recent designations of fishery management MPAs include the Sitka Pinnacles Marine Reserve and crab protection areas in Alaska (Witherell unpubl.), extensive trawl closures along the Pacific West Coast to protect rockfish stocks (Hastie 2005), and multiple closed areas in New England for groundfish recovery (Murawski et al. 2000). While these management measures tend to target single species or species groups, they encompass a wider range of ecosystem components and functions than those explicitly targeted, and therefore they constitute an EAM in the sense of applying what we know about the ecosystem in managing fisheries.

Ecosystem Approach to Management (EAM). NMFS made its first formal efforts to articulate EAM in the late 1980s by forming a group of scientists charged with developing a strategic plan. The plan was developed, but not implemented as the result of the change from a government that was environmentally friendly to one that was less supportive (Boehlert pers. comm.). Still, the concept was being explored on many fronts; Island Institute organized a high level conference at Harvard University in 1992 under the title 'The System and the Sea' (Platt 1993), and major journals devoted special issues to ecosystems and fisheries (Mooney 1998). The National Research Council was charged with reviewing fishery management and it advised that an ecosystem approach was needed (NRC 1999).

Through the SFA, the U.S. Congress in 1996 mandated a review of the application of ecosystem principles in federal fisheries management and requested a report on how to increase their application. Congress charged NMFS to appoint a 20-member panel to carry out this task. The panel comprised a diverse group of academics, fishery managers, fishery scientists, ecologists, economists, non-governmental environmental organizations and industry representatives from around the USA (full disclosure compels me to inform readers that I had the privilege of serving as chair of this panel). Over a year-long process of meetings, hearing from fisheries experts, managers, fishing and environmental interests, the panel derived a template of ecosystem principles, management goals and policies that were needed in EAM (EPAP 1999).

When the panel assessed the application of this EAM template on federal fisheries, it concluded that examples of EAM could be found in each of the regional fishery management areas, but that the principles, goals and policies were not applied systematically. We found that the most consistent application emerged from groundfish management in the Alaska region, which (1) places caps on total removals, (2) sets conservative harvest quotas, (3) develops a yearly report on ecosystem considerations to be used in the context of management decisions, (4) employs an Ecosystem Committee to organize discussion and public forums to exploring EAM, (5) manages bycatch and counts it against harvest quotas, (6) uses marine protected areas, i.e. spatially explicit closures of gear types for fishery management, and (7) has an extensive observer program (Witherell et al. 2000).

Based on this review our primary recommendation was that regional management councils develop Fish- 
ery Ecosystem Plans (FEP) to consolidate information about the ecosystem and ecosystem trends in a format that would generally inform fishery management, and would specifically be applied to actions under separate fishery management plans (EPAP 1999). The first iteration in the development of the FEP as a tool in U.S. fishery management would be experimental and not action-forcing. The FEP would be broader in scope and longer term than the requisite National Environmental Policy Act (NEPA) assessment for environmental impact analysis. The FEP would (1) delineate the geographic extent of ecosystems; (2) develop a conceptual model of the food web; (3) describe the habitat needs of different components of the 'significant food web'; (4) calculate total removals and relate them to standing biomass, production, optimum yield, natural mortality and trophic structure to ensure that they are not excessive; (5) assess uncertainty and how buffers are included in conservation and management actions; (6) develop indices of ecosystem health as targets for management; (7) describe long term monitoring and how it is used; (8) identify the elements external to the fishery management process that affect fisheries and their ecosystems and to engage with other management institutions to reduce adverse impacts.

The panel saw full implementation of the SFA measures as initial steps toward EAM. We felt that development of EAM was more likely to be effective if it were bottom up, incremental and adaptive, rather than if it were top down, abrupt and rigid. We wanted a recommendation that could be implemented by NMFS under existing rules, although we were sensitive to the potential lack of incentive to change and funding for development without a legislative mandate. Fundamentally, it was most important to demonstrate the utility of EAM in fishery management and to gain experience using it.

The panel's expectation was that NMFS would encourage regional councils to prepare 'pilot' or 'demonstration' FEPs to gain experience that could be used in developing future legislative proposals. The recommendation was generally well-received by Congress, fishery management councils and NMFS; it was greeted warily by fishing interests, because they doubted its utility, and it was seen as being too timid by environmental interests, because they preferred a weaker focus on fisheries. Within NMFS, 2 major factors worked against immediate implementation of the panel recommendations: (1) NMFS could not absorb this major initiative while it was over-worked with implementation of the SFA; (2) NMFS was defending itself in serious legal challenges to mandated tasks and to its record of NEPA compliance.

Developing EAM after the panel report. The EAM efforts in U.S. fisheries are part of the developing global interest in fishery management reform (FAO 2003, Sinclair \& Valdimarsson 2003, Gable 2004, Walters \& Martell 2004, Hennessey \& Sutinen 2005). The International Council for Exploration of the Sea (ICES) convened a major international meeting on ecosystem effects of fishing (Hollingsworth 2000) and its Pacific counterpart, the North Pacific Marine Science Organization developed an assessment of marine ecosystem approaches (PICES 2004), and convened 2 study groups to develop EAM (King 2005, Jamieson \& Zhang 2005).

The first FEP initiative came through the National Oceanic and Atmospheric Administration's (NOAA) Chesapeake Bay office, which began developing an FEP for Chesapeake Bay in 2000 (NOAA 2004) to provide a synthesis of ecosystem information as decision support to the various fisheries and environmental managers in the region. The original FEP concept was designed for the 8 regional fishery management councils. The Chesapeake Bay FEP serves as a decision support tool for a very complex system of state level management, and FEP development provided valuable feedback on proof of concept.

At approximately the same time, NMFS convened a panel under the auspices of the Marine Fisheries Advisory Committee to further develop technical guidance for implementing an EAM in fisheries; this led to the preparation of a report to supplement the EPAP (1999) report (Busch et al. 2003). Based on this advice, members of Congress have since 2000 introduced bills which include provisions similar to the EPAP (1999) recommendations (see http://thomas.loc.gov). In addition, 2 recent national-level ocean commission reports have endorsed EAM for U.S. fisheries (USCOPS 2004, POC 2003) and the Ocean Action Plan of the U.S. government states that it continues to work toward EAM in decision-making (Office of the President 2004).

Following the endorsement of EAM by the 2 ocean commissions, efforts began NOAA-wide to develop an EAM that would apply across its broad spectrum of marine regulatory, science and resource management activities. In late summer 2004, NOAA convened a workshop on delineation of regional ecosystems (DeMaster \& Sandifer 2004). The most recent statement from NOAA about EAM developments extends the discussion relative to EAM in fisheries (NMFS 2004b), but intensive work continues inside that agency. Apparently, this has caused some concerns from the Chairs of the regional fishery management councils, who want to be involved more in the development of EAM for NMFS and in congressional activities on EAM (CCED 2005, Waugh 2005; see http://managingfisheries.org).

Regional fishery management councils are making very diverse and interesting efforts to advance EAM. 
In 2004, NMFS made funding available to the New England, Mid Atlantic, South Atlantic and Gulf of Mexico councils, for developing pilot projects on ecosystem-based management (Managing Fisheries 2005). The South Atlantic Fisheries Management Council is adopting its current Habitat Management Plan towards a prototype FEP (see http://map.mapwise. com/safmc). The Western Pacific council has developed a Coral Reef Fisheries Ecosystem Plan (WPFMC 2001) and is considering the development of archipelagic FEP as a means of downscaling its Pacific-wide FMPs for greater relevance to the people and fisheries in archipelagos. The NPFMC is considering the development of an EAM for Alaskan ecosystems (Evans \& Wilson 2005) and of an area-specific management approach to the Aleutian Islands that is similar to the FEP (NPFMC 2005).

Synopsis. Over the last decade the discussion of EAM in fisheries management has been moved from the lunchrooms of scientists to the main stage of U.S. fisheries management. It is being propelled by an increasing awareness that insights from EAM can improve management of fisheries and assist in identifying and mitigating adverse effects of fishing. While EAM is not limited to fisheries management, the fisheries context provides a basis for advancing from concept to action. Fisheries management is accustomed to decision-making at ecosystem scales and is now realizing that more discrete spatial and temporal management is necessary. Presently, there is tension between those experts who advance a central management approach that focuses on top down and standardized implementation of EAM, and those who endorse regional approaches that are experimental and adaptive to diverse circumstances.

\section{LITERATURE CITED}

Babcock EA, Pikitch EK (2004) Can we reach agreement on a standardized approach to ecosystem-based fishery management? Bull Mar Sci 74:685-692

Brodziak J, Link J (2002) Ecosystem-based fishery management: what is it and how can we do it? Bull Mar Sci 70: $589-611$

Busch WDN, Brown BL, Mayer GF (eds) (2003) Strategic guidance for implementing an ecosystem-based approach to fisheries management. DOC/NOAA/NMFS Tech Rep, Silver Spring, MD

Callicott JB, Mumford K (1997) Ecological sustainability as a conservation concept. Conserv Biol 11:32-40

Coleman F, Travis J (eds) (2000) Essential fish habitat and marine reserves. Proc 2nd Mote Int Symp Fish Ecol. Bull Mar Sci 66:525-1009

CCED (2005) Positions of the regional fishery management council chairs on reauthorization of the MagnusonStevens Fishery Management and Conservation Act [sic] April 28. Regional Fishery Management Council Chairs and Executive Directors, Silver Spring, MD

DeMaster D, Sandifer P (2004) Executive summary: workshop on delineation of regional ecosystems. NOAA, Charleston, $\mathrm{SC}$

EPAP (1999) Ecosystem-based fishery management: a report to Congress by the Ecosystems Principles Advisory Panel. NOAA/NMFS, Silver Spring, MD (available at: www. st.nmfs.gov/st7/documents/epap_report.pdf)

Evans D, Wilson B (2005) Role of the North Pacific Fishery Management Council in the development of an ecosystem approach to management for the Alaska large marine ecosystems - draft. North Pacific Fishery Management Council, Anchorage, AK (available at: www.fakr.noaa. gov/npfmc)

FAO (2003) Fisheries management 2: the ecosystem approach to fisheries. FAO, Rome

Fluharty D (2000) Habitat protection, ecological issues, and implementation of the Sustainable Fisheries Act. Ecol Appl 10:245-255

Gable FJ (2004) A large marine ecosystem approach to fisheries management and sustainability: linkages and concepts towards best practices. NOAA Tech Memo NMFS-NE-184

Garcia SM, Zerbi A, Aliaume C, Do CT, Lasserre G (2003). The ecosystem approach to fisheries: issues terminology, principles, institutional foundations, implementation and outlook. FAO Fish Tech Pap 443. FAO, Rome

Hanna SJ (1998) Institutions for marine ecosystems: economic incentives and fishery management. In: Mooney HA (ed) Ecosystem management and sustainable marine fisheries. Ecol Appl (Suppl)8:S170-S174

Hastie J (2005) Managing bycatch in the West Coast groundfish fishery. In: Wooster WS, Quinn J (eds) Summary Proc Symp on Improving fishery management: melding science and governance. School of Marine Affairs, University of Washington, Seattle, WA (available at: www.sma. washington.edu/fishsymp/)

Hennessey T, Sutinen J (eds) (2005) Sustaining large marine ecosystems: the human dimension. Large marine ecosystems, Vol 13. Elsevier, Amsterdam

Hennessey T, Healy M (2000) Ludwig's ratchet and the collapse of New England groundfish stocks. Coast Manag 22:119-145

Hilborn R, Orensanz JM, Parma AM (2005) Institutions, incentives and the future of fisheries. Phil Trans R Soc Lond Ser B 360:47-57

Hobart WL (1995) Baird's legacy: the history and accomplishments of NOAA's National Marine Fisheries Service. NOAA Tech Memo NMFS-F/SSPO-18

Hollingsworth CE (ed) (2000) Ecosystem effects of fishing. ICES J Mar Sci 57:465-791

Jamieson G, Zhang CI (eds) (2005) Report of the study group on ecosystem-based management science and its application to the North Pacific. Sci Rep 29, PICES, Vancouver

King JR (ed) (2005) Report of the study group on fisheries and ecosystem responses to recent regime shifts. Sci Rep 28, PICES, Vancouver

Kurland J (2004) Protecting fish habitat. In: Witherell D (ed) Managing our nation's fisheries: past, present and future. Proc Conf Fisheries Management in the United States. North Pacific Fisheries Management Council, Anchorage, AK, p 170-175

Managing Fisheries (2005) Developing ecosystem approaches to fisheries. (available at: http://managingfisheries.org)

Mooney HA (ed) (1998) Ecosystem management and sustainable marine fisheries. Ecol Appl (Suppl)8:S1-S174

Murawski SA, Brown T, Lai HL, Rago PJ, Hendrickson L (2000) Large-scale closed areas as a fisheries management 
tool in temperate marine systems: the Georges Bank experience. Bull Mar Sci 66(3):775-798

NMFS (1998) Managing the nation's bycatch: priorities, programs and actions for the National Marine Fisheries Service. NOAA/NMFS, Silver Spring, MD

NMFS (2001) Regional council approaches to the identification and protection of habitat areas of particular concern. DOC/NOAA/NMFS, Silver Spring, MD

NMFS (2003) Implementing the Sustainable Fisheries Act: achievements from 1996 to the present. NOAA/NMFS, Silver Spring, MD

NMFS (2004a) Evaluating bycatch: a national approach to standardized bycatch monitoring programs. NOAA Tech Memo NMFS-F/SPO-66

NMFS (2004b) NOAA Fisheries' requirements for an ecosystem approach to management of living marine resources. DOC/NOAA/NMFS, Silver Spring, MD

NOAA (2004) Chesapeake Bay fisheries ecosystem plan. NOAA/NMFS, Annapolis, MD

NPFMC (2005) Draft area-specific management for the Aleutian Islands. Discussion paper, North Pacific Fishery Management Council Anchorage, AK (available at: www. fakr.noaa.gov/npfmc)

NRC (2001) Marine protected areas: tools for sustaining ocean ecosystems. National Research Council, National Academy Press, Washington, DC

Office of the President (2004) U.S. ocean action plan: the Bush administration's response to the U.S. Commission on Ocean Policy. Washington DC

POC (Pew Oceans Commission) (2003) America's oceans: charting a course for change. Pew Trusts, Pew Oceans Commission (available at: www.pewtrusts.org)

PICES (2004) Marine ecosystems of the North Pacific. Spec Publ 1, PICES, Vancouver

Platt DD (ed) (1993) The system in the sea: applying ecosystems principles to marine fisheries, vol 2. Proc Island Institute Conference at Harvard University. Island Institute, Rockland, ME

Sinclair M, Valdimarsson G (eds) (2003) Responsible fisheries in the marine ecosystem. FAO, Rome \& CABI Publishing, Wallingford

Steele L (2004) Technology, data and information in bycatch management. In: Witherell D (ed) Managing our nation's fisheries: past, present and future. Proc Conf Fisheries Management in the United States. North Pacific Fisheries Management Council, Anchorage, AK, p 202-207

Tagert J (2004) Policy perspectives on bycatch. In: Witherell D (ed) Managing our nation's fisheries: past, present and future. Proc Conf Fisheries Management in the United States. North Pacific Fisheries Management Council, Anchorage, AK, p 196-201

USCOP (2004) An ocean blueprint for the 21st century: final report. U.S. Commission on Ocean Policy, Washington, DC (available at: www.oceancommission.gov)

Walters DJ, Martell SJD (2004) Fisheries ecology and management. Princeton University Press, Princeton, NJ

Waugh GT (2005) Ecosystem-based management-to amend or not amend (the Magnuson-Stevens Act) that is the question? http://managingfisheries.org

WPFMC (2001) Fishery management plan for coral reef ecosystems of the Western Pacific Region: final environmental impact statement. Western Pacific Fishery Management Council, Honolulu, HI

Witherell D, Pautzke C, Fluharty D (2000) An ecosystembased approach for Alaska groundfish fisheries. ICES J Mar Sci 57:771-777

\section{Implementing the ecosystem approach: making ecosystems matter}

\author{
Michael F. Hirshfield \\ Oceana, 2501 M Street NW, Washington, DC 20034, USA \\ Email: mhirshfield@oceana.org
}

Introduction. It should be no surprise that conservation organizations are strong proponents of ecosystem-based management of the oceans. At their core, most conservation organizations are committed to protecting ocean ecosystems; their mission statements often include specific references to 'healthy' ecosystems. Conservation groups want to see oceans that include apex level predators, longlived rockfish, complex living benthic habitat, agestructured fish populations, and the maintenance of diverse marine communities. They want to see exploitation at levels, and using methods, that will not compromise these and other ecosystem functions-anywhere in the ocean. For conservation organizations, the promise of ecosystem approaches is that their use will require those who manage ocean users (in particular those who manage fishers) to give greater value to the condition of non-fish components of the ecosystem, in contrast to a singleminded focus on 'production' (or other extractive uses). These components include not only so-called 'charismatic' creatures such as sea turtles, whales and dolphins, but also other members of marine communities, including in particular invertebrates and fishes other than those targeted by fishers. As a result of this shift in perspective, conservationists hope that the health of our ocean ecosystemswidely considered to be severely compromised (POC 2003, USA Commission on Ocean Policy 2004) — will begin to improve.

For an idea whose time has clearly come (and that arguably arrived over a decade ago), ecosystem based management remains remarkably controversial and seemingly ill defined. It is common to hear speakers at conferences say 'of course we all agree that we need ecosystem based management, but we're still not sure what it means.' The debate includes disputes over what problems it is intended to solve, what measures are appropriately considered ecosystem based, and, indeed, whether it is needed at all. For conservationists, ecosystem based management encompasses all of the threats to ocean ecosystems, including pollution and non-fisheries based habitat destruction. A previous MEPS Theme Section on the ecosystem approach (Browman \& Stergiou 2004) focused on one component of ecosystem based management-ecosystem approaches to fisheries management (EAF). 
Conservationists think that healthy ecosystems can only coexist with fisheries where managers have solved the triple problems of overfishing, bycatch, and habitat destruction. We conservationists think that the EAF is essential to solving those problems. We also think that the EAF is the only way to integrate our understanding — and management — of the cumulative impacts of our actions on the ocean. EAF also provides the opportunity - indeed the necessity - to put precautionary management into practice.

Overfishing from an ecosystem perspective. As discussed in several of the previous MEPS Theme Section contributions (Hilborn 2004, Mace 2004, Sissenwine \& Murawski 2004), single species fishery management has been largely driven by the concept of maximum sustainable yield (MSY). While many fisheries scientists have argued that MSY should be a limit, and not a target, there is no question that MSY has indeed been the target for many of the world's fisheries. There is also no question that MSY is a frequently overshot target, and this has resulted in what fisheries scientists usually refer to as 'overfishing.' In fact, the dictionary definition of 'to overfish' has nothing to do with MSY; it is much more closely aligned with ecosystem considerations - 'to fish (a body of water) to such a degree as to upset the ecological balance or cause depletion of living creatures.' (American Heritage Dictionary of the English Language 2000). Conservationists hope that this definition of overfishing will become the standard for fisheries managers.

For conservationists, the premise of fisheries management, that there is a 'surplus' of fish waiting to be caught by humans, is flawed. We must always be aware that any pollock we eat is not available, e.g. for a Steller sea lion. Successful fisheries management means not just sustainable catches of fish for humans. Intact ecosystems must be maintained-not necessarily pristine, but retaining their components and interrelationships, as well as adequate resistance and resilience to disturbance. The implication that overfishing is the only (or the main) problem in the world's oceans has the unfortunate consequence of relegating other ecosystem impacts such as habitat destruction to secondary importance and demonstrates precisely the lack of ecosystem perspective that so concerns conservationists.

Conservationists hope that the EAF will inject much needed ecological and biological information into management systems, which currently either lack or discount it. As a consequence, the EAF should help address several specific problems with MSY-based single species management approaches as currently practiced. (1) It is becoming clear that the typical target of reductions in biomass of 50 to $70 \%$ below unfished levels (tacitly or explicitly endorsed by many fisheries sci- entists; e.g. Mace 2004, Sissenwine \& Murawski 2004) is dangerous for slow-growing, late-maturing, longlived species (such as many rockfish and sharks); higher levels of abundance (and hence lower fishing rates) are essential to maintain healthy populations. (2) There is increasing evidence that it is dangerous to presume that all mature female fish are of equal importance for the population; protecting the older, larger females (Berkeley et al. 2004) may be essential for population viability, especially for long-lived, late-maturing species. (3) Conservationists have significant concerns about the ecosystem consequences of heavy fishing on fast-growing, highly productive species, where the populations can seemingly sustain very high levels of fishing mortality; many of these species are relatively low on the food chain, and by fishing heavily on them, humans act as a superior competitor, potentially devastating the food supply for other species. For example, fishing levels may be too high on menhaden in the eastern USA; menhaden are prey for striped bass, a highly prized species for recreational anglers.

The management of the krill fishery by the Commission for the Conservation of Antarctic Marine Living Resources (CCAMLR) was meant to address this last problem, and is an excellent example of the EAF in application. Butterworth (2000) describes the approach (precautionary by design) as follows: 'If only krill were to be taken into account, an appropriate target level for this ratio [target biomass as \% of unfished biomass, M.F.H.] in terms of conventional fisheries management might be $50 \%$. On the other hand, the best situation for the predators would be no fishing at all, i.e. a ratio of $100 \%$. The preliminary target adopted is halfway between these 2 'extremes', i.e. $75 \%$.'

One of the biggest challenges facing those who are concerned about conventional use of MSY for either mortality rate or biomass targets (or limits) is to identify a generally acceptable alternative criterion. If biomass levels of $40 \%$ of the unfished biomass are too low, either for the species or for the ecosystem it is embedded in, what is the correct level? How should optimal yield (OY) be set, without being viewed as completely arbitrary? Managers in the USA have proposed that the fishing rate to achieve optimal yield should be $75 \%$ of the fishing rate to achieve MSY (Fmsy) for precautionary purposes (Restrepo et al. 1998); on the other hand, Roughgarden \& Smith (1996) proposed maintaining $75 \%$ of unfished biomass, based only on single species models. As noted above, the precautionary level set for the krill fishery was also $75 \%$. From the perspective of conservationists, fishing to population levels of $75 \%$ of the unfished biomass seems to be a prudent limit, at least until the behavior of the fishery (and consequences for target and other species) can be monitored. 
Conservationists are greatly concerned that the search for OY in an ecosystem context will result in the development of ever more complex, ever more data-hungry models that will purport to give the 'right' level of fishing for each species. Alternative approaches that begin with a traditional single species analysis and proceed to adjust fishing rates based on criteria related to the state of the fish population and its community, as was done e.g. for the krill fishery, appear to provide pragmatic and transparent approaches, (see Mangel \& Levin 2005; also Froese 2004 for suggestions concerning fisheries for which data are scarce).

I completely agree with one point frequently made by fisheries scientists - if conservationists assume that simply shifting from single species benchmarks to ecosystem benchmarks will solve problems of overfishing, we are likely to be disappointed. As Mace (2004) pointed out, many, if not most, current overfishing problems do not result from insufficiently conservative stock assessments. Rather, they are the result of political decisions that ignore scientific advice. As discussed in Mace (2004), managers are often unwilling to reduce catches to levels below Fmsy, because it would result in short-term reductions in fishers' catches and lead to political problems. How likely, then, are managers to heed a call to reduce catch levels even further, for the sake of some seemingly intangible long-term benefit, or for the sake of some other ecosystem components? It is clear, however, that fisheries management needs to move to a perspective that explicitly recognizes that a species may be overfished from an ecosystem perspective, even if it is not overfished by conventional standards (Pikitch et al. 2004). Ultimately, because any removal of fish affects the marine ecosystem to some degree, it will be up to the public, including fishers and conservation groups, to determine the level of 'acceptable' fishing. Although this level must be informed by science, it is not a purely scientific decision, and may well vary from place to place or country to country (e.g. in the developed versus the developing world).

Bycatch. The EAF promises to focus much-needed attention on bycatch-and even more importantly, it also promises a change in perspective. Currently, fishers and managers tend to view bycatch either as a waste issue (how can we fish without catching those undersized individuals we have to discard?) or a legal issue (how can we fish without getting in trouble for catching protected species?). As a consequence, bycatch management generally ignores the entire range of species that are not commercially or recreationally targeted by any fishery and that are not yet legally protected or endangered. Under the current approach, conservationists concerned about ecosystem health, biodiversity, or particular species are frequently forced to use relatively blunt instruments (e.g. in the USA: Endangered Species Act and Marine Mammal Protection Act). However, for species being driven towards extinction as a result of bycatch, such as the smalltoothed sawfish or white marlin, effective management action may only be taken when protected status is reached; the effort may be fruitless by then, as the population (and ecosystem) may not be able to recover. Under a properly implemented EAF, the management threshold would be reached earlier, potentially averting a crisis.

We do not need to wait for formal ecosystem plans to improve bycatch management. An increase in observer coverage (with observers who count everything, not just target and protected species); hard caps or quotas for key bycatch species, as well as for targets; and incentives for shifting from dirty gear with high bycatch to cleaner gear-all of these should be implemented now in order to reduce bycatch. The North Pacific Fishery Management Council has systems in place, for example, where fisheries are shut down when a bycatch quota is reached. This provides a strong incentive for fishers to avoid bycatch in the first place. However, the only bycatch species that merit such management are those that are valuable to other sectors of the fishing industry. In the EAF, this approach would apply to all species. Alternatives are needed to the potentially hundreds of stock assessments required under such an approach. More feasible methods could use indicator species for different ecosystem components that could be tracked using either fisheries or survey data. Changes in the abundance of these species could then be used to trigger appropriate management action.

'Habitat' protection. Habitat protection may be the biggest beneficiary of the EAF. Under most current approaches, habitat protection is considered for the purpose of conserving commercially or recreationally valued species. Indeed, the very word 'habitat' is only defined in reference to another organism: 'The area or environment where an organism or ecological community normally lives or occurs: a marine habitat.' (American Heritage Dictionary of the English Language 2000).

Conservationists want organisms that have been considered only as 'habitat' components to be valued in their own right and preserved for their own sake. Along with most marine biologists, conservationists think that all components of an ecosystem have intrinsic value, even if there is no obvious or direct link to species with cash value. Conservation groups are unanimous in their concern about vulnerable, fragile, and long-lived species such as deep sea 
corals and sponges, which are easily destroyed by gear such as bottom trawls. EAF promises to implement more effective management of such 'habitats'for example, by preventing expansion of destructive trawling into unfished areas, by closing areas identified as containing any vulnerable ecological communities, and by incorporating invertebrates into observer programs and bycatch management. EAF means a shift from an approach that allows habitat to be destroyed unless it is demonstrated to be valuable for commercial species, to an approach that protects species from fishing impacts unless it can be demonstrated that the fishing impacts are not harmful. Such a shift in perspective is essential, given the extraordinary difficulty of understanding community dynamics in marine ecosystems, and the destructive capacity of modern fishing gear.

Cumulative impacts and precaution. Conservationists hope that the EAF will help solve 2 of the more intractable problems of current management:

(1) The EAF promises to require a more thorough assessment of the cumulative effects of human activities on ecosystem components and processes. Under an ecosystem approach, issues such as the cumulative level of bycatch in a fishery would become more explicit, since one key question for ecosystem based management is the level of production of the entire ecosystem that can sustainably be extracted. Simple ecosystem models, combined with information on landings and bycatch, can provide useful information concerning the level of primary or secondary production extracted, providing insight into limits on captures. Similarly, if every fish is counted (in an approximate sense), the sum of all impacts can finally be addressed. Conservationists think that one of the best ways to assess cumulative impacts is through environmental impact assessments, as recommended by Jennings (2004). In the USA, environmental impact statements (EISs) are increasingly being used to supplement traditional fisheries management approaches, and they provide an opportunity to raise and address many of the questions and concerns described above. Some of the most important actions taken to protect ecosystems, such as the recent decision to close over $60000 \mathrm{~km}^{2}$ of fishable habitat to bottom trawling in the Aleutian Islands region, are the result of environmental impact assessments that thoroughly considered alternatives to the status quo. Unfortunately, despite the fact that conservationists consider EISs as an essential part of fisheries management (or perhaps because of that fact!), many managers view them, at best, as a waste of time.

(2) Conservationists also hope that the EAF will finally provide a tool for the implementation of precaution in fisheries management, a concept already incorporated in both international and national laws. Conservationists are concerned, however, that fisheries advocates will seize on calls for EAF in order to maintain the status quo, delaying action until complex ecosystem models can be fed with new data. Unfortunately, we lack a detailed understanding of community dynamics and ecosystem function for many ocean ecosystems, and given the extremely high cost and inherent difficulties of ocean research, lack of information is likely to be a problem for the foreseeable future. Such ignorance must not be allowed to preclude management actions. It makes no sense, in my view, for scientists to reach a consensus that fishing effort needs to be reduced substantially, but for managers to fail to reduce it at all, because there is no consensus on the precise amount of reduction. Caution can be implemented in a number of ways (see Mangel \& Levin 2005 for a conceptual framework). Conservationists' overarching hope is that management will be increasingly based upon indicators of ecosystem health, and not simply on assessment of individual species. The 2004 Symposium on Quantitative Ecosystem Indicators for Fisheries Management (see www.ecosystemindicators.org/) is evidence that such an approach may be gaining favor among scientists and managers.

Conclusions. Conservationists have embraced the EAF because we hope it will deal with many issues that have been inadequately addressed to date by conventional management. One of our concerns is that implementing the EAF will provide an excuse to continue the status quo indefinitely while processes and procedures are being debated. At least in the USA, the legal framework already exists for fisheries managers to implement many, if not all, of the elements of an EAF, should they choose to do so. The fact that intensive debate about the EAF continues, as well as resistance to implementing it, is an indication not of the scientific difficulties with the concept, but rather of political difficulties. Scientific uncertainty will always allow managers a margin of judgment in decision-making; conservationists hope that, in the face of uncertainty, the EAF will result in the benefit of the doubt going to ocean protection; fishers hope the benefit of the doubt will go to them. Conservationists think that protecting ocean ecosystems - using the EAF - will result in fishers who fish less, and who fish less destructively when they do. It is not surprising that fishers and their political allies oppose the EAF. Nevertheless, if the EAF is not implemented, either explicitly or by incorporating it into existing management schemes, there is little reason to expect the health of our oceans to improve. That is the challenge for all of us-to fish as if the ecosystem depended on it. Because it does. 
Acknowledgements. Many of the ideas in this paper are the result of discussions with colleagues at Oceana, particularly Janis Searles and Jim Ayers, as well as with other colleagues in the ocean conservation community. John Warrenchuk, Charlotte Hudson, and Janis Searles provided helpful comments. The opinions expressed are my own.

\section{LITERATURE CITED}

American Heritage Dictionary of the English Language (2000) 4th edn. Houghton Mifflin, Boston, MA

Berkeley SA, Hixon MA, Larson RJ, Love MS (2004) Fisheries sustainability via protection of age structure and spatial distribution of fish populations. Fisheries 29:23-32

Browman HI, Stergiou KI (eds) (2004) Perspectives on ecosystem-based approaches to the management of marine resources. Mar Ecol Prog Ser 274:269-303

Butterworth DS (2000) Krill. In: Koch KH (ed) (2000) Understanding CCAMLR's approach to management; available at www.ccamlr.org/pu/e/e_pubs/am/p5.htm\#(a)_Krill

Froese R (2004) Keep it simple: three indicators to deal with overfishing. Fish Fish 5:86-91

Hilborn R (2004) Ecosystem-based fisheries management: the carrot or the stick? In: Browman HI, Stergiou KI (eds) (2004) Perspectives on ecosystem-based approaches to the management of marine resources. Mar Ecol Prog Ser 274: $275-278$

Jennings S (2004) The ecosystem approach to fishery management: a significant step towards sustainable use of the marine environment? In: Browman HI, Stergiou KI (eds) (2004) Perspectives on ecosystem-based approaches to the management of marine resources. Mar Ecol Prog Ser 274: 279-282

Mace PM (2004) In defence of fisheries scientists, single species models and other scapegoats: confronting the real problems. In: Browman HI, Stergiou KI (eds) (2004) Perspectives on ecosystem-based approaches to the management of marine resources. Mar Ecol Prog Ser 274: 285-291

Mangel M, Levin PS (2005) Regime, phase and paradigm shifts: making community ecology the basic science for fisheries. Philos Trans R Soc Lond B 360:95-105

POC (Pew Oceans Commission) (2003) America's living oceans: charting a course for sea change. Summary report: recommendations for a new ocean policy. Pew Oceans Commission, Arlington, VA

Pikitch EK, Santora C, Babcock EA, Bakun A and 13 others (2004) Ecosystem-based fishery management. Science 305:346-347

Restrepo VR, Thompson GG, Mace PM, Gabriel WL and 7 others (1998) Technical guidance on the use of precautionary approaches to implementing National Standard 1 of the Magnuson-Stevens Fishery Conservation and Management Act. NOAA Tech Memo NMFS-F/SPO31, Silver Spring, MD

Roughgarden J, Smith F (1996) Why fisheries collapse and what to do about it. Proc Natl Acad Sci USA 93: 5078-5083

Sissenwine M, Murawski S (2004) Moving beyond 'intelligent tinkering': advancing an Ecosystem Approach to Fisheries. In: Browman HI, Stergiou KI (eds) (2004) Perspectives on ecosystem-based approaches to the management of marine resources. Mar Ecol Prog Ser 274:291-295

USA Commission on Ocean Policy (2004) An Ocean Blueprint for the 21st Century, Final Report. Commission on Ocean Policy, Washington, DC

\section{PICES' role in integrating marine ecosystem research in the North Pacific}

\author{
Patricia A. Livingston
}

\author{
Alaska Fisheries Science Center, 7600 Sand Point Way NE, \\ Seattle, Washington 98115, US \\ Email: pat.livingston@noaa.gov
}

Introduction. The North Pacific Marine Science Organization (PICES) is an international intergovernmental organization whose primary purpose is to promote and coordinate marine research in the North Pacific. Established in 1992, it is relatively new compared with other marine science organizations such as ICES, which has existed for over a century. However, the roles of these organizations in advancing and communicating scientific knowledge of marine ecosystems are similar. Despite its relative youth as an organization, PICES has begun to produce integrated scientific advice and products that reflect the emerging focus on ecosystem approaches to management and that serve the broader needs of its member countries outside of the scientific community. These scientific products highlight critical issues for ocean managers, such as sources and causes of harmful algal blooms, factors influencing production of marine fish stocks, and population dynamics of marine mammals and seabirds. Advice is given to PICES member countries regarding human and climate influences on North Pacific ecosystems. This advice will allow member countries to improve protection and responsible management of ocean resources, in accordance with accepted international standards. The organization is thus integrating national scientific efforts and shaping international views of ecosystem-based management approaches in the North Pacific.

Evolution of PICES. Organization: Descriptions of the history and scientific structure of PICES can be found at www.pices.int. The members comprise most of the countries on the rim of the North Pacific: Canada, People's Republic of China, Japan, Republic of Korea, Russian Federation, and USA. The organization has defined geographic regions for reporting scientific activities, which are at the large marine ecosystem (LME) scale of Sherman (1995). This scale is becoming recognized in the USA and elsewhere as a starting point for management of marine regions.

The terms of reference for the organization mainly deal with advancing scientific knowledge, exchanging scientific information and coordinating marine research. These activities occupied the marine research community of PICES in its first decade of operation, when the organization increased the involvement of a broad 
spectrum of marine science disciplines, as well as collaboration across scientific disciplines. This is an important stepping-stone towards providing scientific advice that addresses an ecosystem approach to management.

Initial scientific products: It became evident over time that, although the PICES scientific network was growing in influence among the scientific community, it did not have a strong mandate for providing scientific advice to its member countries. This was due partly to the mainly scientific terms of reference of PICES, and to the lack of a heavily used marine region shared by many countries (as opposed, e.g. to the North Sea in Europe). This is in contrast to ICES, which is the main source of scientific advice to governments and international regulatory bodies that manage activities, particularly fisheries and environmental protection, in the North Atlantic Ocean. The scientific products that PICES was producing were scientific reports and special volumes of peer-reviewed journals in which the primary target audience was the scientific community.

At the same time, some of the PICES member countries appeared to be disengaging from the convention. Although the reasons were never explicitly communicated, countries were having difficulty meeting the relatively small financial obligations required to keep the organization going. Scientific participation of some countries was waning and the discussions among member countries regarding budget and annual dues payments were becoming more difficult. It seemed likely that some member countries did not view their financial contribution to PICES as providing a net benefit to the country.

Therefore, PICES needed to move beyond its focus on communication among the scientific community and find a new role that would elevate the usefulness of the organization to its member countries. Provision of scientific products that would be of use to member countries seemed to be the logical next step.

It was during this time that ecosystem approaches to management (EAM) of marine resources was emerging as the new paradigm to advance management of marine areas, particularly with regard to fisheries management (e.g. Grumbine 1993, Larkin 1996, Christensen et al. 1996, Haeuber \& Franklin 1996, Mooney 1998, Browman \& Stergiou 2004), and scientists began to discuss what types of scientific advice would be needed to implement these approaches. Ecosystem status reports were becoming a common form of providing such advice. Development of sensitive ecosystem indicators of changes in ecosystem status to include in such reports was a high priority activity (Hollingworth
2000). It was during this period that PICES developed a concept for a North Pacific Ecosystem Status Report as a way to provide useful information to member countries on the status of ecosystems in the North Pacific.

Recent activities of PICES. Scientific advice: The North Pacific Ecosystem Status Report was first proposed to the PICES Science Board, which consists of the chairpersons of the various scientific committees and programs. The Science Board presented the idea to the respective members of the scientific committees for approval. Scientific committees, which consist of national representatives of the scientific discipline of the particular committee, discussed and approved the proposal. Next, the Governing Council of PICES, which consists of high level representatives of the academic community and governmental agencies of each member country, also discussed and approved the concept.

The approved proposal contained an outline to provide the following information on North Pacific LMEs: (1) status and trends in large scale atmospheric forcing in the North Pacific; (2) status of lower trophic level variables such as nutrients, phytoplankton and zooplankton; (3) condition of living marine resources such as fish and crustaceans, and of top-level predators such as seabirds and marine mammals; (4) factors involving human populations, contaminants and habitat modifications that might be placing stresses on the marine ecosystem.

Several alternatives were proposed for the procedures by which the scientific community of PICES should produce regional status reports. Reports were already being produced for some regions, such as Alaska in the USA and British Columbia in Canada, but in other regions, particularly the shared seas of the western North Pacific rim, scientists had not yet begun sharing the necessary information.

A PICES working group was formed to produce the North Pacific Ecosystem Status Report. The group had representatives of the scientific committees and programs and the PICES Secretariat. International commissions such as the International Pacific Halibut Commission (IPHC), North Pacific Anadromous Fish Commission (NPAFC), and the Inter-American Tropical Tuna Commission (IATTC) were also invited to provide contributions to the status report. Because the western Pacific countries had not yet begun to produce regional ecosystem status reports, 3 PICES workshops were organized around the theme of providing ecosystem information for the PICES report. In 2002 and 2003, workshops were held in Seoul (twice) and Vladivostok to describe the status and trends in the marginal seas of the western Pacific. These efforts 
brought the scientific community on the western side of the Pacific Ocean together to agree on pressing management and science issues in the North Pacific, and they were an important first step in moving these countries towards an understanding of ecosystembased management.

When the scientists gathered to synthesize the findings of the status report, there was no disagreement with regard to the science issues and conclusions. However, controversy emerged over the naming conventions (in English) of a regional sea shared by Japan and Korea. The English name that had been adopted by PICES over the years acknowledged the traditional naming of both member countries of this sea: Japan/East Sea. But this practice was challenged by one of the countries when the draft status report was prepared, which used this naming convention. This issue nearly derailed the publication of the report and threatened the continuing participation of some countries in PICES. It seemed for a while that the North Pacific ecosystem status report, conceived to bring the scientific experts of the member countries together to provide important advice to the respective countries, would actually accomplish the opposite. The report (PICES 2004) was published after a 3 yr gestation, following lengthy discussions of the naming convention among the national delegates to PICES and with the Intergovernmental Oceanographic Commission (IOC).

Since the production of the status report, the Government of the USA made a request to PICES to provide scientific advice with regard to the implications of the 1998 regime shift for North Pacific fisheries. Regime shifts, which are abrupt shifts in ecosystem composition and regional climate that persist for several years or decades, have the potential to change the viability of fishing communities that rely on the production of these ecosystems for their livelihood. The PICES scientific community had already held several symposia (e.g. McKinnell et al. 2001) and had a large interest in ocean regime shifts, and this request was a logical way to bring that expertise to bear on a question that had important economic consequences for the USA. PICES responded to this request by gathering its experts and publishing an advisory report on implications of regime shifts for management of marine resources (PICES 2005).

Future scientific products: Thus, PICES is now moving beyond its initial focus on activities and products of interest primarily to scientists, to include activities focused on applying that scientific knowledge to address societal needs, such as prediction of regime shifts for marine fisheries managers, understanding causes of harmful algal blooms, or documenting the amounts and sources of pollutants through marine webs. This information will assist member countries in the wise use of the North Pacific Ocean. The newly developed PICES Strategic Plan explicitly recognizes this important activity, which serves to integrate national marine ecosystem scientists from governmental organizations and universities and efforts of national and international programs such as GLOBEC into a deeper understanding of our oceans and the factors influencing them.

PICES recently formed an ecosystem-based management working group. Its mandate is to describe and implement a standard reporting format for ecosystem-based management initiatives in each PICES member country, including a listing of the ecosystem-based management objectives of each country. This will improve the scientific advice contained in future North Pacific ecosystem status reports and help PICES scientists to understand and advise governments on factors influencing change in the earth's oceans.

\section{LITERATURE CITED}

Browman HI, Stergiou KI (2004) Perspectives on ecosystembased approaches to the management of marine resources. Mar Ecol Prog Ser 274:269-303

Christensen NL (ed) (1996) The report of the Ecological Society of America Committee on the scientific basis for ecosystem management. Ecol Appl 6(3):665-691

Grumbine RE (1996) What is ecosystem management? Conserv Biol 8(1):27-38

Haeuber R, Franklin J (eds) (1996) Forum: perspectives in ecosystem management. Ecol Appl 6(3):694-747

Hollingworth C (ed) (2000) Ecosystem effects of fishing. ICES J Mar Sci 57(3): 465-791

Larkin PA (1996) Concepts and issues in marine ecosystem management. Rev Fish Biol Fish 6:139-164

McKinnell SM, Brodeur RD, Hanawa K, Hollowed AB, Polovina JJ, Zhang C (2001). An introduction to the Beyond El Niño conference: climate variability and marine ecosystem impacts from the tropics to the Arctic. Prog Oceanogr 49:1-6

Mooney HA (ed) (1998) Ecosystem management for sustainable marine fisheries. Ecol Appl 8(1):S1-SS174 supplement

PICES (1996) Report of the PICES-GLOBEC international program on climate change and carrying capacity. PICES Sci Rep No. 4. North Pacific Marine Science Organization, Sidney, Canada

PICES (2004) Marine ecosystems of the North Pacific. PICES Spec Publ No. 1. North Pacific Marine Science Organization, Sidney, Canada

PICES (2005) PICES advisory report on fisheries and ecosystem responses to recent regime shifts. North Pacific Marine Science Organization, Sidney, Canada

Sherman K (1995) Achieving regional cooperation in the management of marine ecosystems: the use of the large marine ecosystem approach. Ocean Coast Manage 29(3): 165-185 


\section{Implementing the ecosystem approach: experiences from the North Sea, ICES, and the Institute of Marine Research, Norway}

\section{Ole Arve Misund*, Hein Rune Skjoldal}

\author{
Institute of Marine Research, PO Box 1870, 5817 Bergen, \\ Norway \\ *Email: ole.arve.misund@imr.no
}

The ecosystem approach. The ecosystem approach is a management principle which builds on the recognition that nature is an integrated entity and that we must take a holistic approach to nature management. The science to support ecosystem approach to management must also be integrated and holistic. A core element of this science is ecology, with a focus upon the properties and dynamics of ecosystems (Fenchel 1987). Many scientists and managers have recognised the need for an ecosystem approach for a long time (Likens 1992), although it is only during the last 10 to $15 \mathrm{yr}$ that a broader awareness of this has developed.

The increased awareness and formalisation of the ecosystem approach have emerged as a result of international environmental agreements within the framework of the United Nations, and a fundamental description of the basis of an 'ecosystem approach' was first formalised in the Stockholm Declaration in 1972 (Turrell 2004). The most authoritative account of the ecosystem approach is probably in Decision V/6 from the meeting of the Conference of the Parties to the UN Convention on Biological Diversity in Nairobi, Kenya, in 2000. This decision has an annex with a description, principles and operational guidance for application of the ecosystem approach (www.biodiv.org/decisions/?m=cop-05).

The Large Marine Ecosystem (LME) concept has been the basis for a practical development of the ecosystem approach to the management of marine resources and environment (Sherman 1995, Duda \& Sherman 2002). Currently, 64 LMEs have been identified, dividing mainly the shelf regions of the globe into management units. Scientific and management issues concerning these LMEs have been the subject of a large number of symposia and books (see www.edc.uri.edu/lme).

In many fisheries science institutions, advisory communities and management bodies, practical implementation of the ecosystem approach has been a central issue for the last years. There is no unified understanding or protocol on how to deliver scientific advice for management of fish stocks under the broad scope of the ecosystem implications of fishing, as compared to the traditionally narrow consideration of the population dynamics of single fish stocks. The FAO Expert Consultation on Ecosystem-based Fisheries Management in Reykjavik in 2001 (FAO 2003, Garcia et al. 2003) produced an overall, pragmatic solution for implementing the ecosystem approach to fisheries (EAF) by merging ecosystem management and fisheries management. The EAF principles are yet to be implemented by most of the fisheries scientific and advisory bodies around the world.

The ecosystem approach has been a central issue in political processes such as the Fifth International Conference on the Protection of the North Sea held in Bergen in 2002 (NSC 2002), and the development of a governmental white paper on integrated marine management in Norway in 2002 (Anonymous 2002). Similarly, the ecosystem approach was a basis for the development of the strategic plan of the International Council for the Exploration of the Sea (ICES 2002), and in the reorganisation of the Institute of Marine Research (IMR), Norway (Anonymous 2001, Misund et al. 2005). We reflect here on our experiences from the political processes for the North Sea and in Norway on developing the ecosystem approach to management. We go on to give our views on the development of the ecosystem approach within 2 scientific organizations that must deliver scientific advice according to the ecosystem approach, ICES and our home institute (IMR) in Norway.

Development of the ecosystem approach for the North Sea. The first International Conference on the Protection of the North Sea was held in Bremen in Germany in 1987, followed by the 2nd and 3rd Conferences in London in 1988 and The Hague in 1990. The Ministers at the 3rd Conference in The Hague requested that OSPAR (the Convention for the Protection of the Marine Environment of the North-East Atlantic) and ICES should establish a North Sea Task Force (NSTF), for producing a Quality Status Report (QSR) for the North Sea. This QSR was completed in 1993 (NSTF 1993) and identified fisheries as having major impacts on the North Sea ecosystem. At the 4 th Conference in Esbjerg in 1995, these fisheries impacts were discussed by the Ministers responsible for the environment.

As host for the 5th Conference, Norway arranged an Intermediate Ministerial Meeting on the Integration of Fisheries and Environmental Issues in Bergen in March 1997. In their Statement of Conclusions (IMM 1997), the Ministers responsible for fisheries and the environment in the countries bordering on the North Sea agreed that an ecosystem approach should be developed and implemented as a guiding principle for the further integration of fisheries and environmental management measures. This was followed by a workshop in Oslo in 1998 where a framework for an eco- 
system approach was drawn up (Anonymous 1998). This framework was adopted with slight modifications by the Ministers at the 5th Conference in Bergen 2002 (NSC 2002).

The framework for an ecosystem approach to management consists basically of 5 major elements or modules in a management cycle (Fig. 1). Objectives should relate to the state of the ecosystem. Monitoring and research should be performed to provide updated information about status and trends (monitoring) and insight into mechanisms and causal relationships (research). Assessments should use information from monitoring and research to evaluate whether objectives are being met or whether progress is being made towards meeting them. Scientific advice should be formulated clearly to translate the natural complexity into a clear and transparent basis for decisions. Finally, management should respond to the advice and to the needs for actions to meet the agreed objectives.

The Ministers at the 3rd Conference in The Hague had requested that methodology for setting ecological objectives should be developed. This work was initiated by the NSTF and continued by OSPAR after 1993. Workshops were held at Bristol in 1992, Geilo in 1993, and Ulvik in 1995 to consider terminology, feasibility and selection criteria for formulating Ecological Quality Objectives (EcoQOs). This resulted in a general methodology or approach for setting EcoQOs (Skjoldal 1999). In 1997 OSPAR agreed to apply this methodology to the North Sea as a test case. This work was subsequently linked to development of the ecosystem approach, filling the need for ecological objectives in the latter. Based on the outcome of 2 workshops held at Scheveningen in 1999 and Schiphol in 2001, and

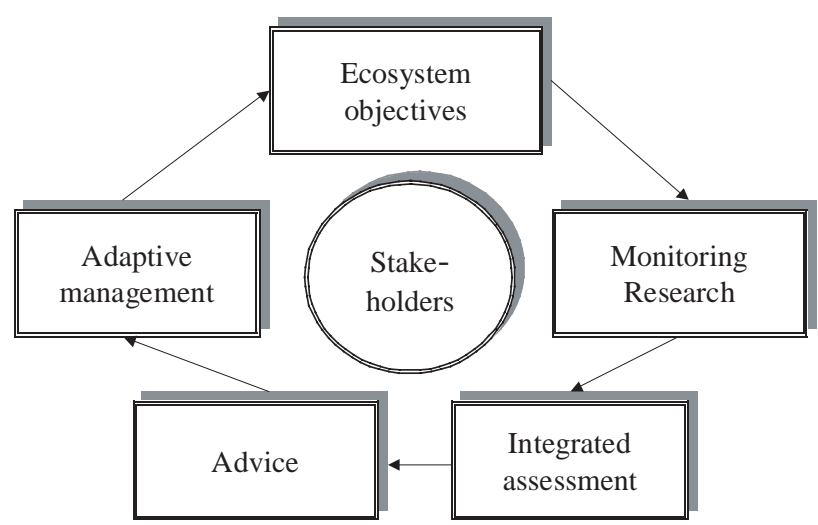

Fig. 1. Framework for the ecosystem approach to ocean management with main components or modules shown in an iterative management decision cycle. This is a simplified version of the framework in the Bergen Declaration (NSC 2002). Stakeholders should be included in the process, to promote openness and transparency considerable input from ICES (Advisory Committee on Ecosystems, ACE Reports for 2001, 2002, 2003; available at www.ices.dk/products/cooperative.asp), a set of 10 EcoQOs were agreed by the Ministers at the 5th North Sea Conference (NSC 2002, Annex 3).

The ICES Study Group on Ecosystem Monitoring and Assessment proposed the following definition of the ecosystem approach (ICES 2000): 'Integrated management of human activities based on knowledge of ecosystem dynamics to achieve sustainable use of ecosystem goods and services, and maintenance of ecosystem integrity.' This formed the basis for the technical definition of ecosystem approach used in a statement from the First Joint Ministerial Meeting of the Helsinki and OSPAR Commissions (JMM) in Bremen in June 2003 (www.ospar.org), and in the work on developing the thematic Marine Strategy within the EU (http://europa.eu.int/comm/environment/water/ consult_marine.htm):

The comprehensive integrated management of human activities based on the best available scientific knowledge about the ecosystem and its dynamics, in order to identify and take action on influences which are critical to the health of marine ecosystems, thereby achieving sustainable use of ecosystem goods and services and maintenance of ecosystem integrity.

It is worth stressing the emphasis on integrated management of human activities in this definition. Integration between different sectors of the society is a key element of the ecosystem approach, and this has scientific and institutional implications. Scientifically, we need the ability to assess the combined impacts from different sectors on the marine ecosystems, and institutionally the sectors need to work closely together. This means for instance that close collaboration between the fisheries and environmental conservation sectors is a prerequisite for an effective ecosystem approach to management.

In the Norwegian Government's White Paper 'Clean and Rich Sea', which shaped Norwegian marine policy (Anonymous 2002), the ecosystem approach is seen as the means of achieving better sector integration. The marine areas under Norway's jurisdiction constitute parts of the North Sea, the Norwegian Sea and the Barents Sea LMEs. The description of the ecosystem approach in the White Paper was modelled very much after the framework developed for the North Sea. In addition to continuing the international work in the North Sea, the Norwegian Government has started to develop a management plan for the Barents Sea. This includes development of EcoQOs and assessments of the key impacts on the Barents Sea ecosystem: fisheries, mariculture, offshore oil and gas production, shipping, long-range transport of pollutants, and climate change. 
Developments within ICES. ICES is an independent scientific and advisory organisation that has existed for more than $100 \mathrm{yr}$ (Rozwadowski 2002). It has traditionally provided governments of the North Atlantic region with advice on harvesting of fish stocks and on environmental issues such as pollution monitoring, aggregate extraction, algal blooms, or mariculture. Recognising the focus on ecosystems and the need for stronger integration, ICES initiated in 1999 a process to develop a functional strategic plan. This plan includes the ecosystem approach as a foundation for the work of ICES, and it was signed by delegates from the 19 participating countries in 2002 (ICES 2002). Since then, the 7 scientific committees of ICES have developed specific action plans to implement the new strategy.

Responding to the foreseen need for more integrated advice on ecosystems, ICES established in 2000 a new Advisory Committee on Ecosystems (ACE) in addition to its 2 existing advisory committees, ACFM (Advisory Committee on Fisheries Management) and ACME (Advisory Committee on the Marine Environment). ACE is the ICES body for providing scientific advice and information on the status of and outlook for marine ecosystems, and on the exploitation of living marine resources in an ecosystem context.

The fishery science and the environmental science within ICES represent 2 different scientific traditions and cultures. Bridging them has not been easy. The fishery science is very computational using models and sophisticated statistical tools to estimate the current and future sizes of fish stocks as a basis for advising on catch quotas. The environmental science covers a much broader spectrum of disciplines with stronger emphasis on processes and descriptions, and less on formalised and standardised computations. The fisheries scientists work on a tight annual schedule with data collection, stock assessments at working group meetings, and provision of advice on next year's quotas to fisheries management institutions. Environmental scientists usually have less time pressure from the management system, with environmental assessments carried out at more irregular and less frequent intervals. The difference between the 2 traditions materialises clearly, for example, in the difficult issue of integrating information about oceanographic variability into the regular fish stock assessment process (Ulltang \& Blom 2003).

The ground layer of the ICES structure consists of $>100$ working or study groups that meet annually or work by correspondence to produce reports addressing specific terms of reference given to them by the ICES Council. These groups cover virtually every aspect of the marine environment. This structure has evolved over the decades in response to past needs, and it has been partly overhauled to meet the current and future needs for information on the status of and outlook for the marine ecosystems in the North Atlantic region.

Integrated assessments of the status and outlook of the marine ecosystems could provide a focus and incentive for ICES to become more operational. ICES activities in the Baltic Sea and the North Sea are serving as test cases. A Regional Ecosystem Study Group for the North Sea (REGNS) was established in 2003 and is now coordinating efforts to produce an assessment of the recent status and trends in the North Sea ecosystem, to be finalised in 2006 (ICES 2004).

There is an increasing awareness that ecosystems are not abstract concepts, but real entities in nature. They are open systems and their boundaries may be fuzzy and to some extent pragmatically determined, depending on the purpose of their delimitation. Nevertheless, there are more or less sharp discontinuities in physical features and distribution of organisms, and these are a help when drawing the boundaries of LMEs based on ecological criteria (Skjoldal 2004a,b).

Compiling and assessing information and advising on the status of and outlook for marine ecosystems requires a geographical focus consistent with the boundaries of the identified LMEs. This means in practice that experts on different aspects within each ecosystem, e.g. physical oceanography, plankton, benthos, fish, must work together to provide the integrated analyses and a synthesis of the information. Some rearrangement of the ICES working groups is required to account for regional aspects. Thematic groups to deal with general issues (e.g. methods, climatic driving forces) common to all or several specific ecosystems must be maintained. We therefore support development of a streamlined and ecosystem-oriented advisory function with regional working groups, much along the lines proposed by the ICES Study Group on the Advisory Committees and Working Group Protocols (ICES 2003), to enable ICES to deliver scientific advice according to the ecosystem approach.

Developments at IMR. The leaders of the Institute of Marine Research (IMR), Norway, considered that the organization of the institute was not strategically suited to deliver holistic ecosystem-based science and advice to support the ecosystem approach to management. The IMR had 4 science centres (for living resources, environment, aquaculture, and coastal studies) that acted to some extent as separate entities within the institute. The centres conducted their activities within advisory and science programmes that were specific to each centre. The centres were, furthermore, managed as separate economic units, each 
with the responsibility to manage the budget with a positive balance in the long run. Cooperation between the centres was less than would be desirable, both scientifically and administratively, and it was difficult to achieve the level of cooperation between centres that is required for dealing with ecosystem issues.

Based on a recommendation from the directors of IMR, and its acceptance by the Ministry of Fisheries and Coastal Affairs, the IMR Board initiated in spring 2002 a process to develop a new organisation for the institute. The introduction of the ecosystem approach in the White Paper of the Norwegian Government, in the Bergen Declaration of the 5th North Sea Conference, and the new strategic plan for ICES were triggers of the reorganization of IMR. During a $1.5 \mathrm{yr}$ internal process initiated by the leader group and extended with representatives from the major labour unions, a new organisation was developed (Misund et al. 2005). The classical, discipline-oriented structure with centres for marine environment, marine resources, coastal zone and aquaculture was abandoned. The former programme structure with 4 advisory programs following the centre structure, and up to 10 science programmes across the centre structure, was also abandoned.

The new organization has 3 ecosystem-based programmes and 1 thematic science and advisory programme, 19 research groups, a technical department divided into 9 research technical groups, an administrative department that includes the former centre administrations, and an unchanged research vessel department to operate the fleet of the institute (Fig. 2). These programmes provide a structure for the scientific and advisory activity of IMR by defining all activities into projects that are carried out by the research and technical groups.

The 3 ecosystem-based programmes are set up according to the division of LMEs in the North-Eastern Atlantic (Sherman 1995, Sherman \& Skjoldal 2002). There is one programme that covers the Barents Sea LME and one that covers the Norwegian Sea and the North Sea LMEs together. A 3rd programme covers the coastal zone of Norway. The 4 th programme is thematic and covers the aquaculture activities of the institute.
The ecosystem programmes build on a common, simplified understanding of the ecosystem approach to focus on 3 main operational goals: (1) a clean sea (monitoring and advice to secure the lowest possible level of contamination of anthropogenic pollutants in the marine environment and seafood); (2) better advice for sustainable harvest of marine resources (single species models are still applied, but multispecies considerations and ecosystem information will be taken more into account); (3) reduced ecosystem effects of fishing (improvement of the size and species selectivity of fishing gears and reduction of impacts on bottom fauna).

Parts of the Barents, Norwegian and North Seas LMEs are within Norwegian jurisdiction. Norway is only one of the countries that have the right to harvest the living marine resources within these ecosystems. International cooperation at the political, scientific and management levels is important for effective implementation of an ecosystem approach. The natural and anthropogenic drivers that influence the ecosystem

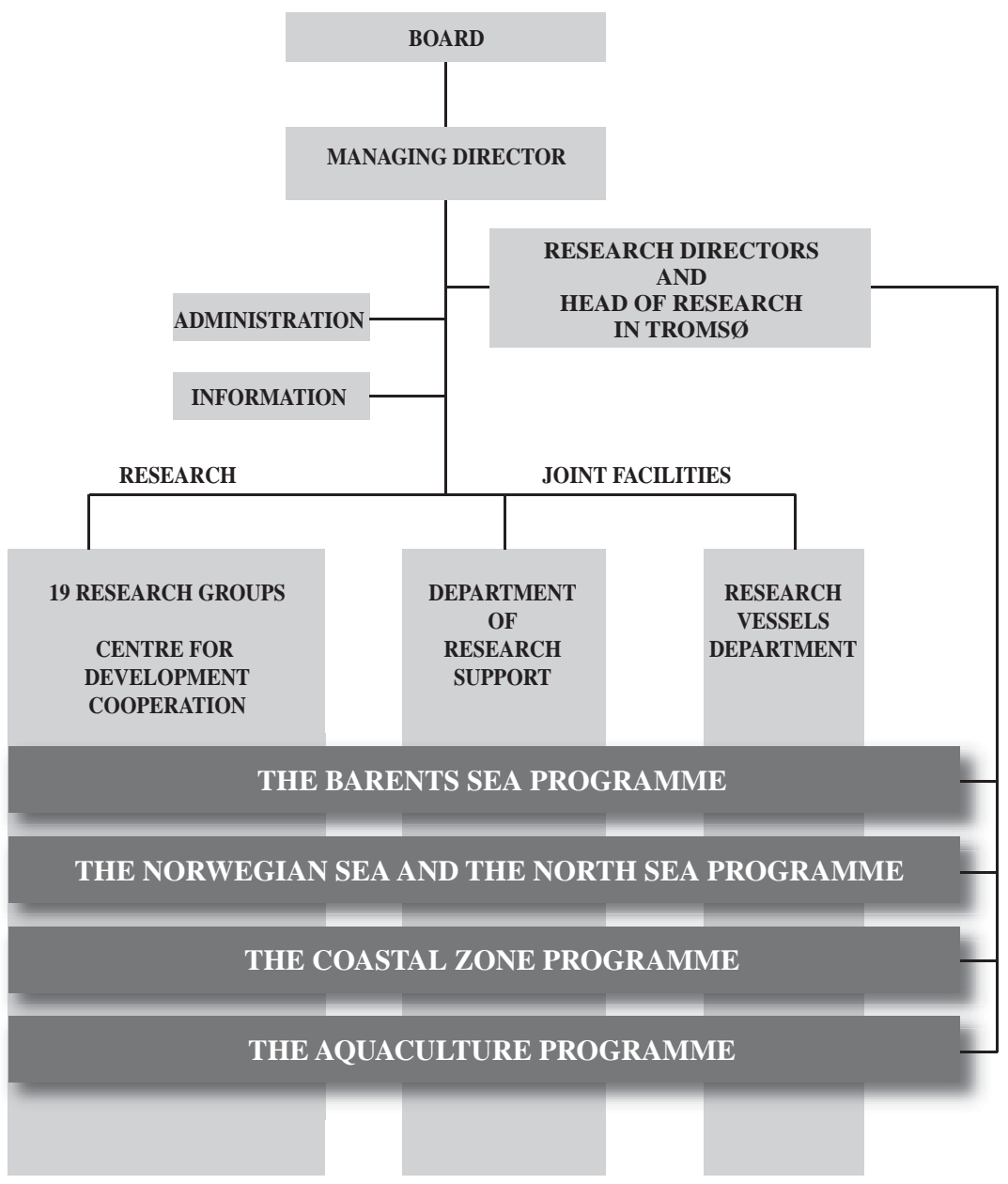

Fig. 2. Present organisational chart (tentative) of the Institute of Marine Research (IMR), following reorganisation in 2004 for adaptation to the ecosystem approach to ocean management. 
structure, productivity and major living resources within these LMEs are different. The science and advisory programmes therefore have taken somewhat different approaches in building up their project portfolios.

Within the new organization of IMR, the science and advisory programmes are still in an early phase of development. In the years to come, attention will be given to further refine and develop the ecosystem approach as their central element. Surveys in the Barents Sea and the Norwegian Sea now have a clear ecosystem focus, including simultaneous monitoring of hydrographic conditions, plankton, fish stocks and marine mammals. The North Sea surveys, however, are still focused on single aspects such as demersal (IBTS surveys) or pelagic fish stocks (e.g. the herring surveys). These activities have a long tradition of ICES coordination, and it will take some time to adjust the various activities coordinated by ICES to support an effective ecosystem approach to North Sea management.

In developing the new organisation and structuring the scientific and advisory activities within IMR, we have chosen a pragmatic strategy. Our philosophy is that we will further develop the ecosystem approach within our scientific and advisory activities 'as we go along'. The choice of a new structure and way of functioning of the institute lowers the effect of the 'resistance to change' inherent in any organisation, and forces all persons involved to consider the new requirements by an ecosystem approach free from the constraints and empowerments from the previous structure. In the years to come, the objectives of the ecosystem approach to management of fisheries and marine ecosystems will be clarified and made more explicit, and we believe our new organization is well suited to deliver the scientific support for achieving those objectives.

\section{LITERATURE CITED}

Anonymous (1998) Workshop on the Ecosystem Approach to the Management and Protection of the North Sea, Oslo, Norway 15-17 June 1998. TemaNord 1998:579, Nordic Council, Copenhagen. ISBN 92-893-0245-3

Anonymous (2001) Rapport fra Havforskningsinstituttets arbeidsgruppe for økosystembasert forvaltning' (Report from the Working Group of the Institute of Marine Research on ecosystem based management; in Norwegian). Institute of Marine Research, Bergen

Anonymous (2002) Rent og rikt hav, St.meld. nr. 12 (2001-2002) (Clean and rich sea, Government White Paper; in Norwegian), Ministry of Environment, Oslo. (available at: http://odin.dep.no)

Duda AM, Sherman K (2002) A new imperative for improving management of large marine ecosystems. Ocean Coast Manage 45: 797-833

FAO 2003. The ecosystem approach to marine capture fish- eries. FAO Technical Guidelines for Responsible Fisheries, No. 4 (Suppl 2)

Fenchel T (1987) Ecology-potentials and limitations. In: Kinne O (ed) Excellence in ecology, Book 1. International Ecology Institute, Oldendorf/Luhe

Garcia SM, Zerbi A, Aliaume C, Do Chi T, Lasserre G (2003). The ecosystem approach to fisheries. Issues, terminology, principles, institutional foundations, implementation and outlook. FAO Fish Tech Pap No. 443. Rome, FAO

ICES (2000) Report of the Study Group on Ecosystem Assessment and Monitoring. ICES CM 2000 / E:09, International Council for Exploration of the Sea, Copenhagen

ICES (2002) Towards the 21st century: A strategic plan for ICES. International Council for the Exploration of the Sea, Copenhagen (available at: www.ices.dk/iceswork/ strategic\%20plan-final.pdf)

ICES (2003) Report of the Study Group on ACFM, ACE, ACME, and Working Group Protocols. ICES CM 2003 / MCAP:02, International Council for Exploration of the Sea, Copenhagen

ICES (2004) Report of the Regional Ecosystem Study Group for the North Sea. ICES CM 2004 / ACE:06. International Council for Exploration of the Sea, Copenhagen

IMM (1997) Statement of conclusions. Intermediate Ministerial Meeting on the Integration of Fisheries and Environmental Issues, 13-14 March 1997, Bergen, Norway. Ministry of Environment, Oslo (available at: http://odin.dep.no/nsc)

Likens G (1992) The ecosystem approach: its use and abuse. In: Kinne O (ed) Excellence in ecology, Book 3. International Ecology Institute, Oldendorf/Luhe

Misund OA, Torrissen O, Bjordal ^, Moksness E, Lønne OJ, Toft KØ (2005) A reorganized Institute of Marine Research, Norway, to meet the requests for ecosystem approach in science, surveillance and management advice. Proc 4th World Fisheries Congress, Vancouver, May 2004. Am Fisheries Soc Books, Bethesda, MD

NSC (North Sea Conference) (2002) Bergen Declaration. Fifth International Conference on the Protection of the North Sea, 20-21 March 2002, Bergen, Norway. Ministry of Environment, Oslo. ISBN 82-457-0361-3

NSTF (North Sea Task Force) (1993) North Sea Quality Status Report 1993. North Sea Task Force, Oslo and Paris Commissions, London

Rozwadowski H (2002) The sea knows no boundaries. A century of marine science under ICES. International Council for the Exploration of the Sea and University of Washington Press, Seattle, WA

Sherman K (1995) Achieving regional cooperation in the management of marine ecosystems: the use of the large marine ecosystem approach. Ocean Coast Manage 29: 165-185

Sherman K, Skjoldal HR (eds) (2002) Large marine ecosystems of the North Atlantic. Changing states and sustainability. Elsevier, Amsterdam

Skjoldal HR (1999) Overview report on Ecological Quality (EcoQ) and Ecological Quality Objectives (EcoQOs). Institute of Marine Research, Bergen. ISBN 82-7461-050-4

Skjoldal HR (2004a) An introduction to the Norwegian Sea ecosystem. In: Skjoldal HR, Sætre R, Fernø A, Misund OA, Røttingen I (eds) The Norwegian Sea ecosystem. Tapir Academic Press, Trondheim, p 15-32

Skjoldal HR (2004b) Fish stocks and fisheries in relation to climate variability and exploitation. In: Wolanski E (ed) Natural resource system challenge: oceans and aquatic ecosystems. Encyclopedia of Life Supporting Systems (EOLSS), Developed under the auspices of the UNESCO. Eolss Publishers, Oxford. www.eolss.net 
Turrell WR (2004) The policy basis of the 'ecosystem approach' to fisheries management. EuroGOOS Publication No. 21, EuroGOOS Office, SMHI, 60176 Norrköping, Sweden. ISBN 91-974828-1

Ulltang $\varnothing$, Blom G (ed) (2003) Fish stock assessments and predictions: integrating relevant knowledge. Sci Mar 67 (Suppl. 1)

\section{Implementation of the Ecosystem Approach to Fisheries Management - asynchronous co-evolution at the interface between science and policy}

\author{
Jake C. Rice
}

Department of Fisheries and Oceans, Canadian Science Advisory Secretariat, 200 Kent Street, Ottawa, Ontario, Canada K1A 0E6 Email: ricej@dfo-mpo.gc.ca

Introduction. I write from the perspective of a scientist with a background in terrestrial post-MacArthur (1972) community ecology. I began to work on marine ecosystem research problems more than $20 \mathrm{yr}$ ago, and was drawn into the web of problems of advising managers and policy developers first on fisheries, and then on a progressively much broader range of issues. For the past decade my advisory work for fisheries management and policy has been primarily through ICES - where since 1996 I have attended most meetings of their Advisory Committees on Fisheries Management (ACFM), Marine Environment (ACME) and Ecosystems (ACE) - and DFO (as director of the Science Advisory Secretariat). The change of the relationship between science and policy on ecosystem issues has been particularly apparent in these fairly formal advisory settings. Here is what I have seen.

The role of science in formulation of policy on the Ecosystem Approach to Fisheries (EAF) is fundamental-but primarily it has been a supporting role, not one of leadership. This is frustrating for both sides, but it is an inevitable consequence of the reality that science growth is incremental, whereas policy changes are saltatory. Few people in either science or policy understand why that is inevitable, and this lack of understanding frustrates communication and impedes progress, as each group may perceive the other as behaving irrationally. The different nature of change in science and change in policy also provides unlimited ammunition to those exercising hindsight, to the detriment of effective communication and true progress. Because of the importance of this difference in how change occurs in science and in policy, it is worthwhile to consider its origins.

Why policy changes are saltatory. There are pressures both outside and inside governments to maintain a stable policy environment. On the outside, resource users want stability to plan their operations rationally. It is hard enough for industries to keep up with changes in markets and operating conditions, without being uncertain about the regulatory framework in which they will have to work. On the inside, managers want stability to develop management plans for achieving a specified set of objectives, monitoring the effectiveness of the plans, and adapting management tactics to correct discrepancies. If the policybased objectives change frequently, then effective management planning and implementation becomes impossible.

In a democracy, major change in policies and regulations requires at least consultation, if not legislation. Both take time and have significant inertia. As a result, major policy changes are not highly risk prone. For consultation to demand major change, a groundswell of support for a new approach already has to exist, or else a convincing case for change has to be made by the government promoting the change. Governments, in turn, want some confidence that they are making a change for the better, if they are shaking up a status quo to which many primary constituencies have adapted. Even when there is widespread perception that change is needed, consultation and political processes which follow democratic practices will be biased towards those options that the public wants, not the options recommended by the science community. Before the science can have a major impact on policy change, it has to be mature enough, so that the scientists can convince political decision makers that the associated costs and benefits are known and that the costs are justified.

Why science is out of synchrony with policy changes. The lack of synchrony factors is largely due to 2 factors: (1) Ideas gain influence in science slowly. Some ideas, although rarely disputed, are just hard to document fully enough to support management actions, and the science basis for changes to policy and management accumulate incrementally. For example, it has been acknowledged since the first years of fisheries science that predator-prey interactions are important to management (Smith 1994, Rozwadowski 2002). However, each time a science body made a serious effort to bring those relationships into the advisory process, it took a decade or more to collect the necessary information and develop the corresponding models (North Sea: Pope 1991; Barents Sea: Yndestad 2004; Antarctica: CCAMLR 2004), and even more time to convince the wider science community to accept the specific tools and the estimates of the interaction rates. It has been argued that really new ideas in science are revolutions not evolution (Kuhn 1970), but even in this case, acceptance of the revolutionary idea has to 
spread from the first visionaries to the larger community. The notion of regime shifts as a dominant pattern of environmental variation may be such a quantum change in scientific thinking about ecosystem dynamics. Nearly a decade elapsed after the first papers framing the idea (e.g. Wooster \& Hollowed 1991) appeared, until a major symposium devoted to the topic (McKinnell et al. 2001) was held. Even then, most papers at the symposium presented evidence to support the validity of the concept, rather than addressing the implications of this type of environmental change for policy and management (Rice 2001, Cury et al. 2003).

(2) Those scientists who see the need for policy development soonest rarely articulate advice in a way that is useful to policy. I have observed a number of shortcomings at the science-policy interface when a new area of scientific inquiry develops:

- The most imaginative scientists may have a vision of how better future policies would use their new insights, but they are 'naïve' about how to bring about the necessary policy changes. I conjecture that the imagination that allows them to be among the first to envision new ecosystem considerations in management is in conflict with the patience required to have science influence policy. Their proposals for change may be direct, but policy development rarely is.

- Early scientific advice is often unhelpful in guiding policy. If the new insights come from theoretical generalists, these generalists tend to be fuzzy about the policy changes that are needed, as well as their consequences. If the new insights come from disciplinary specialists, they often present their calls for policy change from the perspective of their favourite part of the ecosystem, rather than from the perspective of governance and societal consequences, which are essential considerations to policy specialists. Either problem renders the science advice on policy ineffective, due to a lack of clarity about risks and consequences crucial to those making policy decisions.

- The science disciplines that support policy and management most directly, as well as those conducting basic research, both misunderstand and stereotype each other. This magnifies the first 2 shortcomings, as scientists from the 2 streams do not help each other and often end up neutralising their respective potential contributions.

- Scientists with different theoretical preferences and practical traditions are highly critical of each other's work, creating many opportunities for managers and stakeholder who are reluctant to change to play off one viewpoint against the other.

Interactions when science is 'ahead' of policy. As the scientific basis for the ecosystem approach begins to mature and consolidate, we are seeing 2 new impediments to a close harmony of science and policy.
(1) The reported uncertainty (sensu Rosenburg \& Restrepo 1994) in the scientific advice on policy increases when ecosystem considerations are taken seriously. This is in marked contrast to statements made as the field was developing, that a more complete modelling framework would reduce uncertainty. This contradiction and the greater reported uncertainty both retard policy implementation. The true uncertainty associated with a policy choice always did include model uncertainty, e.g. due to unknown functional relationships of species interactions and environmental forcing to the status of populations, as well as the uncertainty due to the unpredictability of future states of nature. However, the uncertainty actually included in the scientific advice often was little more than uncertainty in estimates of parameter values due to natural variability and measurement error, in an assessment formulation which did not explicitly include the environmental forcing and species interactions. Moreover, not only does the reported uncertainty in the science advice increase when the ecosystem approach is adopted, but also the factors causing the increase are ones that the science advisors had rarely mentioned to the managers receiving the advice, because the advisors had been encouraged to keep their messages simple and clear. Policy experts and managers obviously do not embrace this change (unless they are working in nonprecautionary frameworks where greater uncertainty allows them to defer painful decisions). Some time is needed until scientists are able to phrase their treatment of uncertainty in a way that makes sense to nonscientists, and during this transition period both sides are frustrated with the other's inability to deliver.

(2) When science is struggling with uncertainty, scientists who are more interested in impact of policy than in doing sound science can gain the spotlight. The ground is fertile for them, because the ecosystem approach is beginning to consolidate, so a partial but incomplete foundation for advice exists. These advocates offer answers that deemphasise the uncertainty, and guide policy towards apparently simple solutions to complex problems. Science advocates who are enthusiastic about, e.g., the Ecosystem Approach are likely to oversell the support that science can deliver and undersell the transition costs. They may be trying merely to accelerate change, but in the process they oversimplify complex issues. This may have happened in the debate about marine protected areas (MPAs; Hilborn et al. 2004), management based on trophicdynamic balance (http://dels.nas.edu/osb/ecosystem effects.shtml), and bottom-trawling (ICES 2000).

The advisory situation is awkward at present with respect to the EAF. The basic message of the advocacy scientists, to reduce an activity damaging the ecosystem, is right. Even the most experienced and practical science advisors support it, although with some trepi- 
dation, because they know that they are extrapolating further than they normally go in their advisory role. The body of sound science is not yet great enough to document fully advice within an ecosystem-based policy framework, but the science advisors can extrapolate as readily as anyone from the trends in the knowledge that has accumulated. Hence the ease with which concepts such as 'reference direction' are substituted for 'reference point' (Link et al. 2002), i.e. instead of advising on how to reach a specific state that is identified as safe (the 'reference point'), advisors only take on the simpler task of advising on the desirable direction of change (the 'reference direction'). It will not be until after policy is changed that hard advice will be needed. As soon as the questions about implementation of the policy are received, advising on the direction of change will not be enough. Much of the trepidation in experienced advisors was due to the fact that they knew that the hard questions about implementation would follow, and they lacked the information to answer them.

When scientific results are oversold and transition costs are deemphasised, policy experts are led to believe that there is a complete and tested science basis for implementing change. The U.S. Ocean Commission Report (USCOP 2004) and the Pew Report (POC 2003), and in Europe the Koge and Rotterdam meeting reports (EC 2003, 2004), all include the message that policy makers believe that the science framework for an ecosystem approach to marine management is complete. USCOP (2004, p. 47) goes so far as to recommend that 'Conservation decisions should be made by NMFS ... They should be based on recommendations from regional science and technical teams composed of federal, state, and academic scientists. Conservation decisions should precede and remain unchanged by allocation decisions ...' - the ecosystem science is ready to be the sole basis for public-interest decisions. In these documents, consistent with the impact of advocacy science on ecosystem policy issues, much is made of the opportunities, and little of the costs to get there. Most of these major commissions have recommended an increase in funding of science to address these challenges, but those recommendations are often slow to be translated into real increases in science funding.

These are the conditions when the leap in policy is made from rarely mentioning ecosystems to featuring them as the cornerstone of policy, as in the Preamble to Canada's Oceans Act (http://laws.justice.gc.ca./en/ O-2.4/index.html), where the Ecosystem Approach is listed as one of the 3 foundations of the provisions in the Act, and in the Bergen Declaration (2001). Policy makers do not know they have leapt into a poorly charted wilderness. After years of lagging ever further behind the accumulating body of science, in one set of policy revisions policy makers believe that they have moved to where science has been saying that policy should be based. They can be surprised and disappointed when they find that careful science advisors don't really know the territory well after all, and can provide only limited support for the new policies. The advisors know that science has merely been indicating the necessary direction of change. Much more research will be needed to determine how much change is needed to reach new, safe reference points in an ecosystem content. Policy makers, encouraged by the advocacy scientists to move boldly, now believe that they have reached this safe zone well ahead of the science.

Interactions when policy moves 'ahead' of science. After a decade of frustration, when science was ahead of policy, science advisors are faced with a new problem. Once the policy commitment is made, those associated with its development and implementation expect solid advice (Ludwig et al. 2001). Will it come from practical science advisors, who are well aware that much more research and monitoring is needed for full implementation of an ecosystem approach (Pikitch et al. 2004), or from those willing to speak with great confidence and certainty, even if neither is justified?

This is a dangerous time. Scientists experienced in advising decision makers are embracing the EAF as a necessary step forward. However, they stress that implementation must be incremental, a message in which managers take some comfort, for it does not upset their stability of process too dramatically. For example, both Annex 5 to the FAO Code of Conduct (FAO 2003) and the Implementation Guidelines for the EU Marine Strategy (Rice et al. 2005) stress that change will be incremental, as scientific knowledge and management experience continue to grow, and as industries and communities adapt to change. The ecological aspects of the ecosystem approach are amenable to incremental change. Assessments and advice can account incrementally for environmental forcing factors and for predator-prey impacts on stock dynamics, as the functional relationships are identified and parameterised (ICES 2002, 2003, 2004). Ecosystem effects of fishing can be taken into account in the same way.

The danger is that the increments may not be the 'right' size. They can be perceived as being too large. In Canada, for example, opposition to the inclusion of marine species under the new Species At Risk Act (SARA) is deep among coastal communities, fishers' organisations, and even fisheries management communities (e.g. DFO 2005), because listing under SARA would mean a step from the present fisheries management to mandatory prohibitions of all activities causing death or harassment, unless very stringent conditions are met. Comparable opposition is found in many other jurisdictions (FAO 2002). On the other hand, implementation of existing ecosystem knowledge in 
routine fisheries management has proceeded slowly, allowing acknowledged environmental crises to persist (Rice 2005a,b).

How do we ensure that implementation of an ecosystem approach occurs swiftly enough to generate real improvements in marine ecosystem status, but not so swiftly that society fails to adapt and chooses to oppose change altogether? The parts of the ecosystem approach addressing governance changes-integrated planning and management, and inclusiveness and transparency (Swan \& Greboval 2004) - must receive as much attention as the ecological components. The governance changes create a context for an adaptive approach that uses science knowledge as it accumulates. Science advisory processes can facilitate these necessary governance changes in inclusiveness and integrated planning, by changing some practices as well.

Science peer review and advisory processes must face the challenges posed by an integrated ecosystem approach. The culture of structured peer review is well developed with regard to the provision of advice on fish stocks, fisheries and pollution. The transition to advising on these processes in an ecosystem context has been difficult in the USA, Canada and Europe for at least 2 reasons.

(1) The questions on which advice is sought are often poorly framed. Requests for advice still come from regulatory agencies, which remain largely sector specific (fisheries, pollution, etc.). Either the 'ecosystem advice' requested is simply a concatenation of the requests from managers in several sectors, or it represents a compromise that is vague, so that none of the managers feels that the jurisdiction of their own sector is being curtailed. In neither case do the requests have the specificity that allows science advisory bodies to provide clear answers.

(2) When scientists work in advisory contexts they do not integrate their knowledge as well as they do in contexts like multi-disciplinary symposia. From my experience with 3 ICES Advisory Committees (Fisheries Management, Marine Environment, and Ecosystems) the same ecosystem issue may be on the agenda of more than one advisory committee, but each discusses different aspects of the issue and gives weight to different considerations about the options. Each advisory body attacks the ecosystem issue by building incrementally on its past work, and because their histories are different, they take different pathways in seeking solutions. Even when the 3 committees are converging in their deliberations, each is likely to stop at the limits of its own expertise. This provides piecemeal rather than integrated science advice, and the different considerations emphasised by the different committees may appear to be inconsistencies. The gaps and perceived inconsistencies do not inspire confidence in managers to act, and give resource users potentially restricted by new ecosystem-based management measures ample opportunity to oppose the basis for these measures.

The obvious step of obtaining integrated ecosystem advice from integrated advisory bodies is being taken by many jurisdictions. These advisory bodies still build their advice from the parts to the whole, with the parts retaining much of their original character. Neither the science advisors nor those they advise are comfortable throwing out tools with which they have gained decades of experience, especially when the new tools for integrating ecosystem considerations into the assessments are still in their infancy. There is much enthusiasm for 'ecosystem indicators' as the new foundation for scientific advice on an ecosystem approach to management (Garcia 1996, Daan et al. 2005), but I have some scepticism regarding that course. Although 'policy relevance' is a core selection criterion for most ecosystem indicator discussions (see review by Rice \& Rochet 2005), the reliability of the indicators used for policy choice is almost never tested in practice (Rochet $\&$ Rice 2005). I think that opening many science review and advisory processes to more diverse types of experiential and traditional knowledge holds more promise for facilitating truly integrated advice (Rice in press). Although participants with experiential knowledge have just as much sectoral focus as the science advisors do, the process of combining experiential knowledge with 'hard science' has meant uprooting the trust in the tools of one's discipline and finding ways to truly merge different kinds of knowledge (Rice in press). Once started, this practice may turn out to be transferable across disciplines. Just as fishermen's knowledge has demonstrated its value in understanding status and trends in fish populations and consequences of management measures (Gray in press), many sources of traditional knowledge may contribute to understanding the state of marine ecosystems relative to their historic conditions, and the effects of human activities on those systems.

It is also necessary to stem the trend towards politicisation of the science applied to management-i.e. towards 'advocacy science'. The motivation for advocacy science is understandable because of the seriousness of environmental crises and the lack of synchrony between advances in science and policy. Scientists passionate about protecting the environment may be tempted to 'spin' the scientific evidence, to make the case for policy changes appear stronger than it really is. However, science has its privileged access to policy and decision-making just because it strives to be impartial and objective. If those goals are sacrificed for cultivating a public-opinion environment that is less sympathetic to harvesting, then science becomes just 
one more special interest group at the table. The science community may win debates sometimes, but it will lose sometimes as well. In the last US election a $2 \%$ margin of victory was called 'significant political capital' by new commentators. If science chooses to enter that political arena, should it fail to win a clear majority of supporters it risks being marginalized in subsequent policy decisions. Scientists can be activist about their beliefs, but Science itself loses its value if it gives up the objectivity and empiricism on which it is founded and uses evidence selectively to build a case for a pre-selected conclusion.

In addition to changes in science advisory processes, management building on the advice has to become more averse to risk in practice. Even if all the harvest implications of an EAF are not known at present, without question there will be a need to harvest less, to accommodate both the target species role in the ecosystem and periods of poor environmental productivity (Rice 2005b). At the same time, as discussed above, the uncertainty presented explicitly in assessments and advice has increased. If management is not averse to risk, greater uncertainty will result in more aggressive harvesting, not in less. This makes the inclusiveness and transparency of both the advisory and management processes even more important, as many of the failures of traditional single-species fisheries management occurred because management was risk prone. If this remains the case, then an EAF will reduce sustainability in fisheries, instead of improving it.

Opportunities and risks. We are in a crucial time. The scientific case for taking an ecosystem approach is now strong enough, so that EAF has been embraced widely by national and international policy agencies. Policy has changed in a leap, from a situation where a growing body of scientific knowledge about ecosystem relationships was having little impact on management, to a situation where science now lacks the ability to reliably and comprehensively support ecosystemgeared policy initiatives. The resulting practice of incremental applications of science to management is fully consistent with emerging policy and management frameworks. However, science must be focused on making reliable incremental steps, not taking adventurous leaps towards 'holistic' management, and scientists must integrate the whole science process, not just the final science products. There are signs of some progress in integration, such as the creation of the Working Group on Regional Ecosystem Descriptions and the Regional Ecosystem Group for the North Sea in ICES, which have attracted genuinely diverse mixes of experts. However, there is a long way to go. Few ecosystem scientists and oceanographers attend complete fish stock assessment meetings, and many 'multidisciplinary' research projects quickly evolve into a series of discipline-centred subprojects; they are punctuated by an annual meeting of the teams, at which information is shared, but the work is not conducted in an integrated way throughout the year. Management must make increments in regulations large enough to make a difference. The major benefits will be reaped when science advisors, managers, and policy-makers all take the governance and the ecological components of an EAF equally seriously. We have to accept that uncertainty in the science inputs to management will be larger (and more realistic) in an EAF, and we have to face the fact that decision-making must become more risk averse, or the EAF will leave marine ecosystems worse off, rather than better off.

\section{LITERATURE CITED}

Bergen Declaration (2001) Ministerial declaration: Fifth International Conference on the Protection of the North Sea. Bergen, Norway (available at http://odin.dep.no/archive/ mdvedlegg/01/11/Engel069.pdf)

CCAMLR (2004) CCAMLR's management of the Antarctic. (CCAMLR, Hobart; available at: http://www.ccamlr.org/ pu/E/e_pubs/am/man-ant/p1.2.htm

Cury P, Shannon L, Shin YJ (2003) The functioning of marine ecosystems: a fisheries perspective. In: Sinclair M, Valdimarsson G (eds) Responsible fishing in the marine ecosystem. FAO Fish Tech Pap 400, FAO, Rome

Daan N, Christensen V, Cury PM (eds) (2005) Symposium on Quantitative Ecosystem Indicators for Fisheries Management. ICES J Mar Sci 62:307-614

DFO (2005) Report of the DFO public consultations on SARA listing of Atlantic cod. Department of Fisheries \& Oceans, Ottawa

EC (2003) Communication from the Commission to the Council and the European Parliament: 'Towards a strategy to protect and conserve the marine environment'. Council conclusion March 7, 2003. European Union, Brussels

FAO (2002) An appraisal of the suitability of the CITES criteria for listing commercially-exploited aquatic species. FAO Fish Circ 954, FAO, Rome

FAO (2003) The ecosystem approach to fisheries. FAO Technical guidelines for responsible fisheries No. 4, Suppl 2. FAO, Rome (available at ftp://ftp.fao.org/docrep/fao/005/ y4470e/y4470e00.pdf)

Garcia S (1996) Indicators for sustainable development of fisheries. 2nd World Fisheries Congress, Workshop on Fisheries Sustainability Indicators, Brisbane, Australia, August 1996 (available at: www.fao.org/docrep/W4745E/ w4745e0f.htm)

Gray TS (ed) (in press) Participation in fisheries governance. Springer, Dordrecht

Hilborn R, Stokes K, Maguire JJ, Smith T and 6 others (2004) When can marine reserves improve fisheries management? Ocean Coast Manage 47:197-205

ICES (2000) Report of the Advisory Committee on the Marine Environment 1999. CRR 239, ICES, Copenhagen

ICES (2002) Report of the Study Group on Incorporation of Process Information into Stock-Recruit Models. ICES CM 2002/C:01

ICES (2003) Report of the Study Group on Growth, Maturation, and Condition in Stock Projections. ICES CM 2003/D:02 ICES (2004) Report of the Thirteenth ICES Dialogue Meeting: 
advancing scientific advice for an ecosystem approach to management: collaboration amongst managers, scientists, and other stakeholders. CRR 267, ICES, Copenhagen

Kuhn TS (1970) The structure of scientific revolutions. University of Chicago Press, Chicago, IL

Link J, Brodziak JTK, Edwards SF, Overholtz WJ, Mountain D, Joost JW, Smith TD, Fogerty MJ (2002) Marine ecosystem assessment in a fisheries management context. Can J Fish Aquat Sci 59:1429-1440

Ludwig D, Mangel M, Haddad B (2001) Ecology, conservation, and public policy. Annu Rev Ecol Syst 32:481-517

MacArthur RH (1972) Geographical ecology. Harper \& Row, New York

McKinnell SM, Brodeur RD, Hanawa K, Hallowed AB, Polovina JJ, Zhang CI (eds) (2001) Pacific climate variability and marine ecosystem impacts. Progr Oceanogr 49:1-640

Pikitch EK, Santora C, Babcock EA, Bakun A and 13 others (2004) Ecosystem-based fishery management: reversing the means to an end. Science 305:345-347

POC (Pew Ocean Commission) (2003) America's living ocean: charting a course for sea change. Ocean Trust, Washington, DC; available at: www.pewtrusts.org/pdf/env_pew_ oceans_final_report.pdf

Pope JG (1991) The ICES Multispecies Assessment Working Group: evolution, insights and future problems. In: Daan N, Sissenwine MP (eds) Multispecies models relevant to management of living resources. ICES Mar Sci Symp 193:22-33

Rice JC (2001) Implications of variability on many time scales for scientific advice on sustainable management of living marine resources. Progr Oceanogr 49:189-209

Rice JC (2005a) Will an ecosystem approach mitigate the factors of unsustainability? In: Maguire JJ, Greboval D (eds) 3rd Workshop on Factors of Unsustainability, Sept 14-18, 2004, Siem Reap, Cambodia. FAO Tech Fish Rep 700

Rice JC (2005b) Is the failure of conventional fisheries management making the conservationist approach more appealing, offering a way out of making tough decisions? In: Maguire JJ, Greboval D (eds) 3rd Workshop on Factors of Unsustainability, Sept 14-18, 2004. Siem Reap, Cambodia. FAO Technical Fisheries Report 700

Rice JC (in press) Bringing 'experiential knowledge' into fisheries science advisory processes: lessons learned from the Canadian experience. In: Gray TS (ed) Participation in fisheries governance. Springer, Dordrecht

Rice JC, Rochet MJ (2005) A framework for selecting a suite of indicators for fisheries management. ICES J Mar Sci 62: $516-527$

Rice JC, Trujillo V, Jennings SL, Hylland $\mathrm{K}$, Hagstrom O, Astudillo A, Jensen JN (2005) Guidance on the application of the ecosystem approach to management of humen activities in the European marine environment. ICES Cooperative Research Report 273. ICES, Copenhagen

Rochet MJ, Rice JC (2005) Testing an objective framework for selecting indicators. ICES J Mar Sci 62:528-539

Rosenberg AA, Restrepo VR (1994) Uncertainty and risk evaluation in stock assessment advice for US marine fisheries. Can J Fish Aquat Sci 51:2715-2720

Rozwadowski HM (2002) The sea knows no boundaries. University of Washington Press, Seattle, WA

USCOP (2004) An ocean blueprint for the 21st century. Final Report, US Commission on Ocean Policy, Washington DC (available at: www.oceancommission.gov/documents/ prepub_report/welcome.html)

Smith TD (1994) Scaling fisheries: the science of measuring the effects of fishing 1855-1955. Cambridge University Press, Cambridge

Swan J, Greboval D (eds) (2004) International Workshop on the Implementation of International Fisheries Instruments and Factors of Unsustainability and Overexploitation in Fisheries. Mauritius, 3-7 February 2003. FAO Fish Rep No. 700, FAO, Rome

Wooster WS, Hollowed AB (1991) Decadal scale changes in the northeast Pacific Ocean. Northw Env J 7:361-363

Yndestad H (2004) The cause of Barents Sea biomass dynamics. J Mar Syst 44:107-124

\section{Implementing ecosystem-based approaches to management for the conservation of ecosystem services}

\section{Andrew A. Rosenberg ${ }^{1}$, Karen L. McLeod ${ }^{2}$}

${ }^{1}$ Institute for the Study of Earth, Oceans and Space, Morse Hall 142, University of New Hampshire, Durham, New Hampshire 03824, USA

Email: andy.rosenberg@unh.edu

${ }^{2}$ Department of Zoology, 3029 Cordley Hall, Oregon State University, Corvallis, Oregon 97331, USA

Email: karen.mcleod@science.oregonstate.edu

The need for an ecosystem-based approach to management (EAM). Widespread degradation of ocean resources and continued human pressures on coastal and ocean environments necessitate ecosystem-based approaches to the management of marine resources. A proliferation of ocean-related activities and growing demands for marine resources have given rise to increasingly complicated policies, rules and regulations that ostensibly govern those activities. The declining state of marine ecosystems around the world, under virtually any definition of 'state' (e.g. Pauly et al. 1998, Jackson et al. 2001, Myers \& Worm 2003, Pandolfi et al. 2005), indicates that management changes are needed: society has outgrown the policy models that were developed for managing its impacts on the marine environment (USCOP 2004).

In many parts of the world, policies to manage fisheries, mitigate the effects of coastal development, improve water quality and manage numerous other sectors have been developed and implemented in good faith. Some of these existing policies have slowed the decline or enhanced the recovery of degraded marine ecosystems. For example, the use of large marine protected areas and reductions in fishing mortality have led to the recovery of some depleted species on Georges Bank off the Northeast USA (Murawski et al. 2000). Fisheries management in Alaska appears to be maintaining a stable harvest of target species through stringent catch controls (Witherell 2004). Marine reserves in the Dry Tortugas (Gulf of Mexico) are allowing several species of grouper and other reef fish to recover (Ault et al. 2005). Nevertheless, the broad-scale pattern in the marine environment is one of degradation and, given the escalating scale of human impacts, present policies are clearly insufficient. 
Over the last decade, EAM has been called for in a variety of ocean policy initiatives around the world to address the problems touched on above. In the USA, both the Pew Oceans Commission (POC 2003) and the U.S. Commission on Ocean Policy (USCOP 2004) agreed that more comprehensive, holistic ecosystem-based approaches were urgently needed. Recently, over 200 academic scientists from institutions in the USA agreed by consensus upon a definition of ecosystem-based management for the oceans, given in part here:

Ecosystem-based management is an integrated approach to management that considers the entire ecosystem, including humans. The goal of ecosystem-based management is to maintain an ecosystem in a healthy, productive and resilient condition so that it can provide the services humans want and need. Ecosystem-based management differs from current approaches that usually focus on a single species, sector, activity or concern; it considers the cumulative impacts of different sectors. (McLeod et al. 2005, p. 1)

Keys to shifting beyond single sector-based approaches. As governments at various levels attempt to implement ecosystem-based approaches, key changes are needed to move beyond the current sector by sector approach to management.

(1) Management goals must be framed with respect to the conservation of ecosystem services, i.e. ensuring that marine ecosystems can fully function in order to sustain the delivery of a wide range of services. These include provisioning services (e.g. food and fresh water), regulating services (e.g. climate and flood regulation), cultural services (e.g. spiritual and aesthetic values), and supporting services (e.g. nutrient cycling and primary production) (MA 2005). For most, if not all, sectors of management, this constitutes a major shift in perspective. Primary goals of current policy tend to focus on maximizing catch, business opportunities or economic development, frequently aiming to achieve sustainable levels of these activities. In contrast, ecosystem-based goals would give precedence to the long-term potential of systems to deliver a broad suite of ecosystem services over short-term goals for individual services. Such goals inherently recognize that it is not possible to sustain humans without sustaining ecosystems over long time frames (Grumbine 1997).

(2) An ecosystem-based approach must account for interactions among sectors by integrating management across multiple sectors (Fig. 3A). Current approaches ignore these interactions at the cost of decreasing the overall ability of systems to provide a full range of services, as well as compromising the ability of any given policy to meet individual sector goals. For example, the course of coastal development affects habitat and water quality, which in turn, alter coastal productivity and fisheries. Thus, doing a very good job of managing fishery impacts on the ecosystem is critical, but not suffi- cient for maintaining ecosystem services, including providing high quality, healthy seafood. At the same time, policies themselves interact. For example, coastal development may alter working waterfront areas or limit the ability of fishing businesses to operate. Water quality management measures such as outfall pipes may also impact specific fishing areas. Neither the impacts nor the management policies for each sector are independent of each other. Consequently, ecosystembased fisheries management (Pikitch et al. 2004) is also a necessary, but not sufficient, tool for conserving ecosystem services because both the impact of the interactions among different human activities and interactions among management policies can be substantial.

(3) Cumulative impacts must be explicitly considered in management. The impacts of human activities in aggregate affect ecosystem services. To use a fisheries example again, even if each fishery in a large marine ecosystem is reasonably well managed, the cumulative impacts of all of the fisheries will likely be greater than the summed effects of individual fisheries. Individual

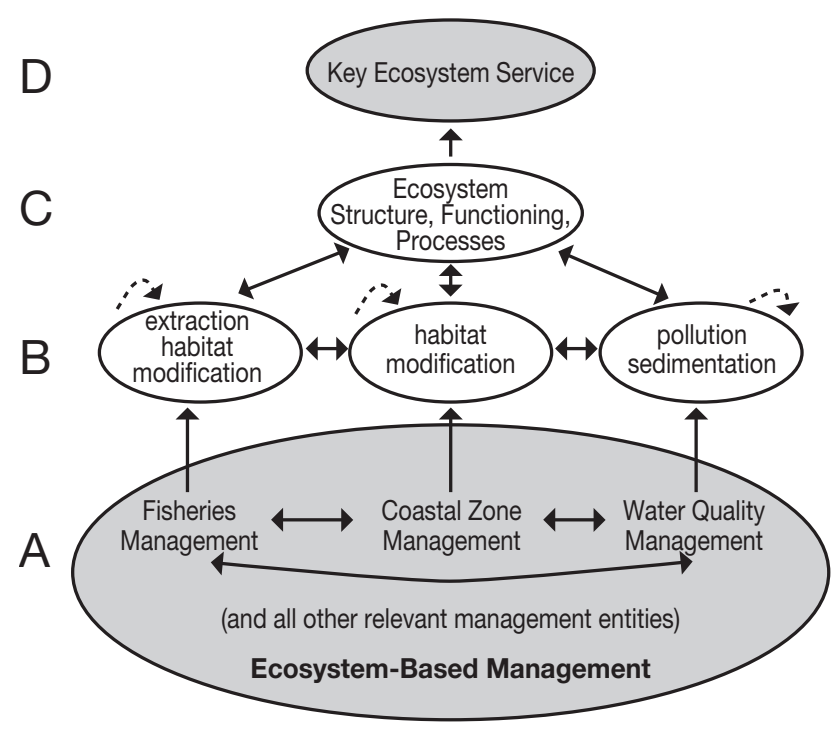

Fig. 3. Key aspects of ecosystem-based management. Current management focuses on regulating the impacts of individual sectors on particular ecosystem services, such as the production of food. In contrast, EAM considers the cumulative and interactive impacts of multiple sectors on the stocks and flows of key ecosystem services. Characteristics include: (A) consideration of interactions among policies, without negating the need for individual sector management, (B) examination of interactions among the impacts of individual sectors (arrows between impacts) as well as the cumulative impacts of individual and multiple sectors through time (dotted feedback loops), and (C) monitoring the effects of these cumulative impacts on ecosystem structure, functioning, and key processes, as well as the way in which reciprocal changes to ecosystems modify those impacts. (D) The goal of ecosystem-based management is to maintain the flows of key ecosystem services that result from ecosystem structure, functioning, and processes 
fishery management plans striving to obtain maximum sustainable yield often ignore predator-prey interactions, e.g. that exploiting an important forage species undermines the productivity of its predator. Cumulative impacts across sectors, such as the habitat impacts of various activities noted above, may also significantly undermine ecosystem services. For example, in a particular area, the habitat impacts of fishing gear may be minor, but when combined with the effects of increased sedimentation from coastal development, the cumulative impacts of the 2 activities on habitat may be significant. Thus, impacts of individual sectors on overall ecosystem structure, functioning, and key processes must be evaluated in the context of concurrent impacts in order to sustain the flows of key ecosystem services (Fig. 3B-D).

(4) Creating more cohesive, integrated management policies that are understandable across sectors is critical. As each sector of activity has expanded, the policies intended to manage those activities have become, in many cases, alarmingly complex. Fisheries rules run to thousands of pages with enormous detail for each type of fishing activity in each season and each area and differ across regions and countries. Other policy arenas are similarly complex, but the bottom line is that the rules as well as the goals for all sectors are disjunct from one another. The result is an enormously confusing patchwork of management measures that leads to frustration and dissatisfaction on all sides. Setting goals that are related to the conservation of ecosystem services should enable managers to begin fitting together the various pieces of management in a more coherent fashion. For example, area closures are a management measure used for a multitude of purposes across many marine sectors. There are fishery closed areas, areas of protected habitat for various species including fishes, whales and turtles, restricted development areas closed to mining or drilling, and marine parks, to name a few. Each closed area is designed for a specific purpose without reference to other area management schemes within a region. The result is a complex set of overlapping restrictions. An alternative is to design zones in the ocean where specific activities are allowed. The overall goals of ocean zoning would be the conservation of ecosystem services and greater clarity in the regulatory structure. Such zones should include some areas that are fully protected from extractive uses, broad areas of habitat protection that serves several species groups and ensures extractive uses are non-destructive, and still other areas that are more intensively utilized for certain activities without undermining the overall sustainability of a wide range of ecosystem services.

Challenges for implementation: science. Challenges from the perspectives of both science and governance must be confronted in order to integrate management using an ecosystem-based approach. However, despite these challenges and the enormous inertia to continue doing business as usual, it is crucial not to delay action. Waiting to improve policy approaches until better information becomes available may well mean that the necessary information never will be developed, and even worse, that marine ecosystems will continue to decline and undergo dramatic shifts. At some point, these changes may be irreversible, as there is often a threshold beyond which altered ecosystems may not return to their original states (Folke et al. 2004).

Many scientific issues need to be considered in order to implement EAM in the marine environment, not the least of which is the culture of science. Scientific enterprises, within academia as well as within government, tend to be organized around sectors or disciplines in much the same way that policy and management institutions are. Water quality scientists do not interact with fisheries scientists or coastal development scientists. Fisheries scientists study the population dynamics of species of commercial interest, while marine ecologists work to understand the dynamics of other species, and so forth. In order to develop a complete picture of the interactive effects of human activities on marine ecosystems, both the scientific and policy communities need to be better integrated (Browman \& Stergiou 2004). The problems facing the world's oceans require more effective bridges among relevant scientific disciplines, and scientists have a responsibility to facilitate such changes with respect to both their own research agendas and their institutions (Lubchenco 1998). It is naïve for us, as scientists, to expect that all of the necessary integration will come at the policy level.

There is also an urgent need for a more complete understanding of cumulative impacts. While it is possible to estimate the impacts of a particular fishery or a particular level of nutrient loading on an individual ecosystem service such as the biomass of a certain fish stock or the degree of coastal eutrophication, understanding the cumulative impacts of all activities on one another is much more challenging (Fig. 3B). An analytical framework that allows for an evaluation of the cumulative impacts of key activities on a suite of ecosystem services is an important and necessary foundation for integrated management. This is a major scientific challenge that requires a concerted research effort and the development of more sophisticated models to support policy development. Although the complexity of ecosystems may be daunting, we can no longer afford to make many of the simplifying assumptions on which current management is based.

We presently have no measurement systems in place for many ecosystem attributes that are fundamental to the provision of ecosystem services, such as biodiver- 
sity, on scales large enough to be relevant to management. Recent efforts to develop ocean observation systems have been slow to incorporate measurement of biological features in general, perhaps because the dimensionality of the problem makes it much more complex than the evaluation of many physical or chemical attributes. In the long-term, such measurement systems are needed to better understand the functioning of marine ecosystems, as well as the effectiveness of management decisions. Similarly, we generally lack experimental systems that are representative of the potential impacts of human activities on ecosystem services. The temporal and spatial scales of many experimental or monitoring studies are simply too small to be relevant to management beyond very local scales.

It is difficult to characterize an appropriate baseline against which to compare degraded systems. Importantly, the baseline for ecosystem services should not be based on recent observations of already degraded systems. For example, estimates of the historical abundance of cod on the Scotian Shelf show that the current biomass is $<5 \%$ of the estimated biomass $150 \mathrm{yr}$ ago (Rosenberg et al. 1995). Results for other areas, using different methods and data, show similar levels of depletion for key commercial species (Myers \& Worm 2003, Jennings \& Blanchard 2004). Most fishery management policy currently incorporates biomassrebuilding targets based on observed biomass and population dynamics over the past few decades at best. In effect this means that the only reference points for management may be from already severely degraded systems, missing the range of services, including from much higher biomasses of highly valued species, that may flow from a restored system. There is a need to look back in time, from an interdisciplinary perspective, to develop a complete picture of marine ecosystems and their services that reflects a broader range of potential states (Jackson et al. 2001, Pitcher 2001, Rosenberg et al. 2005).

Finally, there is a strong tendency, within both scientific advice and policies based on that advice, to emphasize uncertainty. Over the last decade or so, there has been a concerted effort to describe quantitatively the uncertainty in many analyses, e.g. statistical approaches to fisheries stock assessments and the use of simulations to explore the sensitivity of estimated quantities. These are important advances, and it is vital to be clear about uncertainty and risk. However, it is also crucial not to lose sight of the aspects that we do know well because of the weight of evidence. For example, we can well describe the uncertainty in fishery stock assessment estimates, but in many cases we are quite certain that overfishing is occurring, even if the precision in the estimates of harvest rates is quite low (e.g. NOAA 1999). Emphasizing uncertainty without clearly stating those aspects about which we are reasonably certain undermines efforts to take strong policy action. In the context of ecosystem-based management, interaction terms and cumulative impacts will inherently include high levels of uncertainty, but it may be clear that an interaction is occurring and is substantial. In this case, management that accounts for the interaction should move ahead even if the precision of specific parameters is low. For example, if there is an indication that fisheries management efforts to recover an overfished stock are hampered by habitat impacts of, say, cabling or pipeline routing, then management should seek to minimize those habitat impacts, particularly in areas most used by the recovering species. Such protections should not wait for the development of detailed studies on habitat effects if there is even nominal evidence such an impact may be important.

Challenges for implementation: governance. With respect to governance, several key issues need to be addressed to implement ecosystem-based management. Overall, agencies within various levels of government currently lack a shared vision to conserve the breadth of services that humans want and need from marine ecosystems. This will require crossing jurisdictional as well as cultural boundaries and overcoming the inertia of current practices. Managing on an ecosystem basis can quickly devolve into a long and fruitless debate about delineating ecosystem boundaries. At relatively large regional spatial scales, management may be most practical at the scales of large marine ecosystems (Sherman et al. 1990). In practice, boundaries must be delineated with a clear understanding that they will necessarily be leaky and influenced by processes occurring at both larger and smaller spatial scales. Drivers of change, ecosystem processes, and the stocks and flows of ecosystem services all occur at a variety of spatial scales. Thus, effective management will be required at numerous, nested scales, and there will not be a single ideal scale for management.

Most of the primary sectors of human activities that impact marine systems are managed independently under separate statutory authorities, and often by different agencies. The situation in the USA is typical. Fisheries are primarily managed by one of the major offices in the National Oceanic and Atmospheric Administration, the National Marine Fisheries Service, under the Magnuson-Stevens Fisheries Conservation and Management Act. Water quality is managed primarily by the Environmental Protection Agency under the Clean Water Act. Coastal development is managed primarily at the state and local levels with several federal programs providing guidance or support under the Coastal Zone Management Act and other statutes. However, no single agency possesses the mandate to see that the pieces of management across sectors fit 
together, and no one has the mandate to look at interactions among activities with respect to their overall impact on ecosystem services. This does not necessarily imply top-down control or oversight. Rather, each of the implementing agencies needs to be required to work together for joint, ecosystem-based, solutions. They need to be allowed to be more creative in crafting management that addresses more than the narrow spectrum of issues they may have been tasked with in the past. Significant barriers to interagency or crosssector cooperation pose a related challenge. Legally, management is currently required to meet only single sector goals. Budgets and other resources are allocated by sector. Agency cultures at all levels tend to remain within their traditional areas of expertise, much as the science programs do. In order to manage on an ecosystem basis, legal and institutional frameworks must be created to develop policies that allow agencies to integrate management across sectors. A change in culture is needed, so that working to conserve the full suite of ecosystem services is part and parcel of the primary agency mandates for conservation and management within the marine environment. We do not mean to imply that individual sector management is unnecessary. Without question, the main effects of each sector need to be managed, and the mandates to do so need to be strengthened, in the USA and in other nations. However, the authority and mandate to work across sectors is also essential.

Conclusions. As demands for ecosystem services increase, the cumulative effects of numerous human activities on land, along the coasts and in the oceans are collectively diminishing the ability of marine ecosystems to provide those services (MA 2005). Nevertheless, there is currently no clear mandate for management policies that address cumulative impacts and interactions among sectors, nor does any agency possess the overarching goal of managing to conserve ecosystem services. In many cases, it may be possible to reverse the degradation of marine ecosystems, but we cannot afford to delay action. Ocean policies must be reoriented towards comprehensive, integrated EAM with the goal of sustaining the delivery of a broad suite of ecosystem services over long time frames, rather than focusing on particular services to the detriment of the others.

\section{LITERATURE CITED}

Ault JS, Smith SG, Bohnsack JA, Luo J, Harper DE, McClellan DB (2005) Fishery-independent monitoring of coral reef fishes and macro-invertebrates in the Dry Tortugas. Tortugas Reef Fish and Habitat Assessment: 2004 Expedition Report. Univ of Miami, Miami, FL

Browman HI, Stergiou KI (eds) (2004) Perspectives on ecosystem-based approaches to the management of marine resources. Mar Ecol Prog Ser 274:269-303

Christensen V, Guenette S, Heymans JJ, Walters CJ, Watson
R, Zeller D, Pauly D (2003) Hundred-year decline of North Atlantic predatory fishes. Fish Fish 4:1-24

Folke C, Carpenter S, Walker B, Scheffer M, Elmqvist T, Gunderson L, Holling CS (2004) Regime shifts, resilience, and biodiversity in ecosystem management. Annu Rev Ecol Evol Syst 35:557-581

Grumbine RE (1997) Reflections on 'what is ecosystem management?' Conserv Biol 11:41-47

Jackson JBC, Kirby MX, Berger WH, Bjorndal KA and 15 others (2001) Historical overfishing and the recent collapse of coastal ecosystems. Science 293:629-638

Jennings S, Blanchard JL (2004) Fish abundance with no fishing: predictions based on macroecological theory. J Anim Ecol 73:632-642

Lubchenco J (1998) Entering the century of the environment: a new social contract for science. Science 279:491-497

McLeod KL, Lubchenco J, Palumbi SR, Rosenberg AA (2005) Scientific consensus statement on marine ecosystembased management. Signed by 219 academic scientists and policy experts with relevant expertise and published by the Communication Partnership for Science and the Sea (available at: http://compassonline.org/?q=EBM)

MA (2005) Millennium Ecosystem Assessment Synthesis Report. Island Press, Washington, DC (available at: http://www.maweb.org)

Murawski SA, Brown R, Lai HL, Rago PJ, Hendrickson L (2000) Large-scale closed areas as a fisheries management tool in temperate marine systems: the Georges Bank experience. Bull Mar Sci 66:775-798

Myers RA, Worm B (2003) Rapid worldwide depletion of predatory fish communities. Nature 423:280-283

NOAA (1999) Our living oceans: report on the status of U.S. living marine resources. National Oceanic and Atmospheric Administration, NOAA Tech Memo NMFSF/SPO-41

Pandolfi JM, Jackson JBC, Baron N, Bradbury RH and 7 others (2005) Are U.S. coral reefs on the slippery slope to slime? Science 307:1725-1726

Pauly D, Christensen V, Dalsgaard J, Froese R, Torres F Jr (1998) Fishing down marine food webs. Science 279: 860-863

POW (Pew Oceans Commission) (2003) America's living oceans: charting a course for sea change. Pew Oceans Commission, Arlington, VA (available at: www.pewoceans.org)

Pikitch EK, Santora C, Babcock EA, Bakun A and 13 others (2004) Ecosystem-based fishery management. Science 305:346-347

Pitcher TJ (2001) Fisheries managed to rebuild ecosystems? Reconstructing the past to salvage the future. Ecol Appl 11:601-617

Rosenberg AA, Bolster WJ, Alexander KE, Leavenworth WB, Cooper AB, McKenzie MG (2005) The history of ocean resources: modeling cod biomass using historical records. Front Ecol Evol 3:84-90

Sherman K, Alexander LM, Gold BD (eds) (1990) Large marine ecosystems: patterns, processes, and yields. American Association for the Advancement of Science, Washington, DC

USCOP (2004) An ocean blueprint for the 21st century. Final report to the President and Congress. U.S. Commission on Ocean Policy, Washington, DC (available at: www.oceancommission.gov)

Witherell D (ed) (2004) Managing our nation's fisheries: past, present and future. Proc Conf Fisheries Management in the United States, Washington, DC, November 2003. North Pacific Regional Council Presentation, North Pacific Fishery Management Council, Anchorage, AK, p 129-150 


\section{A global movement toward an ecosystem approach to management of marine resources}

\author{
K. Sherman ${ }^{1, *}$, M. Sissenwine ${ }^{2}$, V. Christensen ${ }^{3}$, A. \\ Duda $^{4}$, G. Hempel ${ }^{5}$, C. Ibe $^{6}$, S. Levin ${ }^{7}$, \\ D. Lluch-Belda ${ }^{8}$, G. Matishov ${ }^{9}$, J. McGlade ${ }^{10}$, \\ M. O'Toole ${ }^{11}$, S. Seitzinger ${ }^{12}$, R. Serra ${ }^{13}$, \\ H.-R. Skjoldal ${ }^{14}$, Q. Tang ${ }^{15}$, J. Thulin ${ }^{16}$, \\ V. Vandeweerd ${ }^{17}$, K. Zwanenburg ${ }^{18}$ \\ ${ }^{1}$ Northeast Fisheries Science Center, Narragansett Laboratory, \\ NOAA-Fisheries, 28 Tarzwell Drive, Narragansett, Rhode \\ Island 02882, USA \\ *Email: kenneth.sherman@noaa.gov \\ ${ }^{2}$ Director of Scientific Programs, NOAA-Fisheries, \\ Silver Spring, Maryland 20910-3282, USA \\ ${ }^{3}$ Fisheries Centre, University of British Columbia, Vancouver, \\ British Columbia, V6T 1Z4, Canada \\ ${ }^{4}$ International Waters, Global Environment Facility (GEF) \\ Secretariat, World Bank, Washington, DC 20433, USA \\ ${ }^{5}$ Berater des Präsidenten des Senats für den \\ Wissenschaftsstandort Bremen-Bremerhaven, Senate of Bremen, \\ Tiefer 2, 28195 Bremen, Germany \\ ${ }^{6}$ United Nations Industrial Development Organization (UNIDO), \\ United Nations Compound, Accra, PO Box 1423, Ghana \\ ${ }^{7}$ Department of Ecology and Evolutionary Biology, Princeton \\ University, Princeton, New Jersey 08544-1003, USA \\ ${ }^{8}$ Centro Interdisciplinario de Ciencias Marinas (CICIMAR), \\ Instituto Politecnico Nacional (IPN), La Paz \\ Baja California Sur, 23096, Mexico \\ ${ }^{9}$ Academy of Sciences, Murmansk Marine Biological Institute \\ (MMBI), Azov Branch, Rostov-on-Don 344066, Russia \\ ${ }^{10}$ European Environment Agency, Copenhagen K1050, Denmark \\ ${ }^{11}$ Benguela Current LME Programme, Coordination Unit, \\ Windhoek, PO Box 40728, Namibia \\ ${ }^{12}$ Institute of Marine \& Coastal Sciences, Rutgers, State \\ University of New Jersey, Cook Campus, New Brunswick, \\ New Jersey 08901-8521, USA \\ ${ }^{13}$ Instituto de Fomento Pesquero, IFOP, Valparaiso, Casilla 8-V, \\ Chile \\ ${ }^{14}$ Institute of Marine Research, Bergen 5024, PO Box 1870 \\ Norway \\ ${ }^{15}$ Yellow Sea Fisheries Research Institute, Qingdao 266071, China \\ ${ }^{16}$ International Council for the Exploration of the Sea (ICES), \\ Copenhagen K1261, Denmark \\ ${ }^{17}$ United Nations Environment Programme (UNEP), \\ PO Box 16277, 2500 BE, The Hague, Netherlands \\ ${ }^{18}$ Marine Fish Division, Bedford Institute of Oceanography, \\ Dartmouth, Nova Scotia, B2Y 4A4, Canada
}

The Large Marine Ecosystem Approach. Reports of problems with marine ecosystems are widespread in the scientific literature and the news media. Calls for an ecosystem approach to resource assessment and management are seldom accompanied by a practical strategy, particularly one with a payment plan for the approach in developing countries. However, a global movement that makes the ecosystem approach to management practical already exists. It is known as the Large Marine Ecosystem (LME) approach, and it is being endorsed and supported by governments world- wide, as well as by a broad constituency in the scientific community.

While we concur with the movement toward an ecosystem-based approach to the management of marine fisheries (Gislason \& Sinclair 2000, Pitcher 2001, Stergiou 2002, Garcia et al. 2003, Sainsbury \& Sumaila 2003, Browman et al. 2004, Pikitch et al. 2004), it is important to recognize that a broader, place-based approach to marine ecosystem assessment and management, focused on clearly delineated ecosystem units, is needed and is presently under way, with the support of financial grants, donor and UN partnerships, in nations of Africa, Asia, Latin America and eastern Europe. It is within the boundaries of 64 LMEs that (1) $90 \%$ of the world's annual yield of marine fisheries is produced (Garibaldi \& Limongelli 2003), (2) global levels of primary production are the highest, (3) the degradation of marine habitats is most severe, and (4) coastal pollution is concentrated and levels of eutrophication are increasing (GESAMP 2001). Large marine ecosystems (LMEs) are natural regions of coastal ocean space encompassing waters from river basins and estuaries to the seaward boundaries of continental shelves and outer margins of coastal currents and water masses (cf. Fig. 4). They are relatively large regions characterized by distinct bathymetry, hydrography, productivity, and trophically dependent populations (Alexander 1990, Levin 1990, Sherman 1994; see www.edc.uri.edu/lme).

Since 1995, the Global Environment Facility (GEF) has provided substantial funding to support countrydriven projects for introducing multisectoral ecosystem-based assessment and management practices for LMEs located around the margins of the oceans. At present, 121 developing countries are engaged in the preparation and implementation of GEF-LME projects, totaling $\$ 650$ million in start-up funding. A total of 10 projects including 70 countries has been approved by the GEF Council, and another 7 projects involving 51 countries have GEF international waters projects under preparation (see www.iwlearn.net).

A 5 module indicator approach to assessment and management of LMEs has proven useful in ecosystembased projects in the USA and elsewhere, using suites of indicators of LME productivity, fish and fisheries, pollution and ecosystem health, socioeconomics, and governance. The productivity indicators include spatial and temporal measurements of temperature, salinity, oxygen, nutrients, primary productivity, chlorophyll, zooplankton biomass, and biodiversity. For fish and fisheries, indicators are catch and effort statistics, demersal and pelagic fish surveys, fish population demography, and stock assessments (NMFS 1999). Pollution and ecosystem health indicators include quality indices for water, sediment, benthos, habitats, 


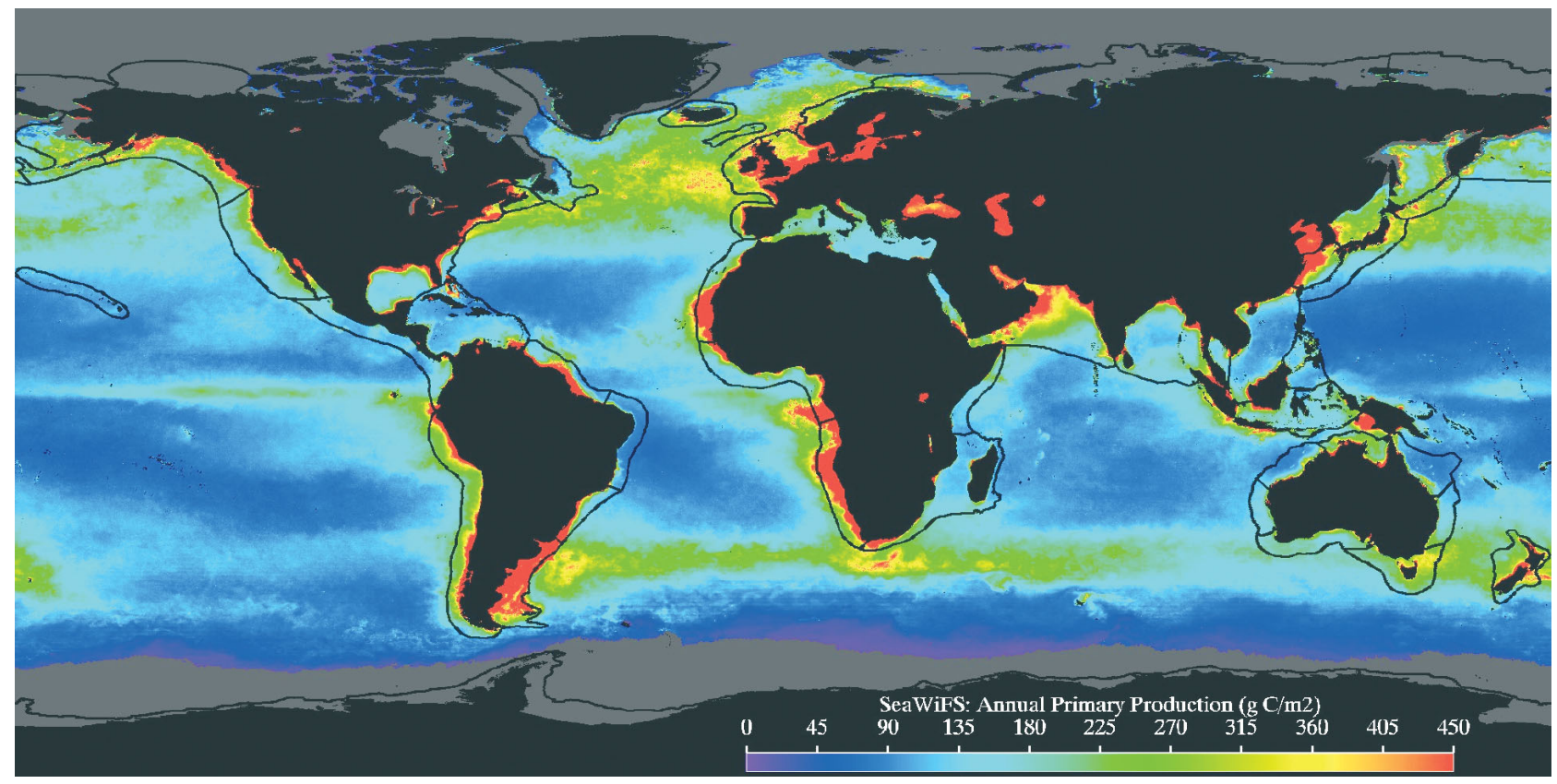

Fig. 4. Boundaries of the 64 Large Marine Ecosystems (LMEs) of the world and primary productivity $\left(\mathrm{gC} \mathrm{m}^{-2} \mathrm{yr}^{-1}\right)$. Annual productivity estimates are based on SeaWiFS satellite data collected between September 1998 and August 1999, and on the model developed by Behrenfeld \& Falkowski (1997). Color-enhanced image provided by Rutgers University (available at: www.edc.uri.edu/lme, Introduction)

and fish tissue contaminants (EPA 2004). Socioeconomic and governance indicators are discussed in Sutinen et al. (2000) and Juda \& Hennessey (2001). The modules are adapted to LME conditions through a transboundary diagnostic analysis (TDA) process, to identify key issues, and a strategic action program (SAP) development process for the groups of nations or states sharing an LME, to remediate the issues (Wang 2004). These processes are critical for integrating science into management in a practical way, and for establishing appropriate governance regimes. Of the 5 modules, 3 modules apply science-based indicators that focus on productivity, fish/fisheries, and pollution/ecosystem health, and the other 2 modules, socioeconomics and governance, focus on economic benefits to be gained from a more sustainable resource base and from providing stakeholders and stewardship interests with legal and administrative support for ecosystem-based management practices. The first 4 modules support the TDA process, while the governance module is associated with periodic updating of the SAP development process. Adaptive management regimes are encouraged through periodic assessment processes (TDA updates) and through updating the action programs as gaps are filled.

The GEF-LME projects presently funded or in the pipeline for funding in Africa, Asia, Latin America and eastern Europe represent a growing network of marine scientists, marine managers, and ministerial leaders who are pursuing ecosystem and fishery recovery goals. The annual fisheries biomass yields from the ecosystems in the network are $44.8 \%$ of the global total, and are a firm basis for movement by the participating countries toward the 2002 World Summit on Sustainable Development (WSSD) targets for introducing ecosystem-based assessment and management by 2010 , and for recovering depleted stocks and achieving fishing at maximum sustainable yield levels by 2015. The FAO Code of Conduct for Responsible Fisheries (FAO 1995) is supported by most coastal nations and has immediate applicability to reaching the WSSD fishery goals. The code argues for moving forward with a precautionary approach to fisheries sustainability, using available information more conservatively to err on the side of lower total allowable catch levels than has been the general practice in past decades. Although fishing effort data are not available in FAO global catch reporting statistics and could bias catch data interpretations, it appears that the biomass and yields of 11 species groups in 6 LMEs have been relatively stable or have shown marginal increases over the period from 1990 to 1999. The yield for these 6 LMEs - the Arabian Sea, Bay of Bengal, Indonesian Sea, North Brazil Shelf, Mediterranean Sea and the Sulu-Celebes Sea-was 8.1 million $\mathrm{t}$, or $9.5 \%$ of the global marine fisheries yield in 1999 (Garibaldi \& Limongelli 2003). The countries bordering these 6 LMEs are among the world's most populous, representing approximately one-quarter of 
the total human population. These LME border countries increasingly depend on marine fisheries for food security, and for national and international trade. Given the risks of fishing down the food web, it would appear opportune for the stewardship agencies responsible for the fisheries of the LME-bordering countries to limit increases in fishing effort during a period of relative biomass stability.

Evidence for species biomass recovery following significant reduction in fishing effort through mandated actions is encouraging. In the USA Northeast Shelf LME, management actions to reduce fishing effort contributed to a recovery of depleted herring and mackerel stocks and an initiation of the recovery of depleted yellowtail flounder and haddock stocks (Sherman et al. 2003); this was in combination with the robust condition of average annual primary productivity $\left(350 \mathrm{~g} \mathrm{C} \mathrm{m}^{-2} \mathrm{yr}^{-1}\right)$ for the past 3 decades, a relatively stable zooplankton biomass at or near $33 \mathrm{~cm}^{3}$ per $100 \mathrm{~m}^{3}$ for the past $30 \mathrm{yr}$ (Sherman et al. 2002), and an oceanographic regime marked by a recurring pattern of interannual variability, but showing no evidence of temperature shift of the magnitude described for other North Atlantic LMEs, including the Scotian Shelf (Zwanenburg 2003), the Newfoundland-Labrador Shelf (Rice 2002), the Iceland Shelf (Astthorsson \& Vilhjálmsson 2002) and the North Sea (Perry et al. 2005). On the other hand, 3 LMEs remain at high risk for fisheries biomass recovery-expressed as a pre-1960s ratio of demersal to pelagic species - the Gulf of Thailand, East China Sea, and Yellow Sea (Pauly \& Chuenpagdee 2003, Chen \& Shen 1999, Tang \& Jin 1999). The People's Republic of China has initiated steps toward recovery by mandating 60-90 d closures to fishing in the Yellow Sea and East China Sea (Tang 2003). The country-driven planning and implementation documents supporting the ecosystem approach to LME assessment and management practices can be found at www.iwlearn.net.

Nitrogen loadings. Globally, LME projects, in addition to rebuilding depleted fish stocks and restoring degraded coastal habitats, are also concerned with the mitigation of the effects of nitrogen loadings. Nitrogen over-enrichment has been a coastal problem for 2 decades in the Baltic Sea LME (HELCOM 2001). More recent human-induced increases in nitrogen flux range from 4- to 8-fold in the USA from the Gulf of Mexico to the New England coast (Howarth et al. 2000). In European LMEs, recent nitrogen flux increases have ranged from 3-fold in Spain to11-fold in the Rhine River basin draining to the North Sea LME (Howarth et al. 2000). This disruption of the nitrogen cycle originated in the Green Revolution of the 1970s as the world community converted wetlands to agriculture, utilized more chemical fertilizer, and expanded irrigation to feed the world (Duda \& El-Ashry 2000). For the estuaries of the southeastern USA (Duda 1982) and for the Gulf of Mexico (Rabalais et al. 1999), much of the increase in nitrogen export to LMEs is from agricultural inputs, from the increased delivery of nitrogen fertilizer as wetlands were converted to agriculture, and from livestock production (NRC 2000). Also, sewage from large cities is a significant contributor to eutrophication, as is increased nitrogen in atmospheric deposition resulting from combustion of fossil fuels by automobiles and industrial activities (GESAMP 2001).

Global forecast models of nitrogen export from freshwater basins to coastal waters indicate that there will be a $50 \%$ increase world-wide in dissolved inorganic nitrogen (DIN) export by rivers to coastal systems from 1990 to 2050 (Seitzinger \& Kroeze 1998, Kroeze \& Seitzinger 1998). Such increases in nitrogen export are alarming for the future sustainability of LMEs. Given the expected future increases in population and in fertilizer use, without significant mitigation of nitrogen inputs, LMEs will be subjected to a future of increasing harmful algal bloom events, reduced fisheries, and hypoxia that further degrades marine biomass yields and biological diversity. Models of nitrogen loading from land-based sources and models of ecosystem structure and function are being applied to LMEs with financial assistance from the GEF. Estimates of carrying capacity using ECOPATHECOSIM food web approaches for the world's 64 LMEs are being prepared in a GEF-supported collaboration between scientists of the University of British Columbia and marine specialists from developing countries. Similarly, a 24 mo training project is being implemented by scientists from Rutgers University in collaboration with IOC/UNESCO to estimate expected nitrogen loadings for each LME over the next decade. Scientists from Princeton University and the University of California at Berkeley are examining particle spectra and pattern formation within LMEs. Additionally, the American Fisheries Society and the World Council of Fisheries Societies are collaborating in an electronic network to expedite information access and communication among marine specialists (for details on the GEF-LME project, see www.gefonline.org/projectDetails.cfm?projID=2474).

The growing number of country-driven commitments to move toward ecosystem-based assessment and management of marine resources and environments provides an unprecedented opportunity for accelerating the transition to sustainable use, conservation, and development of marine ecosystems. The social, economic, and environmental costs of inaction are simply too high for multilateral and bilateral institutions and international agencies not to support the initial efforts of 121 countries attempting to reach the WSSD marine ecosystem targets for restoration and sustainability. Both developed and developing nations 
have a stake in moving toward the use of sustainable ecosystem resources. Momentum should not be lost, as this could result in irreversible damage to coastal ecosystems, to the livelihoods and security of poor coastal communities, and to the economies of coastal nations.

\section{LITERATURE CITED}

Alexander LM (1990) Geographic perspectives in the management of large marine ecosystems. In: Sherman K, Alexander LM, Gold BD (eds) Large marine ecosystems: patterns, processes and yields. American Association for the Advancement of Science, Washington, DC, p 220-223

Astthorsson OS, Vilhjálmsson H (2002) Iceland Shelf LME: decadal assessment and resource sustainability. In: Sherman K, Skjoldal HR (eds) Large Marine Ecosystems of the North Atlantic. Elsevier, Amsterdam, p 219-244

Behrenfeld M, Falkowski PG (1997) Photosynthetic rates derived from satellite-based chlorophyll concentrations. Limnol Oceanogr 42(1):1-20

Browman HI, Stergiou KI (eds) (2004) Perspectives on ecosystem-based approaches to the management of marine resources. Mar Ecol Prog Ser 274:269-303

Chen YQ, Shen XQ (1999) Changes in the biomass of the East China Sea ecosystem. In: Sherman K, Tang Q (eds) Large Marine Ecosystems of the Pacific Rim: assessment, sustainability, and management. Blackwell Science, Malden, MA, p 221-239

Duda AM (1982) Municipal point sources and agricultural nonpoint source contributions to coastal eutrophication. Water Res Bull 18(3):397-407

Duda AM, El-Ashry MT (2000) Addressing the global water and environmental crises through integrated approaches to the management of land, water, and ecological resources. Water Int 25:115-126

EPA (US Environmental Protection Agency) (2004) National coastal condition report II. Washington, DC, EPA-620/ $\mathrm{R}-03 / 002$

FAO (1995) Code of conduct for responsible fisheries. FAO, Rome (available at: www.fao.org/FI/agreem/codecond/ ficonde.asp)

Garcia SM, Zerbi A, Aliaume C, Do Chi T, Lassarre G (2003) The ecosystem approach to fisheries. Rep No. 443, FAO, Rome

Garibaldi L, Limongelli L (2003). Trends in oceanic captures and clustering of large marine ecosystems: two studies based on the FAO capture database. Fish Tech Pap 435, FAO, Rome

GESAMP (2001) The state of the marine environment. Group of Experts on the Scientific Aspects of Marine Pollution, Regional Seas Reports and Studies. UNEP, Nairobi

Gislason H, Sinclair M (2000) Ecosystem effects of fishing. ICES J Mar Sci 57:465-791

HELCOM (2001) Environment of the Baltic Sea area 1994-1998. Baltic Sea Environment Proc 82A, Helsinki Commission, Helsinki

Howarth R, Anderson D, Cloern J, Elfring C and 7 others (2000) Nutrient pollution of coastal rivers, bays, and seas. ESA Issues Ecol 7:1-15

Kroeze C, Seitzinger SP (1998) Nitrogen inputs to rivers, estuaries and continental shelves and related nitrous oxide emissions in 1990 and 2050: a global model. Nutr Cycl Agroecosyst 52:195-212

Juda L, Hennessey T (2001) Governance profiles and the management of the uses of large marine ecosystems. Ocean Dev Int Law 32:41-67

Levin SA (1990) Physical and biological scales and the modelling of predator-prey interactions in large marine ecosystems. In: Sherman K, Alexander LM, Gold BD (eds) Large marine ecosystems: patterns, processes and yields. American Association for the Advancement of Science, Washington, DC, p 179-187

NMFS (National Marine Fisheries Service) (1999) Our living oceans. Report on the status of U.S. living marine resources, 1999. US Dep Commer, NOAA Tech Memo NMFS-F/SPO-41

NRC (National Research Council) (2000) Clean coastal waters: understanding and reducing the effects of nutrient pollution. National Academy Press, Washington, DC

Pauly D, Chuenpagdee R (2003) Development of fisheries in the Gulf of Thailand large marine ecosystem: analysis of an unplanned experiment. In: Hempel G, Sherman K (eds) Large Marine Ecosystems of the world: trends in exploitation, protection, and research. Elsevier, Amsterdam, p 337-354

Perry AL, Low PJ, Ellis JR, Reynolds JD (2005) Climate change and distribution shifts in marine fishes. Science 308:1912-1915

Pikitch EK, Santora C, Babcock EA, Bakun A and 13 others (2004) Ecosystem-based fishery management. Science 305: 346-347

Pitcher TJ (2001) Fisheries managed to rebuild ecosystems? Reconstructing the past to salvage the future. Ecol Appl 11:601-617

Rabalais NN, Turner RE, Wiseman WJ Jr. (1999) Hypoxia in the northern Gulf of Mexico: linkages with the Mississippi River. In: Kumpf H, Steidinger K, Sherman K (eds) The Gulf of Mexico Large Marine Ecosystem: assessment, sustainability, and management. Blackwell Science, Malden, MA, p 297-322

Rice J (2002) Changes to the Large Marine Ecosystem of the Newfoundland-Labrador Shelf. In: Sherman K, Skjoldal HR (eds) Large Marine Ecosystems of the North Atlantic: changing states and sustainability. Elsevier, Amsterdam, p 51-104

Sainsbury K, Sumaila UR (2003) Incorporating ecosystem objectives into management of sustainable marine fisheries, including 'best practice' reference points and use of marine protected areas. In: Sinclair M, Valdimarsson G (eds) Responsible fisheries in the marine ecosystem. FAO, Rome \& CABI Publishing, Wallingford, p 343-361

Seitzinger SP, Kroeze C (1998) Global distribution of nitrous oxide production and $\mathrm{N}$ inputs to freshwater and coastal marine ecosystems. Global Biogeochem Cycl 12:93-113

Sherman K (1994) Sustainability, biomass yields, and health of coastal ecosystems: an ecological perspective. Mar Ecol Prog Ser 112:277-301

Sherman K, Kane J, Murawski S, Overholtz W, Solow A (2002) The US northeast shelf Large Marine Ecosystem: zooplankton trends in fish biomass recovery. In: Sherman K, Skjoldal HR (eds) Large Marine Ecosystems of the North Atlantic: changing states and sustainability. Elsevier, Amsterdam, p 195-215

Sherman K, O'Reilly J, Kane J (2003) Assessment and sustainability of the U.S. northeast shelf ecosystem. In: Hempel G, Sherman K (eds) Large Marine Ecosystems of the world: trends in exploitation, protection, and research. Elsevier, Amsterdam, p 93-120

Stergiou KI (2002) Overfishing, tropicalization of fish stocks, uncertainty and ecosystem management: resharpening Ockham's razor. Fish Res 55:109 
Sutinen JG (ed) (2000) A framework for monitoring and assessing socioeconomics and governance of large marine ecosystems. NOAA Tech Memo NMFS-NE-158

Tang Q, Jin X (1999) Ecology and variability of economically important pelagic fishes in the Yellow Sea and Bohai Sea. In: Sherman K, Tang Q (eds) Large Marine Ecosystems of the Pacific Rim: assessment, sustainability, and management. Blackwell Science, Malden, MA, p 179-198

Tang Q (2003) The Yellow Sea LME and mitigation action. In: Hempel G, Sherman K (eds) Large Marine Ecosystems of the world: trends in exploitation, protection, and research. Elsevier, Amsterdam, p 121-144

Wang H (2004) An evaluation of the modular approach to the assessment and management of Large Marine Ecosystems. Ocean Dev Int Law 35:267-286

Zwanenburg KCT (2003) The Scotian Shelf. In: Hempel G, Sherman K (eds) Large Marine Ecosystems of the world: trends in exploitation, protection, and research. Elsevier, Amsterdam, p 75-92

\section{Differences in economic perspectives and implementation of ecosystem-based management of marine resources}

\section{Ussif Rashid Sumaila}

\author{
Fisheries Centre, University of British Columbia, 2259 Lower \\ Mall, Vancouver, British Columbia, V6T 1Z4, Canada \\ Email: r.sumaila@fisheries.ubc.ca
}

Ecosystem definition. What is an ecosystem, and what is ecosystem-based management? There are many answers to these questions (e.g. Sinclair \& Valdimarson 2003). Here is my summary: an ecosystem is a geographically specified system of organisms, including humans, the environment, and the processes that control the system's dynamics. Similarly, an ecosystem-based approach to the management of marine resources (EAM) is geographically specified; it is also adaptive and takes account of ecosystem knowledge and uncertainties. It considers multiple external influences, and strives to balance diverse societal objectives. EAM requires that the connections between people and the marine ecosystem be recognized, including the short- and long-term implications of human activities along with the processes, components, functions, and carrying capacity of ecosystems.

The fact that ecosystems and the EAM are geographically specified implies that for ecosystems that are shared by 2 or more countries, policies that are transboundary in nature are required to manage them successfully. Many of the world's 64 large marine ecosystems are shared by 2 or more countries (Sherman \& Duda 1999, see also www.seaaroundus.org). For instance, to effectively apply EAM to the management of the Benguela Current Large Marine Ecosystem (BCLME), policies need to be crafted and adopted by the 3 countries bordering the ecosystem, namely An- gola, Namibia and South Africa. In terms of policy, getting countries with diverse societal objectives to agree on and implement joint EAMs is a challenge which must be met if EAM is to gain universal applicability.

I focus on 2 ways by which a country's societal objective regarding the use of marine ecosystem resources can be affected: (1) how the country weights market and non-market values from the ecosystem; (2) which discount rate is applied to flows of net benefits over time from the ecosystem.

Values and valuation. The economic theory of valuation is based on what people want-their preferences (Brown 1984, Arrow et al. 1993). People's preferences are expressed through the choices and tradeoffs they make given the resource and time constraints they face. It is therefore important that we capture a given population's preferences fully in the decision making process on the use and non-use of marine ecosystem resources. The economic theory of valuation of natural and environmental resources calls for a comprehensive compilation of all values into a total economic value (Goulder \& Kennedy 1997). The theory stipulates that the total economic value should include market and non-market values, which consist of direct and indirect use values, option value, existence value (Krutilla 1967), and bequest value (Young 1992).

Market values are traded in the market, e.g. the value of fish caught and sold in the market. Non-market values are not traded in the market. Direct use values capture the value of ecosystem goods and services that are directly used for consumptive purposes, e.g. the value of commercial output such as fish harvest. Indirect use values are values of ecosystem goods and services that are used as intermediate inputs to production, e.g. services such as water cycling and waste assimilation. Option value is the potential that the ecosystem will provide currently unknown valuable goods and services in the future. Existence value (essentially described as non-use value in the literature) is the value conferred by humans on the ecosystem regardless of its use value-an environmental good may be valuable merely because one is happy that it exists, quite apart from any future option to consume it, visit it or otherwise use it; this value may arise from aesthetic, ethical, moral or religious considerations. Finally, bequest value captures the willingness to pay to preserve a resource for the benefit of one's descendants (future generations).

A country's perspective on market and non-market values depends on a number of variables, including, (1) net price per unit of market goods and services, and (2) unit non-market value derived from the ecosystem. In practice, different countries place different emphasis on market and non market values. Countries that put more emphasis on market values tend to maintain 
lower standing biomass offish in the marine ecosystem, for example, than those that place more relative value on non-market values, thereby creating the possibility of policy disagreement on how to implement EAM. The USA with its emphasis on free markets is an example of the former, while Sweden, with less emphasis on free markets, would be an example of the latter.

Discount rates and discounting. The discount rate is a pure number per unit of time (usually in \%) that allows us to convert values to be received in the future into values received today. This process of converting future values into present values is known as discounting streams of benefits. People may discount for many reasons (see Goulder \& Stavins 1997), e.g., (1) people are generally impatient and display a preference for having their benefits today rather than tomorrow (due to uncertainty, high debt levels, poverty, etc.), and (2) the opportunity cost of capital: with the benefits in hand now, one has the opportunity to at least deposit it in a bank account and earn interest.

The following quote attributed to Nietzsche (who is not to be quoted on many things, according to my European friends) captures the motivation for discounting future flows of benefits vividly: 'Egoism is the law of perspectives, as it applies to feelings according to which what is closest to us appears to be large and weighty, while size and weight decrease with our distance from things' (The Globe and Mail, October 27, 2002).

Discount rates thus reflect how much weight a country places on receiving its benefits now, rather than in the future. In this respect, discounting is used to model human behavior. It therefore provides an analytical basis for making value-based decisions. Discount rates reflect uncertainties associated with potential future benefits (Brennan 1997). Everything being equal, high uncertainty about future outcomes will lead to a high discount rate. The discount rate can also be seen as a measure of a country's risk averseness. A risk averse country would adhere more to the precautionary principle, and therefore would shy away from making radical changes to the marine ecosystem. Such a country will, other things being equal, have a lower discount rate. On the other hand, a risk loving country will have a higher discount rate (Pender \& Fafchamps 1997, Binswanger 1980). When the capital employed to exploit the marine ecosystem is non-malleable (Clark et al. 1979, Sumaila 1995), any policy to reduce capital in an overfished fishery, for example, will lead to stiff resistance from fishers, because the cost of this policy looms large while its future benefits seem small today. In this situation, the discount rate is high. Similarly, high levels of poverty and indebtedness in the communities exploiting the marine ecosystem will tend to push a country to apply high discount rates to the flow of benefits from marine ecosystems (Pender 1996).
The discussion above can be expressed mathematically as follows:

$$
\delta_{i}=\delta_{i}(u, p, i n d, r, n m l)
$$

where $\delta_{i}$ denotes the discount rate faced by country $i, u$ is the degree of uncertainty of future outcomes, the parameters $p$ and ind are the levels of poverty and indebtedness, respectively, among users of the marine ecosystem. The parameter $r$ denotes the risk averseness of the country and $\mathrm{nml}$ denotes the level of nonmalleability of the capital employed to exploit the ecosystem.

The partial derivatives below explain how each of the above parameters may affect the discount rate faced by a country.

$$
\frac{\partial \delta_{i}}{\partial u}>0 ; \frac{\partial \delta_{i}}{\partial p}>0 ; \frac{\partial \delta_{i}}{\partial i n d}>0 ; \frac{\partial \delta_{i}}{\partial r}<0 ; \frac{\partial \delta_{i}}{\partial n m l}>0
$$

The 1st partial derivative states that, other things being equal, the higher the level of uncertainty of outcomes is, the higher will be the discount rate. The 2 nd and 3rd partial derivatives state that, the higher the level of poverty and indebtedness among users of the ecosystem is, the higher will be the discount rate (Pender 1996). According to the 4th derivative, the more risk averse a country is, the lower will be its discount rate (Pender \& Fafchamps 1997, Binswanger 1980). The 5th derivative states that the more non-malleable the capital employed in extracting resources from the marine ecosystem is, the higher will be the country's discount rate.

High degrees of uncertainty, high levels of indebtedness and poverty, risk loving attitudes and non-malleability of the capital used to exploit the marine ecosystem, will all result in a country putting too much weight on receiving benefits from the marine ecosystem now, rather than later. The country will tend to enact policies that sacrifice long-term sustainability for short-term benefits.

Discounting has been identified in the environmental economics literature as a source of problems when assessing the costs and benefits of projects and policies with long-term benefits but short-term costs (Heal 1998). It has been argued that discounting future flows of benefits from marine ecosystems affects our ability to manage these resources sustainably for the benefits of both current and future generations (Hasselmann et al. 1997, Weitzman 2001, Sumaila 2004, Sumaila \& Walters 2005).

Differences in discount rates among countries sharing the same marine ecosystem will lead to problems in implementing EAM for the ecosystem, because these differences will be manifest in diverse social objectives for the countries. In the issue of climate change, for instance, this partially explains why low discount rate 
countries signed the Kyoto Accord, while high discount rate countries did not. A key effect of signing the Accord is that a country will have to implement policies and actions that may be costly now, in order to ensure that benefits accrue in the future.

Let us consider 2 countries, $i=1$ and 2, that share a marine ecosystem. Let the per period benefit derived by country $i$ be $V_{i}(m, n m)$, which depends on market $(m)$ and non-market values $(\mathrm{nm})$. Further, these countries are assumed to have discount rates $\delta_{1}$ and $\delta_{2}$, respectively. If one country imputes more value to $m$ relative to $\mathrm{nml}$, and the other country imputes more value to $n m$ relative $n$, then there is potential for disagreement on how to implement EAM for the shared ecosystem. In addition, if the discount rates in both countries are different, their preference with respect to the time at which they want to take their benefits from the ecosystem will be different. This, too, will pose problems for the implementation of the EAM.

Summary. I have identified potential sources of policy differences between countries that share a marine ecosystem. These differences are potential sources of conflict that can hinder progress in implementing EAM of shared ecosystems: (1) relative valuation of market and non-market values, (2) time preference with respect to the valuation of flows of benefits from the ecosystem through discounting. A low discount rate country that places a higher relative value on non-market values will prefer a policy that is more conservationist than a high discount rate country that puts more weight on market values relative to non-market values.

The important question here is, what can be done to close the economic differences that may exist between countries that share a marine ecosystem? Potential solutions to the problem include, (1) 'side payments' by the low discount rate country to the high discount rate country; this is a result from game theory (Munro 1979, Sumaila 1999), and it amounts to using the 'carrot' to get the high discount rate country to change its discounting preferences. (2) The part of the population in a high discount rate country that cares about non-market values will need to raise awareness of the value to society of preserving the flow of both market and non-market values through time; by working to broaden the scope of values that policy makers take into account, the differences between the 2 countries sharing an ecosystem can be eliminated, or reduced significantly — the current role of environmental NGOs and other civil society organizations is partly geared towards achieving this objective. (3) Other countries with low discount rates should use the 'stick and carrot' by imposing economic, social, moral and ethical incentives and sanctions on high discount rate countries to compel them to apply lower discount rates to marine resource values, and place more weight on non-market values.
Economic differences between countries that share a marine ecosystem can be an obstacle to the implementation of EAM. These obstacles need to be removed, not only because of the ecological and scientific benefits of EAM (Browman \& Stergiou 2004), but also because of its economic benefits, as shown in multispecies bioeconomic models (e.g. Hannesson 1983, Flaaten 1988, Fischer \& Mirman 1992). Ensuring that policies are put in place for the conservation of marine ecosystems through time is even more crucial than in the case of terrestrial ecosystems, since people can easily see what is happening on land and therefore are more able to take action to fix emerging problems. This is clearly not the case with marine ecosystems. The use of a combination of the 'carrot' and the 'stick' together with efforts by NGOs and other civil society groups to raise public awareness for the benefit of both current and future generations, will help to get countries sharing marine resources to put together EAM policies that work.

Acknowledgements. The support of the Sea Around Us project and the Pew Charitable Trusts, Philadelphia, OCEANA, the European Community's Programme for International Scientific Co-operation (INCO) through Contract 003739 for the INCOFISH project, and the Benguela Current Large Marine Ecosystem (BCLME) program are very much appreciated.

\section{LITERATURE CITED}

Arrow K, Solow R, Portney PR, Leamer EE, Radner R, Schuman H (1993) Report of NOAA Panel on Contingent Valuation. Federal Register 58(10):4601-4614

Binswanger HP (1980) Attitudes towards risk: experimental measurement in rural India. Am J Agric Econ 62(3): 395-407

Brennan TJ (1997) Discounting the future: economics and ethics. In: Oates WE (ed) RFF reader in environmental and resource management. Resources for the future. Washington, DC

Browman HI, Stergiou KI (2004) Perspectives on ecosystembased approaches to the management of marine resources. Mar Ecol Prog Ser 274:269-303

Brown TC (1984) The concept of value in resource allocation. Land Econ 60:231-246

Clark CW, Clarke FH, Munro GR (1979) The optimal management of renewable resource stocks: problems of irreversible investment. Econometrica 47:25-47

Fischer RD, Mirman LJ (1992) Strategic dynamic interaction: fish wars. J Dyn Control 16:267-287

Flaaten O (1988) The economics of multispecies harvesting theory and application to the Barents Sea fisheries. Studies in contemporary economics. Springer-Verlag, Berlin

Hannesson R (1983) Optimal harvesting of ecologically interdependent fish species. J Environ Econ Manage 10:329-345

Hasselmann $\mathrm{K}$, Hasselmann S, Giering R, Ocana V, von Storch H (1997) Sensitivity study of optimal $\mathrm{CO}_{2}$ emission paths using a simplified structural integrated assessment model (SIAM). Clim Change 37:335-343 
Goulder H, Kennedy D (1997) Valuing ecosystem services: philosophical bases and empirical methods. In: Daily GC (ed) Nature's services: societal dependence on natural ecosystems. Island Press, Washington, DC, p 23-48

Goulder LH, Stavins RN (2002) Discounting: an eye on the future. Nature 419: 673-674

Heal GM (1998) Valuing the future: economic theory and sustainability. Columbia University Press, New York

Krutilla J (1967) Conservation reconsidered. Am Econ Rev 57: $787-796$

Munro GR (1979) The optimal management of transboundary renewable resources. Can J Econ 12:355-376

Pender JL (1996) Discount rates and credit markets: theory and evidence from India. J Dev Econ 50(2)257-297

Pender JL, Fafchamps M (1997) Precautionary saving, credit constraints, and irreversible investments: theory and evidence from semiarid India. J Business Econ Stat 15(2): 180-194

Sinclair M, Valdimarson G. (eds.) (2003) Responsible fisheries in the marine ecosystem. FAO, Rome \& CABI Publishing, Wallingford

Sherman K, Duda AM (1999) An ecosystem approach to global assessment and management of coastal waters. Mar Ecol Prog Ser 190:271-287

Sumaila UR (1995) Irreversible capital investment in a 2-stage bimatrix fishery game model. Mar Resour Econ 3:263-283

Sumaila UR. (1999) A review of game theoretic models of fishing. Mar Pol 23(1):1-10

Sumaila UR (2004) Intergenerational cost benefit analysis and marine ecosystem restoration. Fish Fish 5:329-343

Sumaila UR, Walters C (2005) Intergenerational discounting: a new intuitive approach. Ecol Econ 52:135-142

Weitzman ML (2001) Gamma discounting. Am Econ Rev 91(1):260-272

Young MD (1992) Sustainable investment and resource use: equity, environmental integrity and economic efficiency. Man and the Biosphere Series, Vol 9. UNESCO, Paris

\section{Paradigm shifts, gaps, inertia, and political agendas in ecosystem-based fisheries management}

\author{
Sergi Tudela ${ }^{1}$, Katherine Short ${ }^{2}$
}

\footnotetext{
${ }^{1}$ World Wide Fund for Nature (WWF), Mediterranean Programme Office, Canuda 37, 08002 Barcelona, Spain Email: studela@atw-wwf.org

${ }^{2}$ World Wide Fund for Nature (WWF), Global Marine Programme, Avenue du Mont-Blanc, Gland, 1196 VD, Switzerland Email: kshort@wwfint.org
}

Success of a label and failure to operationalise a concept. There is no doubt that the many different ways to refer to the idea of the ecosystem-based management (EBM) of fisheries have successfully entered the politically correct scientific/managerial jargon. The success of this process is impressive, as demonstrated by widespread reference to the concept in all types of documents, including the crucial project applications to funding agencies and donors (for which it has become a must). This apparent triumph conceals a bitter reality: the lack of a scientific and political consensus on the conceptual basis and limits of EBM, and the unavailability of an operational framework generating clear rules for its practical implementation.

Defining ecosystem-based reference levels for fisheries management, based on indicators of overall ecosystem structure and functioning, and followed by the establishment of thresholds for ecosystem overfishing, is crucial to prove that EBM is much more than an appealing concept. This advance in science should be accompanied by steps toward developing effective management approaches and operational tools (the EBM 'tool kit') and political understanding of the nuances (and their operational effects) in the terminology employed by different stakeholders. These interrelated processes are key to the delivery of a truly functional approach that at its core enables society to continue to derive services from healthy functioning marine ecosystems.

The story of EBM could become that of an interesting debate but a failed approach; the risk of a complete failure is real. Our society, as users of the global marine resources, cannot afford a failure of EBM, however, given the cumulative scientific evidence on the degraded state of marine ecosystems and the way this compromises the future of the world's food supplies.

The underlying debate. The debate on what the EBM concept must be is currently at a crossroads. The discussion that took place in 2003 at the 25th meeting of the FAO Committee on Fisheries (COFI) following the presentation of the FAO Guidelines on the Ecosystem Approach to Fisheries (FAO 2003) clearly demonstrated that 2 radically opposed visions of EBM are struggling against each other.

In one vision, EBM entails a radical change in the paradigm underlying ocean management (including fisheries), accounting for the complexity of exploited ecosystems and recognizing the need for precautionary management of human activities. In this vision, the preservation of ecologically viable populations of ecosystem components is key to maintain species' functional redundancy and the derived structural and functional ecosystem conditions that ensure ecosystem resilience and sustained provision of ecosystem services (Jackson et al. 2001). Application of the precautionary principle and development of robust data-poor management approaches are essential features of this vision.

The other vision regards ecosystems from a purely mechanistic perspective and seeks to maximize human profits by engineering the food web and other ecosystem manipulations. Under this logic, the goal of EBM is to obtain ecosystems that are tailored for supplying the 
optimum harvest of the desired species, e.g. in the case of fisheries. This perspective is used by pro-whaling countries to argue that trophic competition from cetaceans is restricting fish harvests for developing countries, thus strategically trying to align the whaling and food security debates within the UN/FAO political framework.

The FAO Guidelines (FAO 2003) do not readily align with the first vision outlined above-which is fully supported by scientific research on ecosystem dynamics - but they do integrate many essential features of the 'engineering' vision. This way, they envision the EBM of fisheries - now renamed Ecosystem Approach to Fisheries (EAF) - as being an extension of target resources oriented management (TROM). The FAO Guidelines devote considerable attention to ecosystem manipulations such as creating artificial habitats, restocking and stock enhancement, culling and intentional introductions, which are considered as appropriate elements of EAF.

From quantitative ecosystem-based indicators to operational fisheries management frameworks. As outlined above, the development of ecosystem-based indicators is a key to the operational implementation of the EBM, since it opens the door to establish truly ecosystem-based reference levels (Caddy \& Mahon 1995), something essential to any fisheries management process. The success (or failure) to identify and routinely use them will likely determine whether EBM will give way to a fully new approach or, on the contrary, whether it will be restrained to a merely superficial greening of conventional TROM. Besides, indicators are not neutral with respect to the current debate on the real nature of EBM/EAF. Indicators focusing on the emergent properties of exploited ecosystems are more likely to support a precautionary vision of EBM rooted in a paradigm shift than others related to, for instance, simpler predator-prey aspects.

The FAO Guidelines (FAO 2003) provide a useful conceptual framework to address the issue of ecosystem-based indicators:

For practical purposes the indicator should be an ecosystem property that is thought to be modified by the fishery, so that at least there is a controllable fishery impact for which a target level of change is identified. If it is not appropriate to set a target reference point, then at least a limit reference point should be set. ... (L)ack of scientific certainty should not prevent the selection of indicators and reference points that are considered important, or the clear explanation of a basis for selection. (pp 53,55)

Nevertheless, the FAO Guidelines suffer from a lack of concretion that rends them of little operational use. In fact, they already recognize this limitation and entrust the SCOR-IOC Working Group on Quantitative
Ecosystem Indicators for Fisheries Management to identify the appropriate indicators to make FAO's EAF operational.

The IOC/SCOR International Symposium on Quantitative Ecosystem Indicators for Fisheries Management (Paris, March-April 2004), intending to fill the gap described above, resulted in limited progress towards the operationalisation of the EBM. Apart from a few exceptions (see Tudela et al. 2005) most contributions did not address the development of operational frameworks based on the proposed indicators, nor did they elaborate upon precautionary boundaries for ecosystem overfishing (Murawski 2000), which are central aspects to the EBM.

A Khunian revolution in fisheries science. It is hard to understand what is currently going on in fisheries science (and management agencies) without recognizing that the EBM concept has generated a situation that resembles a Khunian revolution (Khun 1962). It is obvious that EBM of fisheries, if understood as a real change in the underlying paradigm of fisheries science, is challenging the validity of classical TROM approaches. This is leading to a well-known situation (inherent to all scientific revolutions) of interim cooccurrence of both approaches, whose advocates are radically opposed to each other, generating a feeling of crisis. What makes this situation even more dramatic is that it concerns an 'applied science', one that is expected to help manage fundamental global food resources, and that it is arising during a real crisis of overfishing (with the consequent perception of failure of the paradigm of the last $50 \mathrm{yr}$ ).

The reluctance to accept the essential holistic paradigm of EBM is at the root of much of the criticism by the scientific establishment. For example, it is often argued that EBM makes management increasingly difficult, since it is assumed to require much more research. The central issue here is that recognising the complex nature of exploited marine ecosystems should lead to reducing our expectations of science to make accurate quantitative predictions. Moreover, precautionary data-poor methodologies, implemented through adaptive management schemes, do not require increasing parameterisation ad infinitum. It is a paradox that the Precautionary Approach to Fisheries was accepted as a mainstream concept before the EBM paradigm was, taking into account that it is precisely the recognition of complexity (and the related uncertainty in our predictions) associated with the EBM paradigm that supports the full implementation of the former.

Another typical element of the process of paradigm change is the common attempt of the establishment to co-opt the new approach, in this case by limiting it to a mere extension of current fisheries management prac- 
tices - as the FAO Guidelines do-or by perverting it so as to further legitimate the old approach, as described above regarding the invigorated claims justifying ecosystem engineering.

Conservation and EBM of fisheries: new opportunities. Under EBM, both the concepts of conservation and management achieve a high level of integration. The fact that resistance in exploited ecosystems is maintained by redundancy in the functionality of the different species (Jackson et al. 2001) supports the need to preserve biodiversity (including functional population levels of the different species) to reduce the risk of ecosystem collapses. This approach (conserving overall biodiversity) is also useful to preserve keystone species, crucial to keep the functional and structural integrity of ecosystems, since they are extremely difficult to identify and change with time within evolving ecosystems. With these premises in mind, it is evident that conserving biodiversity is not only a conservation objective driven by moral considerations, but also a first order objective for fisheries management, under a precautionary EBM approach in fisheries that seeks to maximize ecosystem resistance and resilience. Furthermore, increasing evidence of the shifting baseline effect (the change in scientists' perception about the reference status of ecosystems with generations; Pitcher 2001) and the primacy of (over)fishing as the main factor for ecosystem change (Jackson et al. 2001) reinforces the need for conservation and fisheries management to coalesce. Indeed, both disciplines share the goal of rebuilding exploited ecosystems to a reasonably healthy status from the structural and functional point of view, compatible with the maximum conservation of biodiversity and the supply of the greatest services to society-fisheries ranking high among them.

Whilst conservation per se (in the broadest meaning of the concept: preservation of structurally and functionally healthy ecosystems) might still be considered as just a necessary instrument to deliver 'wilderness' (an ecosystem service highly appreciated by some sectors of society), it is also a prerequisite for healthy ecosystems able to provide other services (e.g supply of food, sewage depuration; Daily et al. 1997). So, a new role for conservation arises, becoming an integral component of any EBM approach.

This leads to the emergence of a new responsibility for conservation NGOs. Far from being seen as 'intruders' in the world of fisheries management (traditionally perceived as more interested in the conservation of pristine habitats, rather than in maintaining livelihoods and securing food supplies), their challenge now is to contribute to EBM experiences drawing on their broad expertise in conservation, multidisciplinary work with a wide spectrum of stakeholders, including the acade- mic world, and with their awareness-raising skills. As for the latter, the ecological footprint issue (the ecological limits to fish production) is a crucial aspect of the EBM paradigm, and it deserves a considerable communications effort. This would allow the public to realize the real extent of the current global fishing crisis and to appreciate what the real limits are for other emerging activities, like mariculture, which is wrongly perceived by many as the ultimate solution for supplying endless amounts of fish.

Conservation NGOs, aware of the opportunities associated with the new approach, are fully involved in the promotion of EBM, often adopting a highly proactive attitude, working together with academics and policy experts, and providing input in virtually all major international processes (FAO Committee on Fisheries, World Summit on Sustainable Development, Convention on Biological Diversity, etc.). Indeed, WWF developed a pioneering document (Ward et al. 2002), suggesting guidelines for the EBM of fisheries and ways to proceed, well before FAO completed its technical consultation on the issue.

Challenges in science for EBM. Owing to its systemic nature, we anticipate that the knowledge of exploited marine ecosystems will never permit at the ecosystem level the kind of mechanistic approach usually followed in single stock management. Therefore, EBM should not seek to emulate the current approach associated with TROM (see Stergiou 2002). It is very important to be fully aware of these inherent limitations, knowing the new 'rules of the game', and avoiding the trap of setting impossible goals in EBM research and management, with the potential frustration and consequent delays in reversing the current trends. This means that in parallel with studies on ecosystem functioning and ecosystem effects of fishing it is crucial to develop new research on precautionary (i.e. data-poor) EBM, with an emphasis on deriving operational reference frameworks for management (Tudela et al. 2005).

A clear focus on comparative studies of exploited marine ecosystems, including their historical evolution (Jackson \& Sala 2001), combined with ecosystem modeling and simulation analyses, is needed at this stage (in line with Cury's 'ecoscope'; Cury 2004). Also, given the emerging consideration of marine reserves as a primary tool for EBM of fisheries, studies focusing on its correct design and implementation should be promoted urgently (see Browman \& Stergiou 2004).

One of the main challenges that research on EBM faces deals with the need to integrate knowledge on non-target species and ecosystem functioning to understand the real dynamics of exploited ecosystems. The highly multidisciplinary approach required to achieve this is a major problem in many regions where 
specialists in disciplines unrelated to traditional fisheries science are absent from fisheries fora. There has been a long and profound separation between 'applied' fisheries researchers, in most cases closely linked to governmental fisheries management agencies, and 'fundamental' marine ecologists and other scientists.

Short-term perspectives and global fisheries governance. Studies aimed at placing fisheries in their ecosystem context during the last decade have provided overwhelming scientific evidence of the dramatic footprint of fisheries on global marine ecosystems (Pauly \& Christensen 1995), and have demonstrated the instrumental role of overfishing in the resulting structural and functional degradation of ecosystems (Jackson et al. 2001). Even so, the separation between the world of traditional fisheries management (and science) and the new ecosystem-based approaches remains largely in place.

Comparing fisheries management to ecosystem management, well after the ICES/SCOR Symposium on the Ecosystem Effects of Fishing held in Montpellier in 1999-a milestone in the process towards the academic recognition of the need for EBM of fisheries - and the 2001 Reykjavik Conference on Responsible Fisheries in the Marine Ecosystem, García et al. (2003) wrote:

Ecosystem management is also supported by science but decision processes (particularly at international level) seem to operate under higher public pressure often organized by NGOs through an efficient use of the media. It is evolving rapidly, supported by a large number of citizens, most of them with limited or no understanding of the costs of change to the sector and who often assume a zero cost to themselves. (p. 48)

This statement implicitly diminishes the strength and legitimacy of the vast amount of scientific evidence supporting the need for a new fisheries management paradigm, by suggesting it is being co-opted by clever, though naïve, NGOs that skilfully manipulate an ignorant society. It also assumes a zero cost of keeping the status quo, failing to internalise the effects of the global fisheries crisis related to the inadequacy of the current fisheries management paradigm.

This is just a further example that reinforces the sense that the natural development of fully fledged EBM of fisheries will in the short term continue to be obstructed by, (1) the lack of confidence in the translation of the new approach into realistic and effective management measures and tools, (2) historical inertia or resistance to change, (3) rivalries between scientific schools (including turf wars between fisheries scientists, unwilling to allow ecologists and other academics to have a say in their business, or perceiving them as competing for funding), and (4) political agendas.
A preliminary assessment of global fisheries (coastal and shelf areas) using ecosystem overfishing criteria indicates that current catches are several times in excess of the estimated ecosystem-based maximum sustainable catches (see Table 2; Tudela et al. 2005). This illustrates that EBM is likely to be more restrictive than TROM with respect to extractive possibilities, and means that in the current overcapacity crisis in the fisheries sector, implementation of EBM will certainly find considerable resistance from the industry and politicians. However, it is precisely this critical situation that makes the development of EBM more necessary than ever.

Only great political momentum will bring EBM beyond mere aesthetic moves (small and scattered marine reserves, a limited reduction of by-catch, etc.). In this sense, the current picture is not optimistic, as illustrated by the fact that scientific arguments (even mainstream TROM ones) are systematically subsumed under political ones, e.g. when the European Council systematically ignores ICES advice regarding the annual fishing quotas; another example is the scandalous political bargaining at ICCAT meetings on tuna management (see Anonymous 2004). This globally widespread picture exacerbates the normal resistance to radically revise the scientific basis for management. Indeed, there is no point in tackling such an effortwith all the costly implications it entails - if there is hardly any fisheries management that is scientifically driven.

Besides, as a side effect of the failure of traditional fisheries management, and given the lack of a unified, coherent vision for an EBM approach to fisheries, many experts postulate that 'common sense' aspects that are essential to any kind of rational fisheries management, including TROM (e.g. stakeholder participation, adaptive management,) are distinctive key elements of the new EBM. This adds further confusion to the proper consolidation of EBM and contributes to the idea of EBM as being a broad improvement of traditional fisheries management, a sort of chimera of the perfect fisheries management in an imaginary perfect

Table 2. Ecosystem-based maximum sustainable catches (EMSC $; \mathrm{t} \mathrm{km}^{-2} \mathrm{yr}^{-1}$ ) at 50 and $70 \%$ probability of sustainable exploitation for different ecosystem types, compared with current levels of catch and discards. Modified from Tudela et al. (2005)

\begin{tabular}{|lccc|}
\hline $\begin{array}{l}\text { Ecosystem } \\
\text { types }\end{array}$ & $\begin{array}{c}\text { Current catch } \\
\text { and discards }\end{array}$ & EMSC $_{50}$ & EMSC $_{70}$ \\
\hline $\begin{array}{l}\text { Tropical shelves } \\
\text { Temperate shelves }\end{array}$ & 2.87 & 1.46 & 0.84 \\
$\begin{array}{l}\text { Coastal areas } \\
\text { and coral reefs }\end{array}$ & 10.5 & 1.38 & 0.80 \\
\hline
\end{tabular}


world. EBM has clearly-defined steps that can be operationalised, whether for an entire ocean or for concrete fisheries (Ward et al. 2002).

There have been some positive developments. In spite of the lack of consensus about an operational framework for EBM, several EBM tools are emerging and gaining acceptance. On one hand, technical improvements to increase the selectivity of gears are being tested and adopted in many fisheries. On the other hand, the concept of marine protected areas (MPAs) as an essential ecosystem-based management tool is also strongly consolidating, supported by increasing scientific evidence pointing to their efficacy to rebuild ecosystems and benefit fisheries (Roberts et al. 2001). Additionally, a number of countries are pursuing an oceans policy approach which has at its core an ecologically-based perspective of the management issues and challenges for the marine realm.

Whatever the outcomes of the current process, it is certain that in the coming years the reader will regularly see the familiar acronyms 'EAF', 'EBM', 'EBFM' or 'EAM' in project proposals, preambles of fisheries regulations, international declarations, FAO documents, Regional Fisheries Management Organisations and other multilateral bodies, etc. However, while it broadly advocates the application of the ecosystem approach in oceans management, the most relevant global agreement dealing with fisheries issued during the 21st century, the Plan of Implementation of the 2002 World Summit on Sustainable Development (WSSD), still maintains the primacy of the highly controversial maximum sustainable yield (MSY) concept (which is single-species-based and intrinsically nonprecautionary) as the proper target reference level in sustainable fisheries management. This is still the state of the art.

The real challenge is to base management on the ecological reality of complex and finite marine ecosystems. It is the mandate of those representing civil society to seek the political space for promoting this change. Making the change and decreasing what we take from the oceans will require a collective effort.

\section{LITERATURE CITED}

Anonymous (2004) Fishing's secretive controllers. Nature 432:785

Browman HI, Stergiou KI (2004) Marine Protected Areas as a central element of ecosystem-based management: defining their location, size and number. In: Browman $\mathrm{HI}$, Stergiou KI (eds) Perspectives on ecosystem-based approaches to the management of marine resources. Mar Ecol Prog Ser 274:271-272

Caddy JP, Mahon R (1995) Reference points for fisheries management. Fish Tech Pap 347, FAO, Rome

Cury P (2004) Tuning the ecoscope for the Ecosystem Approach to Fisheries. In: Browman HI, Stergiou KI (eds)
Perspectives on ecosystem-based approaches to the management of marine resources. Mar Ecol Prog Ser 274:272-275

Daily GC, Alexander S, Ehrlich PR and 8 others (1997) Ecosystem services: benefits supplied to human societies by natural ecosystems. Issues Ecol 2:1-16

FAO (2003) Fisheries management 2. The ecosystem approach to fisheries. FAO, Rome

Garcia SM, Zerbi A, Aliaume C, Do Chi T, Lasserre G (2003) The ecosystem approach to fisheries. Rep no. 443, FAO, Rome

Jackson J, Sala E (2001) Unnatural oceans. Sci Mar 65: $273-281$

Jackson JBC, Kirby MX, Berger WH, Bjorndal KA and 15 others (2001) Historical overfishing and the recent collapse of coastal ecosystems. Science 293:629-638

Khun T (1962) The structure of scientific revolutions. University of Chicago Press, Chicago, IL

Murawski SA (2000) Definitions of overfishing from an ecosystem perspective. ICES J Mar Sci 57:649-658

Pauly D, Christensen V (1995) Primary production required to sustain global fisheries. Nature 374:255-257

Pitcher TJ (2001) Fisheries managed to rebuild ecosystems? Reconstructing the past to salvage the future. Ecol Appl 11:601-617

Roberts CM, Bohnsack JA, Gell F, Hawkins JP, Goodridge R (2001) Effects of marine reserves on adjacent fisheries. Science 294:1920-1923

Stergiou KI (2002) Overfishing, tropicalization of fish stocks, uncertainty and ecosystem management: resharpening Ockham's razor. Fish Res 55:1-9

Tudela S, Coll M, Palomera I (2005) Developing an operational reference framework for fisheries management on the basis of a 2-dimensional index of ecosystem impact. ICES J Mar Sci 62:585-591

Ward T, Hegerl E, Tarte D, Short K (2002) Policy proposals and operational guidance for Ecosystem-Based Management of marine capture fisheries. WWF, Sidney

\section{Aligning incentives for a successful ecosystem approach to fisheries management*}

\section{Grimur Valdimarsson, Rebecca Metzner}

Fisheries Department, Food and Agriculture Organization (FAO) of the United Nations, Viale delle Terme di Caracalla, 00100 Rome, Italy

Emails: grimur.valdimarsson@fao.org, rebecca.metzner@fao.org

The need for 'better' fisheries management. Now that the notion of the inexhaustibility of the oceans has finally been rejected by most people and there is a global consensus on the need to achieve sustainable fisheries, there are increasing efforts worldwide towards 'improved' management of fisheries. A common view is that fisheries must meet 4 criteria to be desig-

\footnotetext{
*The views expressed in this contribution do not necessarily reflect the views of the Food and Agriculture Organization
} (FAO) of the United Nations 
nated as responsibly managed: (1) produce human benefits, (2) be sustainable, (3) have a 'fair' distribution of benefits, and (4) not cause 'unacceptable change' in marine ecosystems (Sissenwine \& Mace 2003). These can be summarized as people, products, profits, and planet.

There is much less consensus on (or even practical consideration of) the mechanics for implementing this. However, while the various objectives of fisheries management tend to diverge, there is one basic objective: to make sure that enough fish are left in the water so that they can keep on producing new generations of fish. This may seem a simple task, but it has proven to be very difficult.

For most fisheries there are very limited or no restrictions on how much fishing can be done. Where maximum limits are set (based upon stock estimates), landings frequently surpass the limits, because there is no commercial incentive to adhere to such limits. Penalties are relatively low, and there are many financial pressures to exceed them. As a consequence, some $25 \%$ of all harvested fish stocks are overfished-by and large by countries that have the greatest technical capability to stick to the catch limits. Thus, it is generally agreed that in terms of controlling the catch, the systems that most countries have adopted so as not to catch too many fish are far from effective.

The main cause of this ineffectiveness, and the fatal flaw of fisheries management, is that most governments and management organizations have chosen to govern their fisheries by command and control methods that rely on top-down management, even though these methods have a proven track record of systematic failure in even fisheries management (FAO 2003). Ironically, such methods have been abandoned in most other sectors of modern economies, such as in the centrally planned industries of the former Eastern Block countries. Given the added data collection and documentation required by the adoption of the ecosystem approach to fisheries EAF management, one can question whether this is likely to succeed. Indeed, if we are failing to achieve the basic requirement of encouraging fishers to leave enough fish in the water for future sustainable harvests, how can we hope that an even more sophisticated system will work?

This essay concludes that EAF management can be successful, but that success will require a fundamental change in the nuts and bolts of daily fisheries management - the development and application of participatory rights-based fishery management regimes.

The origins of EAF management. The overarching principles of EAF management are an extension of the conventional principles and conditions for sustainable development of fisheries. It calls for management to explicitly deal with ecosystem issues such as resource conservation, habitat protection, fishery and nonfishery impacts, etc. The aim is to ensure that aquatic ecosystems can produce fish, food, revenues, employment and, more generally, other essential services and livelihoods for the benefit of present and future generations-despite variability, uncertainty and likely natural changes in the ecosystem. The main implication is the need to cater for human well-being as well as ecosystem well-being (FAO 2004).

There is no shortage of international fishery conservation instruments, guidelines, and international plans of action on how to deal with fisheries issues. The United Nations Convention on the Law of the Sea (UNCLOS) is at the core of the global fisheries management structure. It has been complemented by the Agreement to Promote Compliance with International Conservation and Management Measures by Fishing Vessels on the High Seas (Compliance Agreement) and the Agreement for the Implementation of the Provisions of the United Nations Convention on the Law of the Sea relating to the Conservation and Management of Straddling Fish Stocks and Highly Migratory Fish Stocks (Fish Stocks Agreement).

In 1995 FAO produced the Code of Conduct for Responsible Fisheries (the Code), recognizing the nutritional, economic, social, environmental and cultural importance of fisheries and the interests of all those concerned with the fishery sector. The holistic nature of fisheries and fisheries management was further clarified at the Reykjavik Conference on Responsible Fisheries in the Marine Ecosystem by focussing on defining practical steps to move from the present fisheries management framework to ecosystems-based fisheries management. The Reykjavik Declaration on Responsible Fisheries in the Marine Ecosystem confirmed that 'the objective of including ecosystem considerations in fisheries management is to contribute to long-term food security and to human development and to assure the effective conservation and sustainable use of the ecosystem and its resources'. FAO subsequently published 'The ecosystem approach to marine capture fisheries' as a Technical Guideline under the general title of Responsible Fisheries Management (FAO 2003), which were accompanied by the FAO Fisheries Technical Paper 'The ecosystem approach to fisheries management' (Garcia et al. 2003).

Ten years after the 1992 Rio Declaration on the Environment and Development and, in particular, Chapter 17 of Agenda 21, the 2002 World Summit on Sustainable Development in Johannesburg laid out the ecosystem approach as an inherent part of the fisheries management agenda. In particular, the World Summit called for 'the application by 2010 of the ecosystem approach, noting the Reykjavik Declaration on Responsible Fisheries in the Marine Ecosystem'. 
Perspectives and expectations of EAF management. Although ecosystems cannot be managed as such (they are simply too complicated), we do have some experience in managing human activities through the incentive structures to which humans respond. Thus, we have the ability to manage people and their impacts on ecosystems. The hook-and the challenge - is the need to understand and build upon the various perspectives and expectations of the many stakeholders who are involved in fisheries-related activities.

Fishery biologists: understanding the planet: Fisheries biologists calling for the ecosystem approach have tended to focus on the development of new science, information and knowledge that is capable of addressing the complexity of marine ecosystems. The intention is to understand ecological processes, patterns and limits, to 'help managers to ... avoid the loss of ecosystem integrity and to maintain fisheries in viable states' (Cury 2004, p. 273). This is laudable and exciting in terms of future marine science, and implies many years of research opportunities and challenges.

Ironically, after decades of fisheries development, it is an uphill battle to get even the most rudimentary data about capture fisheries, i.e. the basic statistics on the quantity of fish landed, and the FAO now has a mandate to implement a global strategy to improve the landing statistics worldwide. Why? Because fisheries managers have not implemented regulatory systems that create genuine incentives or strong reasons for fishers to furnish scientists with such information. Indeed, there may be much greater motivation for fishers to provide much needed data to food processors and retailers as part of commercial global traceability initiatives in order to maintain their markets.

Civil society and the general public: caring about people, products, and planet: The oceans and the marine life therein are increasingly viewed as an important part of humankind's natural heritage. There is a growing expectation that there should be increased protection of certain types of marine areas (e.g. reef systems, sea mounts) and species (e.g. endangered species). As a result, the general public, and environmentalists in particular, are increasingly expecting that EAF management will limit, or at least restrict, the effects of fishing on these particular components of the ecosystem. Nonetheless, the general public also expects to enjoy the benefits of safe, quality seafood at reasonable prices, yet consumers are also progressively demanding more of fish products. The emergence of 'feel good' eco-labeled products that are traceable and sustainably harvested is starting to shape the procurement of fish throughout the fish supply chain and from 'deck to dish'.
Fishery industrialists: providing products, profits, and planet: In addition to fishers, there are many industrialists and companies who provide fish products to the public. Their objective is to generate ongoing profits for themselves, wealth for shareholders and, as a result of this, ongoing employment for their work force. For these industrialists, there is a clear incentive to have a successful EAF management to reduce 2 commercial production problems: having predictable and consistent streams of raw materials for their use, and procuring raw materials at the lowest possible cost. In addition, these companies have to be able to satisfy their consumers. Although commercial enterprises are regulated by States and intergovernmental organizations, it is market perception that is increasingly shaping their activities. Having managed to acquire merchandise of ever better quality and ever lower prices by exploiting the forces of the free market, there are now, more than ever, calls from various stakeholder groups for corporate ethical behavior, attention to animal welfare, and care for the environment.

Corporate responses to these perceived consumer pressures include compliance with environmental standards such as ISO 14001 and the rise of the Corporate Social Responsibility movement. Any self-respecting company now must have social and environmental reports. 'Customer perception is our reality' was stated at the 2005 Rome 'CIES - The Food Business Forum' meeting of the largest food retailers in the world. Hence, if consumers want the ecosystem approach applied to fisheries management, then these industrialists will work to ensure that they provide fishery products from fisheries that are managed in this way.

Fishers: generating product in the face of production constraints: Fishers, long (and accurately) touted as the last remaining rugged individualists who are fighting and conquering the seductive but treacherous sea, are increasingly discovering their image being repainted as one of pillagers and plunderers who are sacrificing the oceans' riches on the altar of private sector profits. There is some truth to this: faced with increasingly costly regulatory controls and operating costs, there is very real pressure to compromise their own future operations and earnings just to meet current expenses and market demands. Time and area constraints on fishing operations create pressures that reduce the ability of fishers to fish responsibly and minimize environmental impacts. Due to the commercial nature of fishing, minimization of the complexity and of the impacts of fishing activities on the aquatic ecosystem must provide some benefit to the fishers. They need to have an incentive to provide up to date, on-line information on every fishing trip that can be collated and systematically analyzed by experts to detect emerging abnormalities in their fishery. 
In the face of economic, fiscal and commercial pressures to fish more (and not less), the inevitable additional reporting requirements of the EAF tend to be viewed as unhelpful in terms of either fishers' catches or their bottom line profits. Indeed, under regulatory strategies that increase fishing costs and (perhaps) reduce catches, it is difficult to generate interest in implementing additional reporting requirements.

In short, fishers can support management that provides them with rewards for furnishing and sharing sophisticated ecosystem information freely and willingly, but they need an operating environment that does not create commercial pressures to overcapitalize or race for fish without consideration for conserving the environment. Unfortunately, current command and control management approaches do not create such an operating environment, because they drive up fishers' costs to the extent that fishers are forced to forego future profits to meet current expenses.

Politicians: juggling people, production, profits, and planet: Many countries are increasingly relying on the fisheries and aquaculture sectors as important sources of jobs, income, and food. Fisheries have not traditionally constituted a large component of national economies, yet export earnings from fisheries have been increasing around the world. In the absence of other social safety nets, the small-scale fisheries sector is also frequently used as a 'safety valve' and source of social security for the most vulnerable and may be left to open access even at the potential risks of overfishing and ecosystem degradation. Ironically, doing so also puts established small-scale fishing communities at risk.

What is more, capture fisheries and aquaculture activities are only one component of coastal zone portfolios and have to be integrated with interests and demands from the tourism, transportation, and recreation sectors. Finally, to add to the political burden, consumers (also known as constituents) are becoming vocal in expressing their concerns to politicians about the safety, quality, and traceability of fish products. Having to balance such a vast array of consumer, commercial, development, and human needs makes the fisheries portfolio extremely demanding in terms of legislative, consultative, institutional, and political resources.

Political expectations of EAF management are long term, yet political timeframes for activism are typically short term. This creates a gap between truly sustainable levels of fishing activities and politically rewarding actions. Under such conditions, there is strong political motivation to express support for ecosystem approaches, but less motivation to withstand immediate pressures to potentially alter ecosystems at more local levels. Consequently, what is frequently consid- ered or perceived as a 'lack of political will' to improve the legal and institutional environment in which fisheries operate, may merely be a reflection of the degree of difficulty in embarking upon such lengthy, contentious and difficult activities.

Fisheries managers: the key to affecting people, production, and planet: The conservation measures frequently implemented by fisheries managers are important tools for complementing the core objectives of fisheries management (leaving enough fish in the water for future sustainable harvests). Such approaches, whilst being genuinely well intentioned, typically advance the use of innovative conservation tools - but without necessarily considering the financial and economic impacts of their initiatives and regulations on the commercial aspects of fishing operations.

Fisheries management needs to understand commercial fishing realities, financial issues, and business management practices. When it does not, and simply tries to administratively control the operations and actions of fishers, it does not result in conditions that align conservation with commerce. Such approaches inevitably result in (1) mistrust and escalating conflicts-not only between fishers, but also between managers and fishers and other stakeholders; (2) decreased profitability; and (3) undermined sustainability. Indeed, it is in countries where there is a relatively high proportion of economists in government and, in particular, in fisheries agencies - such as in Australia, Iceland, and New Zealand - where one finds a greater alignment of conservation and commercial interests.

If managers are going to attempt to minimize the impacts of complex human activities on the aquatic ecosystem, they must implement management systems in which fishers' objectives coincide with those of management, so that fishers have reasons for complying with managerial decisions and regulations, willingly contributing to research, and supporting monitoring, control and surveillance (MCS) activities. In New Zealand, Iceland, Australia, and some USA fisheries the industry pays for and actively participates in the research and MCS work that supports their fisheriesbecause it is in the industry's long term financial interest. However, this requires: using management systems and rules that transform the fishing process from hunting to a calculated enterprise that is commercially friendly; and creating real reasons - assets in the form of user rights - that fishers will want to enhance by incorporating environmental objectives into their shortand long-term commercial bottom lines.

Aligning people, production, profits, and the planet for a successful ecosystem approach to fisheries management. On its own, the adoption of EAF management will not necessarily lead to the desired win-win outcome of socially responsible and sustainable fish- 
ing. Indeed, at the extreme, the application of EAF management may lead to a situation where the environment, the fisheries sector, and the public are losers and these efforts end up being discouragingly delusional (Table 3). At the other end of the spectrum, successful application of EAF management is simply good business practice.

There are probably few, if any, examples of topdown fisheries management that can deliver the sophistication that EAF management requires. However, where user rights have been implemented under incentive aligning management programs, the participants actively deliver such sophistication. The ultimate solution requires setting up management that connects profit and planet by aligning the interests of people, production, and profit with the desire for conservation (Table 4).

The adoption of EAF management will be successful only if there is a concomitant and fundamental change in the way in which fisheries are managed. Defined and secure fishing rights are the core of good fisheries governance (Sinclair et al. 2002). In simple terms, good governance must motivate fishers to ensure that their fishing activities are responsible and do not impose unacceptable impacts on the ecosystem.
The irony is that we have the tools to support successful EAF management-but the collective will to do so cannot emerge under the current command and control management approaches that antagonize commercial fishers by driving up their costs. Thus, if there is to be a genuine petition for a successful ecosystem approach to management of fisheries and the marine environment, it is up to politicians to drive the adoption and implementation of secure, legally protected user/ fishing rights systems.

\section{LITERATURE CITED}

Cook C (2005) A survey of corporate social responsibility. The Economist, 22 January, p 3-18

Cury PM (2004) Tuning the ecoscope for the Ecosystem Approach to Fisheries. Mar Ecol Prog Ser 274:272-275

FAO (2003) The ecosystem approach to marine capture fisheries. FAO Tech Guide for Responsible Fisheries, No. 4 (Suppl 2). FAO, Rome

FAO (2004) Ecosystem-based management of fisheries. Marine Resources Service, FAO, Rome (available at: www.fao.org/figis/servlet/topic?fid=3197)

Garcia SM, Zerbi A, Aliaume C, Do Chi T, Lasserre G (2003) The ecosystem approach to fisheries. Issues, terminology, principles, institutional foundations, implementation and outlook. FAO Fish Tech Pap No. 443. FAO, Rome

Table 3. Sustainable development: People, Products/production, and Planet. Possible scenarios of EAF management

\begin{tabular}{|c|c|c|}
\hline & EAF management that increases social welfare & EAF management that reduces social welfare \\
\hline $\begin{array}{l}\text { EAF management } \\
\text { that increases } \\
\text { commercial profits }\end{array}$ & $\begin{array}{l}\text { Successful EAF management } \\
\text { - Cooperative regulatory environment for } \\
\text { managers, fishers, industrialists, civil society } \\
\text { - Fishers have reason to actively take up } \\
\text { ecosystem considerations } \\
\text { - Social benefits, including sustainability, } \\
\text { biodiversity, quality products }\end{array}$ & $\begin{array}{l}\text { Destructive EAF management } \\
\text { - Cynical obedience to EAF rules } \\
\text { - Dubious social and environmental benefits } \\
\text { - Expensive regulatory environment (for } \\
\text { management, fishers, and industrialists) }\end{array}$ \\
\hline $\begin{array}{l}\text { EAF management } \\
\text { that reduces } \\
\text { commercial profits }\end{array}$ & $\begin{array}{l}\text { Superficial EAF management } \\
\text { - Antagonistic compliance with EAF rules } \\
\text { - Uncertain product } \\
\text { - Indeterminate quality } \\
\text { - Dissipated social benefits }\end{array}$ & $\begin{array}{l}\text { Delusional EAF management } \\
\text { - Expensive regulatory environment (for } \\
\text { management, fishers, and industrialists) } \\
\text { - Dubious sustainability } \\
\text { - Questionable products, quality }\end{array}$ \\
\hline
\end{tabular}

Table 4 . What do stakeholders care about?

\begin{tabular}{|c|c|c|c|c|}
\hline \multicolumn{5}{|c|}{ Stakeholder concerns } \\
\hline & People & Products and production & Profit & Planet \\
\hline Fisheries biologists & & & & $\mathrm{X}$ \\
\hline Civil society & $\mathrm{X}$ & & & $\mathrm{X}$ \\
\hline General public & & & & $\mathrm{X}$ \\
\hline Fishery industrialists & & $\mathrm{X}$ & $\mathrm{X}$ & $\mathrm{X}$ \\
\hline Politicians & $\mathrm{X}$ & $\mathrm{X}$ & $\mathrm{X}$ & $\mathrm{X}$ \\
\hline Fisheries managers & $\mathrm{X}$ & $\mathrm{X}$ & $\begin{array}{l}\text { Managers can set up rules that } \\
\text { minimize fishers' costs / maximize } \\
\text { profits within catch limits }\end{array}$ & $\mathrm{X}$ \\
\hline Fishers & & $\mathrm{X}$ & $\mathrm{X}$ & $\begin{array}{c}\text { Fishers will fish responsibly } \\
\text { if conservation makes } \\
\text { economic sense }\end{array}$ \\
\hline
\end{tabular}


Sinclair M, Arnason R, Circes R, Karnicki Z, Sigurjonsson J, Skjoldal HR, Valdimarsson G (2002) Conference report on responsible fisheries in the marine ecosystem. Fish Res 58: 255-265

Sissenwine MP, Mace PM (2003) Governance for responsible fisheries: an ecosystem approach. In: Sinclair M, Valdimarsson $G$ (eds) Responsible fisheries in the marine ecosystem. FAO, Rome, p 363-390

\section{Policy and science: different roles in the pursuit of solutions to common problems}

\section{Wendy M. Watson-Wright}

\author{
Science Sector, Fisheries and Oceans Canada (DFO), \\ 200 Kent St., Ottawa, ON, Canada K1A 0E6 \\ Email: watson-wrightw@dfo-mpo.gc.ca
}

Introduction. In the marine and fisheries sectors, major policy initiatives often begin with science. However, at least initially, they are not recognizable as such. Rather, scientifically generated evidence raises an alarm about something that is going on 'out there'. For a while, the science may develop in the 'discovery' phase, accumulating knowledge about something new. The point at which the science is complete enough to allow for prediction of potential consequences is an important benchmark. If the potential consequences are severe, such predictions draw attention, even if they are equivocal. Awareness spreads first within the science community. However, if the predicted scenario is inconsistent with the goals of existing policy and management strategies, it does not take long for those involved in policy and management to pay attention. Nonetheless, how policy pays attention to the science is variable.

I will illustrate the range of interactions that can occur between science and policy using as examples 2 long-standing issues: climate change and invasive species. Then I will evaluate where the emerging issue of an ecosystem approach to fisheries (EAF) fits within this range. Such an evaluation may suggest ways in which both science and policy can improve the effectiveness of how they address this crucial issue.

In the case of climate change, the initial science appeared to be scattered and lacking a central focus. Scientists working with data from various monitoring programs covering very different parts of the oceanatmosphere system and in different parts of the world began to identify trends in their individual time series. These trends could not be reconciled with either random variation around an average condition, or with historic oscillations between alternating warm and cold periods (IPCC 1990). Gradually, these independent trends were brought together, often by other scientists who were users of the time series collected by the specialists (NRC 1995). Scientists had to establish that the trends were real, that they were present in enough different data sets to reflect a common underlying cause, and that they were consistent with mechanisms that could be linked to directional climate change. Only after this had taken place was the science case considered credible enough to stimulate policy action. This process of building the science case for policy action is still under way, because notwithstanding important policy commitments already made through the Kyoto Protocol and national initiatives, debate continues about the magnitude of the threat and the appropriate policy and societal actions (IPCC 2001; see also http://gcmd. gsfc.nasa.gov/Resources/pointers/glob_warm.html).

On the other hand, both scientists and the general public have long been aware of the huge impact that invasive species can have on native ecosystems. In North America, the consequences of chestnut blight and Dutch elm disease were easy to see and familiar to everyone with even a casual acquaintance with eastern woodlands or the prairie riparian habitats (Anagnostakis \& Hillman 1992, Hubbes 1999). The effects of rabbits introduced into Australia are comparably familiar, and are cited in introductory university biology texts throughout the world (see www.deh.gov.au/ biodiversity/invasive/publications/rabbit/index.html). Thus, the problem of invasive species was recognized widely, but the missing piece was a theoretical framework that could pull the numerous individual invasions together into a single issue amenable to policy action and provide the basis for appropriate policy and management measures. The theoretical framework required unifying advances in theoretical ecology through the 1960 s to the 1980 s with conservation biology, which focused ecological theory on applied problems. By the time that zebra mussels invaded the lakes and rivers of eastern Canada both the scientific community and the public could call for policy action to address the threats of invasive species (MacIsaac 1996, D'Itri 1997). The Canadian government now considers invasive species to be a high priority issue. It promotes implementation of more stringent preventive measures (where they are cost effective) and monitoring to detect invasives as early as possible. Nonetheless, although the science evidence was convincing enough to gain wide support for restrictive policies, it is not yet possible to really say what should be done to address the threat when a new species is detected.

How issues develop in science and policy. Once a new issue has become credible within the science community, there are still many possible reactions by policy makers. In the case of invasive species, Canadian policy agencies have asked directly for guidance from science. They acknowledge the conservation 
issue and confirm that they are ready to act on it. They want advice on what should be done to reduce risk and protect Canadians and the environment. In the case of climate change, policy responses have been less decisive. Many high profile international meetings were needed to develop science-based policy initiatives, and debate continues about which actions are needed. There is ample room to speculate on why these issues were treated differently. It is possible that the managers developing the policy responses considered the scientific evidence to be more credible in the case of invasive species than in the case of climate change. It is also possible that the differences in management reflect differences in the costs of the measures considered as necessary, and the impacts of those measures on businesses and the public. For example, current policy measures to address aquatic invasive species prohibit recreational anglers from using certain bait in given watersheds or require commercial ships to exchange ballast in specified zones at sea (see www.invadingspecies.com). On the other hand, to address climate change, each adult Canadian is being asked to reduce production of greenhouse gasses by $1 \mathrm{t} \mathrm{yr}^{-1}$ (www.climatechange.gc.ca/onetonne/english/ index.asp). The impacts of the policies to address invasive species are inconvenient to a few groups of Canadians, whereas policies to address climate change ask all citizens to undertake significant lifestyle changes. Some may think it reasonable to expect a higher standard of scientific evidence in the second case than in the first.

Notwithstanding the differences in the demands on science there is a common thread in the policy responses in these examples. At some point the sciencepolicy dialogue changes from a science 'push' to a policy 'pull'. It begins with science working to inform policy officers of the need for new or changed policies. Once the policy sector becomes engaged in the issue, though, policy-makers increasingly influence the nature of the dialogue. The policy-makers have 2 particular requirements from science: (1) science advice on actions which will improve the situation in the short term, so they can see (and show to the public) benefits of the policies they implement; (2) science support to make their policies credible to the public, so the public will support adoption of the policies, and compliance with them after they have been adopted. The science community may be most interested in how the issue relates to scientific theories and understanding of natural processes, and find these needs from policy not particularly interesting. Nonetheless, the science community must treat these needs as research priorities. Without science support for the credibility of policy initiatives, there is a high risk that the policies will be abandoned, particularly if they are costly to implement or require societal sacrifice. Without science guidance towards effective policies, the policies that are implemented may achieve little. If science focuses only on policy actions which pay off in the long term, there is a risk that the public will reject the policies when they do not see improvements to a situation they consider unsatisfactory. The science-policy interface remains important, but the driver changes.

Outreach and engagement of partners. When science and policy each become interested in an emerging issue, both reach out to other institutions and departments. However, there are some important differences between the communities with whom they establish or strengthen networks. These differences reflect both different institutional cultures and the different roles and responsibilities of the 2 sectors. The differences in institutional cultures are important to the short-term interactions of science and policy, but can be confused with the differences in their respective roles and responsibilities.

For science, the responsibility is to be sound and objective, and to understand as much about the issue and its consequences as possible. The tool for determining soundness and objectivity is independent peer review. The way to acquire data, knowledge, and understanding quickly is to share with colleagues. Both of these mechanisms have fostered a sense of internationalism within the science community. International marine science organizations such as the International Council for the Exploration of the Sea (ICES) and the North Pacific Marine Science Organization (PICES) have flourished, and the science community is eager to use these international bodies to focus the expertise of the global science community on emerging science challenges. When policy interest in a science issue grows quickly, one sees proposals for so many international symposia that the science community has difficulty providing new results fast enough to support them all, a situation developing now with invasive species and the ecosystem approach to fisheries.

The responsibilities of policy are different. The discussions are more often with other government departments and other levels of government. In Canada, Provinces, Territories and municipalities may all be facing the same issue, but in different contexts. For invasive species, many federal departments are concerned about threats to native ecosystems, including the Departments of Agriculture, Environment, Natural Resources (which includes forestry), Fisheries and Oceans (DFO), Transport, Food Inspection and several departments with responsibilities in international relations and trade. Provinces and communities must address invasive species issues as well, and have jurisdictional roles which must be respected. The Government of Canada also has a commitment to consult 
widely with affected stakeholders, from environmental organizations to resource users and those involved in trade and commerce. Some groups in Canada, such as Aboriginal groups and Wildlife Management Boards, have the right to be consulted entrenched constitutionally and in legislation. If a policy may impact the responsibilities of these parties, the sponsoring Department must coordinate and cooperate with all of them. Even for policies solely within the jurisdiction of a single department, such as policies on fisheries management in DFO, successful implementation of a major new policy requires at least the cooperation of other departments with economic portfolios, as well as coastal communities, industry and provinces.

Hence, the policy and science sectors both engage in discussion with other experts and institutions, but generally with different ones. Science experts reach out internationally within their fields of expertise. Policy-makers network largely within the country, but across many parts of the governance systems. Science experts do network with the science experts in other government departments, but only to the extent that the science interests and issues are shared. Science may have many meetings and even joint projects when there are common science issues. For example, DFO and Environment Canada have supported joint projects on species-at-risk issues. However, there is usually little interaction between scientists and officers from departments interested in trade and economic aspects of issues. Policymakers do network internationally, but generally the focus is on ensuring that international standards are harmonized. In these discussions, the trade and economic implications of policy changes often have center stage.

Implementing an ecosystem approach to fisheries (EAF). When we consider developing the scientific foundations for EAF management and implementing it in policy, all of the above considerations are in play. Some aspects of the EAF have been well established for many years, and are already reflected in management. For example, Canada has applied a very cautious approach to fishing on lower trophic levels since the 1970s. Capelin quotas were set with an acknowledgement that the needs of predatory fishes, seabirds and marine mammals had to be accommodated before the human harvest could be allocated (Winters \& Carscadden 1978). Similarly, despite a number of requests for exploratory fisheries for krill, only a very restricted fishery has been authorized in 1 inlet in British Columbia (Romaine et al. 1996). Even though management approached fishing on lower trophic levels very cautiously, there was no call for a comprehensive policy on such fisheries until the mid-1990s. However, when the policy was brought forward, it was supported strongly by scientists, fisheries managers and policy-makers (DFO 2004a).
Some other aspects of the science underlying the EAF have developed more slowly. In Canada, science and management paid little attention to by-catch of non-target species, except in special cases such as entanglements of marine mammals in fishing nets or when some fishing gears were prohibited from taking species allocated to another gear sector. Passage of Canada's Species-at-Risk Act made by-catch of noncommercial species a major legal issue, and science and fisheries management are both struggling to make up for lost opportunities to quantify fisheries catches completely (CSAS 2002a). Protecting fragile features of the seafloor from damage by fishing gears is also a recent issue in Canada, and again science is scrambling to identify where such features may be located (CSAS 2002b, 2004a). These are cases where policy responded quickly to new legislation and public expressions of concern, even though science was and is not well prepared to advise on exactly what should be done to implement the policies.

On the other hand, Canadian research and monitoring has contributed to the evidence that fisheries have ecosystem-scale impacts, such as 'fishing down the food web' and the loss of large individuals from fish communities (Pauly et al. 2001, Myers \& Worm 2003). Some of these scientific papers have sparked controversy about how the data are analysed and interpreted, and which scientific conclusions can be drawn from the patterns (http://dels.nas.edu/osb/ecosystem_ effects.shtml). In these cases, policy has been much slower to pick up on the scientific views as they have emerged. The slower rate of policy change cannot be attributed to science, because the policy implications of the science on ecosystem effects of fishing have been clear for some time-take less out and be much more selective in what, where, when, and how to harvest (FAO 2002, Rice in press). It is the social and policy implications that make policy slow to act, since the required policy and management changes will impact the fishing industry and fishery-dependent communities negatively, at least in the short term. Science has to help policy build support in the communities for the new approaches, and help management build a willingness in the industry to comply with the new policies.

Impediments that must be overcome. Dealing with uncertainty: Science's role in showing the public that a policy change is needed can be as important as science's role in showing policy-makers what provisions the policy should contain. In the case of the EAF, though, science is encountering some of the same impediments that have characterized the sciencepolicy interface on climate change. All science contains some uncertainty, and when the science addresses questions as complex as the ecosystem effects of fish- 
ing, the uncertainty is large. For policy experts, large scientific uncertainty is a major liability. For example, placing fisheries management in an ecosystem context will reduce employment opportunities in fisheries, and increase production costs (Rice in press). There is uncertainty about how large these socio-economic impacts will be and how long they will last. However, the uncertainty about how large the ecological benefits will be, and how long it will take to secure them, will almost always be much greater than the uncertainty about short-term social and economic costs.

This is an imbalance where good science, making the uncertainties transparent to the users of the science advice, impedes policy actions. It is easy to argue that politicians are elected to protect a nation's ecosystems from harm, but they are also elected to protect communities and workers from unnecessary harm. Science advisors on fisheries have argued for decades that short term 'pain' to fisheries will be more than compensated by longer-term improved yields from the target species, yet these arguments often fail to convince managers and policy makers to take decisive measures early (Rice in press). Advice on ecosystem effects of fishing is more uncertain than single species advice. In fact, science advisors may be able to indicate little more than the direction in which policy change is needed, and very little about exactly what benefits will accrue (Link et al. 2002). In those circumstances, politicians may feel they are being fully responsible in asking how much social and economic harm is necessary to manage the risk of harm to marine ecosystems. When science advisors are uncertain about even the point at which perturbation of an ecosystem property becomes 'harm', policy makers may feel quite justified in making changes in very small increments. This approach has often contributed to failures of single-species management, where uncertain science advice allowed politicians to reduce harvests too gradually to prevent collapses (Walters \& Maguire 1996). Science experts and policy makers individually have learned important lessons from crises like the one surrounding the Canadian Atlantic groundfish in the early 1990s. Nonetheless, the social and political circumstances in which decision-making is played out have not changed much. Science remains uncertain about all but the 'big picture' parts of what will be required to achieve sustainability at the scale of the ecosystem as well as of the harvested stocks themselves. This uncertainty remains a major impediment to decisive policy change and effective management action.

Reversing the burden of proof: Because uncertainty is an impediment to policy and management action, some agencies have proposed adopting a reversal of burden of proof for at least some parts of the EAF. This is an extension of the precautionary principle written into the agreements from the United Nations Conference on Environment and Development (Rio) and the World Summit on Sustainable Development (Johannesburg) (UN 2002). In Canada, the Species at Risk Act includes this approach explicitly, by specifying that activities which might harm protected species can be permitted only when it can be demonstrated that the harm will not jeopardize recovery (Government of Canada 2002). In the United States, NOAA's discussion paper on the EAF (NMFS 1999) proposes to extend this approach through the application of ecosystem approaches to policy and management. This reversal of burden of proof may be the only realistic way to deal with the significant scientific uncertainties that will continue to be present in the science advice on EAF. However, it will be extremely challenging to obtain support from other parts of government and from the stakeholders who will bear the greatest share of shortterm costs from application of the EAF.

The reversal of burden of proof is a long-standing practice in the protection of human health. For example, new drugs cannot be marketed until they are demonstrated to be safe, or at least until the side effects are known. However, in natural resource conservation, reversing the burden of proof places high costs on industries and user groups who have not traditionally borne them (Tickner 2002). These industries commonly feel that they do not have sufficient financial resources (e.g. compared to major pharmaceutical companies, which invest millions of dollars in developing and testing a new drug before they can market it and begin to recoup the investment). Conservation advocates have sometimes been a bit naïve in promoting the view that the resistance to reversing the burden of proof in industries like fishing is based only on greed and a fear by the industry that it will not be able to show that it is sustainable. Industries where the reversal of burden of proof is standard practice operate from quite different economic (and policy) footings than fisheries and similar resource-based industries. Unlike the pharmaceutical industry, for example, the fishing industry still has many very small independent operators who lack the financial resources for large upfront investments. There are also many coastal areas which are economically and culturally dependent on fishing, and many countries, including Canada, have policy goals of keeping such communities viable (Government of Canada 2004).

It may be necessary to reverse the burden of proof if science evidence is to influence policy and management to take an ecosystem approach to fishing. However, DFO is encountering strong community opposition to listing marine fish species as threatened or endangered under the Species at Risk Act, Canada's 
first environmental act to contain provisions which explicitly reverse the burden of scientific evidence (DFO 2004b). This experience suggests that the change to an EAF is going to be very difficult.

Clarifying the implications of EAF: There is another practical impediment to widespread implementation of the EAF and of ecosystem based management of other marine activities. The ecosystem approach still appears to be a vague and fuzzy concept to many in policy and management. Even science advisors can interpret the concept differently. This is the situation in Canada, for example, despite several key events intended to facilitate development of an ecosystem approach. A key Canadian landmark was the workshop on the Ecosystem Approach to Management in March of 2001 (CSAS 2001). The workshop produced a set of 10 conceptual ecosystem objectives and supporting principles, as well as a science roadmap to make them operational. Nonetheless it took a science-oceans management-policy working group over a year to adapt the science products into a formal proposal and plan of action for DFO senior management. As soon as projects began under the plan of action, it became clear that the 'conceptual objectives' were not being interpreted the same way by scientists from different specialties and different regions of Canada, let alone by the policy and management sectors, nor by stakeholders. Another week-long science workshop was needed in the winter of 2003 to agree on how to interpret the main ecological terms in the conceptual objectives (CSAS 2004b).

Another initiative within DFO fared little better. The Objectives Based Fisheries Management initiative was intended to develop explicit biological, social, and economic objectives for each Fisheries Management Plan adopted by DFO. Objectives were to be selected following an inclusive and consultative approach. Agreement was reached quickly that the biological objectives should include objectives for conservation of key ecosystem properties potentially affected by the fisheries, and not just for the target species. In practice, again, not even separate groups of scientists could develop lists of ecosystem-related objectives which had some minimum of consistency around Canada's 3 oceans, or sometimes within a single Region. The problem was not that the different fisheries had different potential effects on the marine ecosystems (although to some extent this is always true). Rather, there was no consistent framework to assist in deciding which ecosystem considerations are obligatory (and thus must be addressed with an operational objective) versus those which could be considered optional within an EAF. Without a framework for implementation, groups of scientists relied on the particular research interests and strengths of each regional sci- ence laboratory. Because these strengths usually differed from laboratory to laboratory, the biological objectives proposed for keeping the fishery sustainable within an ecosystem context differed as well. Despite $3 \mathrm{yr}$ of committed effort in some parts of the DFO, the Objectives Based Fisheries Management produced suites of ecosystem-related objectives for very few fisheries, and the objectives included rarely amounted to more than avoiding excessive by-catch and not damaging habitats of iconic significance.

In 2004 a new science-policy - oceans management fisheries management working group has again been formed to develop an ecosystem approach for DFO's policies and programs. It builds on the work accomplished to date by the previous initiatives, and is trying to dispel the fog surrounding the concept of 'ecosystem approach'. However, progress has not been swift, and to this point there has been little agreement on which pilot programs would best illustrate what the ecosystem approach really is, and what it is not.

The difficulty in making progress reflects the complexity of the task, and not a lack of commitment. All sectors recognize the need to make timely progress towards implementation of EAF. It is just that such progress will affect almost everything that DFO does and manages. With good reason, every sector wants to understand the implications of the EAF for their own work, and for how they will interact with-and be reacted to by - the stakeholder and user groups with whom they work most closely. The science-policy interface is back in center-stage, and policy is pulling the science. Policy needs science to create an understanding of EAF that is complete and explicit enough for other sectors to realize and pursue their responsibilities.

Summary. The main messages from my perspective are 3-fold:

(1) Policy making is often an evolutionary process, beginning with a science 'push', but punctuated with policy 'pulls'; the science-policy interface is and should be an iterative process, and neither side should have to 'push' or 'pull' too hard to elicit cooperation from the other.

(2) Uncertainty is an issue for politicians and for the policy-making process. Scientists accept uncertainty as part of the process, and have many approaches for measuring and packaging it. However, high uncertainty makes it difficult to build political support for tough policies, and harder still to gain cooperation in their implementation. The precautionary principle and the reversal of the burden of proof are aimed at neutralizing these political challenges, but they have their limitations when decision-making is based on participation and stewardship, and when science is uncertain. 
(3) Creating public understanding for scientific concepts takes time, and consolidation of the evidence for the concepts takes even longer. Nonetheless, it is crucial for policy makers to be fully comfortable with the concepts and their operational ramifications prior to using these concepts as the basis for major policy changes. Continued dialogue and mutual understanding are essential in order to enact science-based policy, particularly if policies are intended to anticipate and address crises proactively, instead of being merely reactive.

Acknowledgements. Thanks to Serge Labonte and Jake Rice for discussions and for helping to collect the background information for this contribution. Comments from the editors improved readability and clarity.

\section{LITERATURE CITED}

Anagnostakis SL, Hillman B (1992) Evolution of the chestnut tree and its blight. Arnoldia 52:3-10

CSAS (2001) Proceedings of the National Workshop on Objectives and Indicators For Ecosystem-based Management. CSAS Proc 2001/09

CSAS (2002a) Proceedings of the National Science Review Meeting on Species at Risk Issues, December 9-13, 2002, Halifax, Nova Scotia. CSAS Proc 2002/35

CSAS (2002b) Proceedings of a Benthic Habitat Classification Workshop, Meeting of the Maritimes Regional Advisory Process. Maintenance of the diversity of ecosystem types: a framework for the conservation of benthic communities of the Scotia-Fundy area of the Maritime Region. CSAS Proc 2002/23

CSAS (2004a) Proceedings of a Benthic Habitat Classification Workshop, Meeting of the Maritimes Regional Advisory Process. Maintenance of the diversity of ecosystem types: benthic classification and usage guidelines for the ScotiaFundy area of the Maritime Region. CSAS Proc 2004/04

CSAS (2004b) Habitat status report on ecosystem objectives. Habitat Status Report 2004/01

D'Itri FM (ed) (1997) Mussels and aquatic nuisance species. Ann Arbor Press, Chelsea, MI

DFO (2004a) Policy on fisheries on forage species. Internal document, Department of Fisheries and Oceans, Ottawa

DFO (2004b) Summary of public consultations on the listing of cod. Internal document, Department of Fisheries and Oceans, Ottawa

FAO (2002a) Guidelines on the Ecosystem Approach to Fisheries. FAO Tech Guide for Responsible Fishing 9. FAO, Rome

Government of Canada (2002) Species at Risk Act (available at: http://laws.justice.gc.ca./en/s-15.3/text.html)

Government of Canada (2004) A policy framework for the management of fisheries on Canada's Atlantic coast. Department of Fisheries and Oceans, Ottawa

Hubbes M (1999) The American elm and Dutch elm disease, For Chro 75:265-269
IPCC (1990) Climate change-the scientific assessment. Houghton JT, Jenkins GT, Ephraums JJ (eds) Cambridge University Press, Cambridge

IPCC (2001) IPCC Third Assessment Report: Climate Change (available et: www.ipcc.ch/)

Link JS, Brodziak JTK, Edwards SF, Overholtz WJ, Mountain D, Jossi JW, Smith TD, Fogarty MJ (2002) Marine ecosystem assessment in a fisheries management context. Can J Fish Aquat Sci 59:1429-1440

MacIsaac H (1996) Potential abiotic and biotic impacts of zebra mussels on the inland waters of North America. Am Zool 36:287-299

Myers RA, Worm B (2003) Rapid worldwide depletion of predatory fish communities. Nature 423:280-283

NMFS (1999) Ecosystem based fisheries management: a report to Congress by the Ecosystem Principles Advisory Panel. Department of Commerce, National Marine Fisheries Service, Silver Springs, MD

NRC (National Research Council) (1995) Natural climate variability on decade-to-century time scales. National Academy Press, Washington, DC

Pauly D, Palomares ML, Froese R, Vakily M, Preikshot D, Wallace S (2001) Fishing down Canadian aquatic food webs. Can J Fish Aquat Sci 58:51-62

Rice JC (in press) Will an ecosystem approach mitigate the factors of unsustainability? In: Maguire JJ, Greboval D (eds) Collected papers from the 3rd Workshop on Factors of Unsustainability. Siem Reap, Cambodia, Sept 14-18, 2004. FAO Tech Fish Rep

Romaine SJ, Mackas DL, Macauley MC, Saxby DJ (1996) Comparisons of repeat acoustic surveys in Jervis Inlet, British Columbia, 1994-1995. Univ of British Columbia, Vancouver. Fisheries Centre Res Rep 43:48-52

Tickner JA (ed) (2002) Precaution, environmental science and preventive public policy. Island Press, Washington, DC

UN (2002) Plan of implementation-World Summit on Sustainable Development. United Nations Organization, New York

Walters CJ, Maguire JJ (1996) Lessons for stock assessment from the northern cod collapse. Rev Fish Biol Fish 6: $125-137$

Winters GH, Carscadden JE (1978) Review of capelin ecology and estimation of surplus yield from predator dynamics. ICNAF Res Bull 13:21-29

The Theme Section may be cited as follows:

Browman HI, Stergiou KI (eds) (2005) Politics and socioeconomics of ecosystem-based management of marine resources. Mar Ecol Prog Ser 300:241-296

Individual contributions may be cited as, e.g.

Rice JC (2005) Implementation of the Ecosystem Approach to Fisheries Management-asynchronous co-evolution at the interface between science and policy. In: Browman HI, Stergiou KI (eds) Politics and socio-economics of ecosystem-based management of marine resources. Mar Ecol Prog Ser 300:265-270 